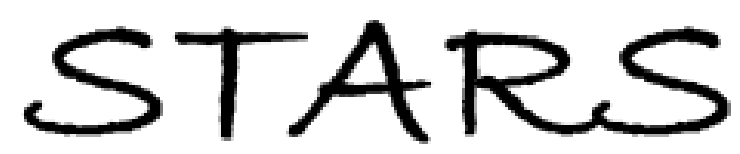

University of Central Florida

STARS

2014

\title{
The Effect of Health Education on Clinical and Self-Reported Outcomes of Diabetes in a Medical Practice
}

Karen Rav-Marathe

University of Central Florida

Part of the Public Administration Commons

Find similar works at: https://stars.library.ucf.edu/etd

University of Central Florida Libraries http://library.ucf.edu

This Doctoral Dissertation (Open Access) is brought to you for free and open access by STARS. It has been accepted for inclusion in Electronic Theses and Dissertations, 2004-2019 by an authorized administrator of STARS. For more information, please contact STARS@ucf.edu.

\section{STARS Citation}

Rav-Marathe, Karen, "The Effect of Health Education on Clinical and Self-Reported Outcomes of Diabetes in a Medical Practice" (2014). Electronic Theses and Dissertations, 2004-2019. 4815.

https://stars.library.ucf.edu/etd/4815

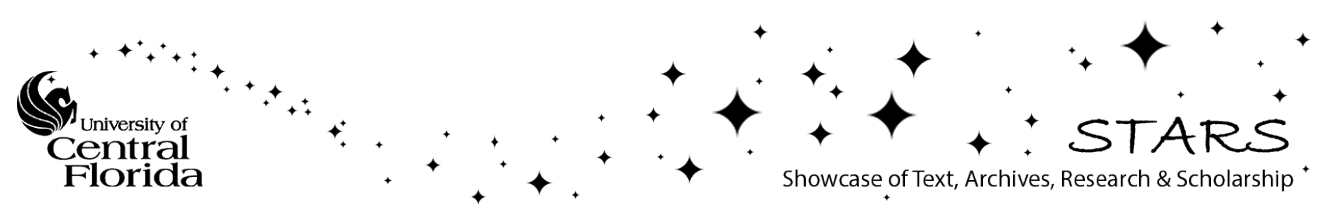




\section{THE EFFECT OF HEALTH EDUCATION ON CLINICAL AND SELF-REPORTED OUTCOMES OF DIABETES IN A MEDICAL PRACTICE}

by

\section{KAREN RAV-MARATHE}

B.S. University of Bombay, 1977

PharmD University of Florida, 2000

M.P.H. University of North Florida, 2006

A dissertation submitted in partial fulfillment of the requirements

for the degree of Doctor of Philosophy

in the Department of Public Affairs

in the College of Health and Public Affairs

at the University of Central Florida

Orlando, Florida

Fall Term

2014

Major Professor: Thomas T.H. Wan 
(C) 2014 Karen Rav-Marathe 


\begin{abstract}
A majority of diabetes self-management programs have been shown to improve knowledge, attitude, practice, and health care outcomes. However, in the literature the underlying causal mechanisms for the improvement attributable to health education have not been explored, especially, how diabetes educational intervention may affect diabetes care outcomes. The purpose of the present study was to identify the causal mechanisms responsible for improved knowledge, attitude, practice and outcomes, so that educational interventions can be tailored efficiently and effectively to patients who are most likely to benefit from self-care management. The study used the knowledge, attitude, practice and outcome (KAP-O) framework. The specific purpose of the study was to examine the causes of variation in the outcomes of glycated hemoglobin (A1C), low-density lipoprotein cholesterol (LDLC), functional capacity (FC), and poor perceived health (PPH).

An experimental study with a randomized control trial design involving 141 participants was conducted. The experimental group $(\mathrm{N}=87)$ and control group $(\mathrm{N}=52)$ were comparable in terms of demographics and major diagnoses. The experimental group received diabetes education. The control and experimental groups received usual customary care. Knowledge, attitude, practice, functional capacity and poor perceived health were measured before and after intervention using reliable and valid instruments. The study used a tailored attitudinal instrument. Glycated hemoglobin (A1C) and low-density lipoprotein cholesterol (LDLC) were measured before and after intervention. Multiple analytic strategies were applied to examine the experimental data.
\end{abstract}

The four outcome variables of (A1C), (LDLC), (FC), and (PPH) did not constitute one common factor measurement model for outcome evaluation. Results of the Independent sample 
t-test showed that health educational intervention directly improves knowledge about diabetes. The path analysis of panel regression showed that health educational intervention directly lowers glycated hemoglobin (A1C). The causal modeling of \{(Exp_Status)-(K-T2)-(A-T2)-(P-T2)\} model showed that health educational intervention also indirectly improves preventive practice via knowledge. The effect of attitude (A-T2) was greater than the effect of knowledge on preventive practice of self-care. The difference-in-differences analysis showed that difference in practice (DP) statistically significantly affects the difference in glycated hemoglobin (DA1C). The greater the preventive practice, the greater the lowering of glycated hemoglobin (A1C), indicating a better control of diabetes. The data from this experiment do not support a strong causal path of experimental effects on outcomes via knowledge, attitude, and practice of selfcare.

The study should be replicated using the KAP-O model in research based on multicenters, multiple providers, and a diverse population of Type 2 diabetes patients. The study should assess outcomes more than four times over a period of one to two years to elicit the trajectory of change in outcome variables. Knowledge and attitude should be assessed at baseline and continuously improved for the duration of the study. 


\section{ACKNOWLEDGMENTS}

I could not have reached this milestone but for the generosity of Dr. Thomas T. H. Wan. I will ever remain grateful to Dr. Wan for his tireless assistance throughout the prospectus, research, and dissertation process. I owe a heavy debt of gratitude to Dr. Wan for his unstinting professional support and personal encouragement.

I wish to express my deep appreciation to my other committee members, Dr. Ning Zhang, Dr. Myron Fottler, Dr. Allan March, and Dr. Jonathan Matusitz for their insight, review, and valuable suggestions.

I wish to thank Mr. Blake Dickeson, President of New Millennia Health and Dr. Allan March for providing the use of Healthy Tutor for this study. They were very responsive and helpful.

I am grateful to my peer, Ms. Yi-Ling Lin, for technical assistance. I also appreciate the kindness and support of my friends Dr. Alice Noblin and Dr. Joe Saviak.

The support of the staff, physician, and patients of Medical Specialists enabled me to reach the goal and complete the research project.

I am thankful to Mrs. Sylvia Wan for her gracious hospitality. I am greatly appreciative of Sharon Koufas whose formatting and technical assistance was invaluable.

I wish to thank my parents, Shridhar and Vimal Marathe for their encouragement and my daughters, Kalyani and Kaveri for their forbearance. My husband Shriram deserves my deepest gratitude for his generous support, guidance, and encouragement. 


\section{TABLE OF CONTENTS}

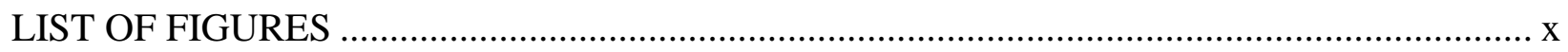

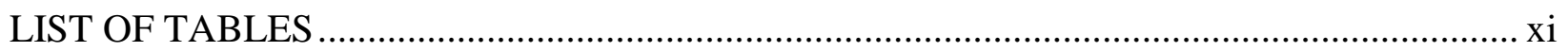

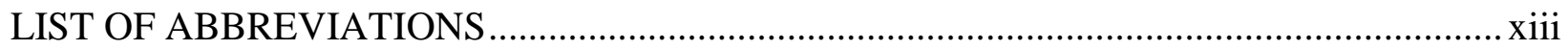

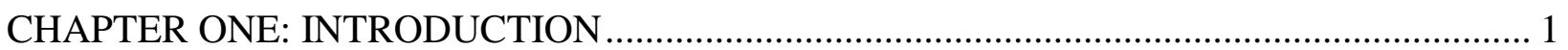

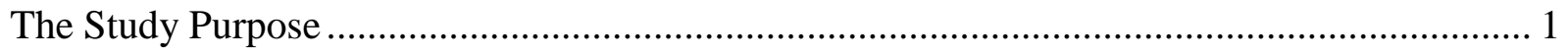

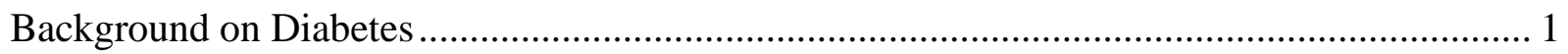

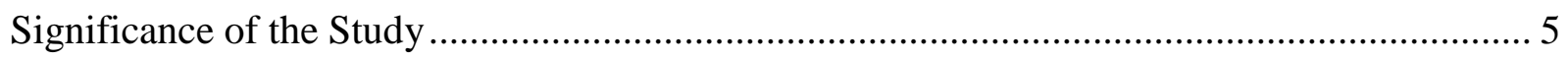

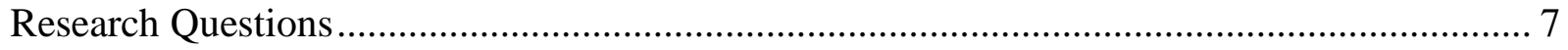

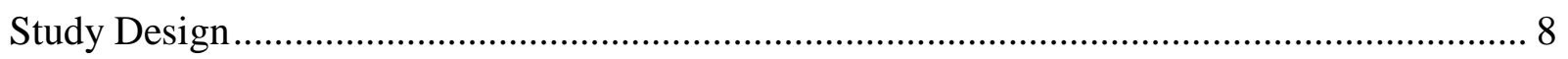

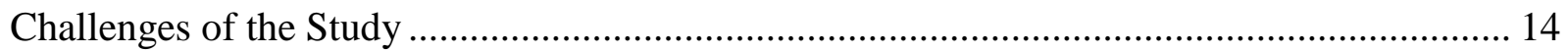

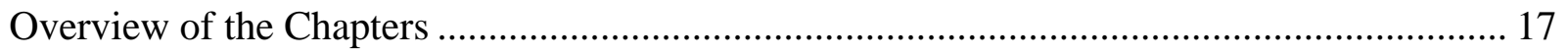

CHAPTER TWO: LITERATURE REVIEW AND THEORETICAL FRAMEWORK................ 18

Review of Conceptual/Theoretical Perspectives .................................................................. 18

The Knowledge, Attitude, Practice Framework …………………………………….............. 21

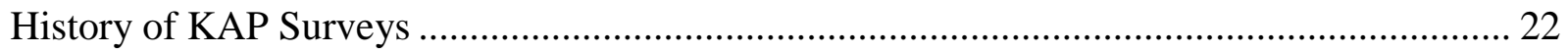

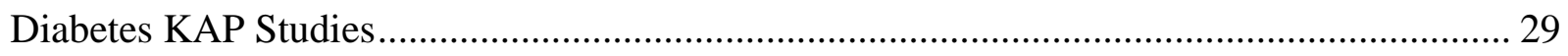

Review of the Methodological Rigor of Previous Research..................................................... 38

Studies Supporting the Concept that Educational Intervention Directly Improves Diabetics'

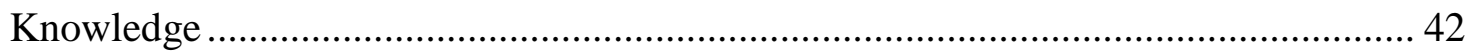

Studies Supporting the Concept that Educational Intervention Directly Improves Attitude.... 45

Studies Supporting the Concept that Educational Intervention Directly Improves Preventive

Practice 
Studies Supporting the Concept that Health Educational Intervention Improves Health Care Outcomes

Studies Supporting the Concept that Educational Intervention Indirectly Improves Practice via Knowledge and Attitude 48

Studies Supporting the Concept that Educational Intervention Indirectly Affects Outcomes,

Mediated via Knowledge, Attitude, and Practice 49

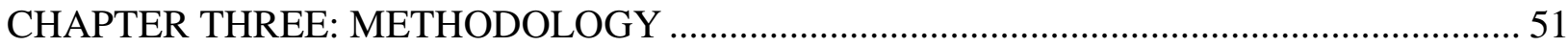

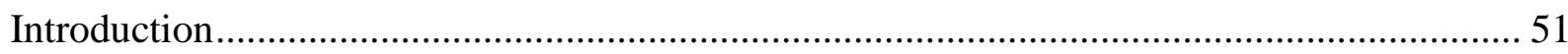

Preparation for a Randomized Controlled Experiment................................................. 52

Description of Intervention and Implementation ........................................................ 53

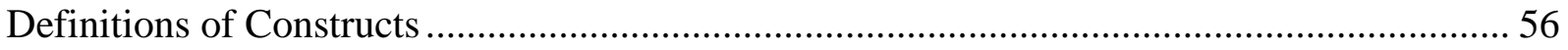

Measurement of the Variables ................................................................................. 58

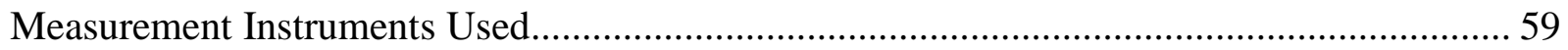

Validity and Reliability of Measurement: Knowledge, Attitude, Practice, and Outcome

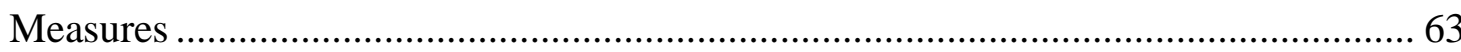

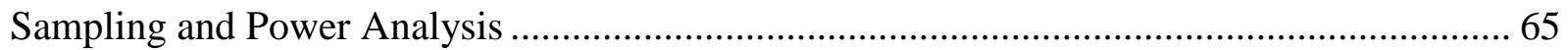

CHAPTER FOUR: FINDINGS ................................................................................. 75

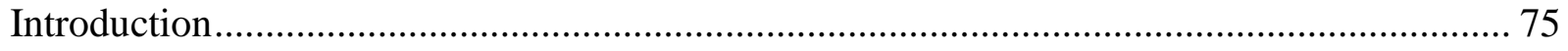

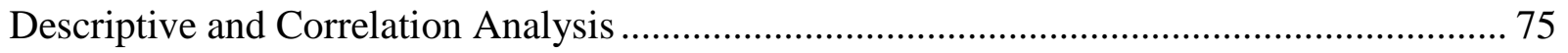

The Intention-to-Treat Analysis: T-Tests ................................................................... 78

Intention-to-Treat Analysis with Statistical Control of the Prior Score ............................... 84

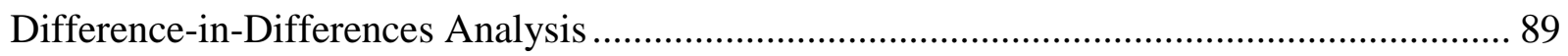

CHAPTER FIVE: SUMMARY, IMPLICATIONS AND CONCLUSIONS .......................... 96 


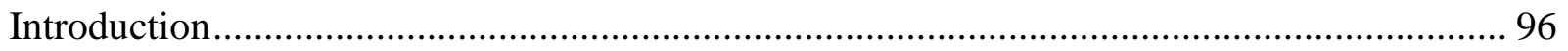

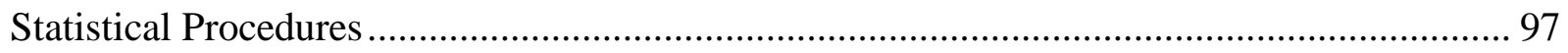

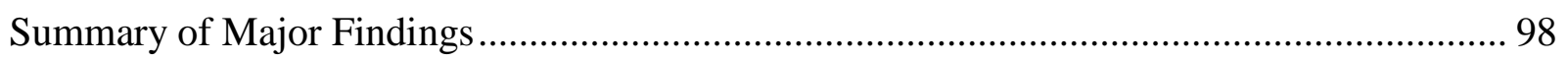

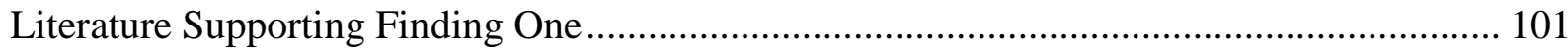

Literature Not Supporting Finding Two ………………................................................... 103

Studies Reporting Improvement in A1C Post-Self-Management Education ......................... 105

Studies Supporting the Indirect Effect of Experimental Status on Preventive Practice via

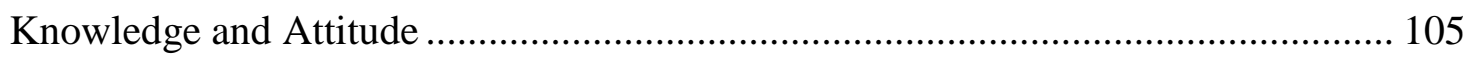

Studies Supporting the Causal Effect of Preventive Practice on Glycated Hemoglobin (A1C) 106

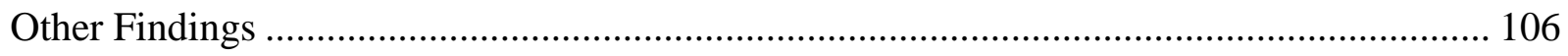

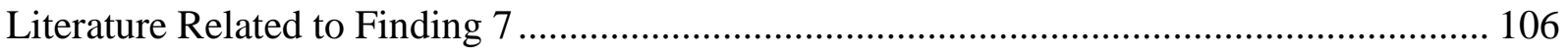

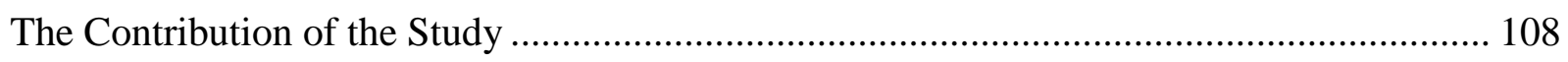

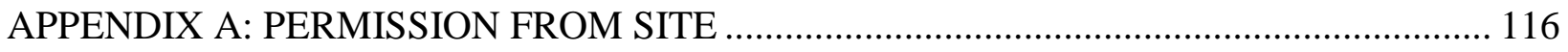

APPENDIX B: UCF IRB APPROVAL OF HUMAN RESEARCH ………………............... 118

APPENDIX C: LETTER TO PARTICIPANTS..................................................................... 121

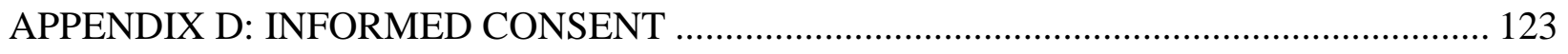

APPENDIX E: LITERACY ASSESSMENT OF DIABETES INSTRUMENT ......................... 128

APPENDIX F: TEST OF FUNCTIONAL CAPACITY (EQ-5D-5L) WITH 5 ADDITIONAL

DIMENSIONS PROPOSED BY PERNEGER AND COURVOISIER (2011) ............. 130

APPENDIX G: TEST OF PERCEIVED POOR HEALTH EUROPEAN QUALITY VISUAL

ANALOGUE SCALE (EQ-VAS) ………………………....................................... 133

APPENDIX H: SUMMARY OF DIABETES SELF-CARE ACTIVITIES INSTRUMENT.... 135 
APPENDIX I: HEALTHY TUTOR DIABETES KNOWLEDGE TEST ............................. 138

APPENDIX J: ATTITUDE INSTRUMENT_............................................................. 147

APPENDIX K: FINDINGS OF ANALYSES NOT INCLUDED IN THE TEXT .................. 152

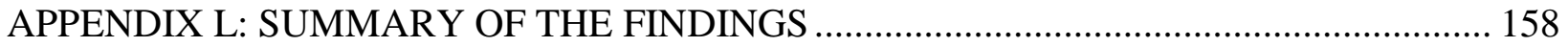

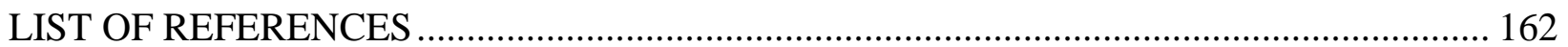




\section{LIST OF FIGURES}

Figure 1. Relationships of KAP-O Components in the Experiment ....................................... 13

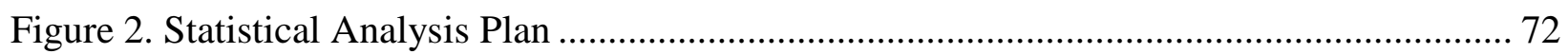

Figure 3. Intention to Treat Analysis Plan .......................................................................... 73

Figure 4. The Net Effect of Experimental Status on Knowledge at T2 (K-T2)........................ 84

Figure 5. Experimental Status, Knowledge (K-T2), Attitude (A-T2), and Practice (P-T2) at T2

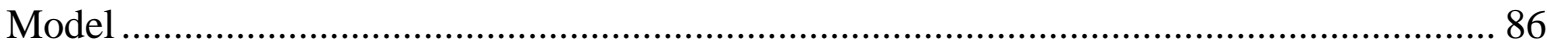

Figure 6. The Net Effect of Experimental Status on Glycated Hemoglobin (A1C) at T2 ......... 88

Figure 7. The Net Effect of Experimental Status and Differences in Knowledge (DK), Attitude (DA), and Practice (DP) on Difference in Glycated Hemoglobin (DA1C) 90

Figure 8. The Net Effect of Experimental Status, and Differences in Knowledge (DK), Attitude (DA), and Practice (DP) on Difference in Low-Density Lipoprotein Cholesterol (DLDLC)

Figure 9. The Net Effect of Experimental Status and Differences in Knowledge (DK), Attitude (DA), and Practice (DP) on Difference in Poor Perceived Health (DPPH).....

Figure 10. The Net Effect of Experimental Status and Differences in Knowledge (DK), Attitude

(DA), and Practice (DP) on Difference in Functional Capacity (DFC)

Figure 11. The Net Effect of Experimental Status on Attitude at T2 (A-T2) ......................... 153

Figure 12. The Net Effect of Experimental Status on Practice at T2 154

Figure 13. The Net Effect of Experimental Status on Low-Density Lipoprotein Cholesterol

(LDLC) at $\mathrm{T} 2$ 155

Figure 14. The Net Effect of Experimental Status on Functional Capacity (FC) at T2 156

Figure 15. The Net Effect of Experimental Status on Poor Perceived Health (PPH) at T2 157 


\section{LIST OF TABLES}

Table 1. Description of Constructs and Their Measurement 61

Table 2. Pearson Correlations of Age, Ethnicity, Gender, and Comorbidities with Experimental Status 76

Table 3. Correlation Analysis of Four Outcome Variables: A1C, LDLC, PPH, and FC 77

Table 4. Experimental Effect on Knowledge Scores at T2 and Differences between T1 and T2 79

Table 5. Experimental Effect on the Scores for Attitude toward Diabetes at T2 and Differences between $\mathrm{T} 1$ and $\mathrm{T} 2$

Table 6. Experimental Effect on the Scores for Preventive Practice at T2 and the Differences between $\mathrm{T} 1$ and $\mathrm{T} 2$

Table 7. Experimental Effect on the A1C Measures at T2 and Differences between T1 and T2. 81 Table 8. Experimental Effect on the Measures of Low- Density Lipoprotein Cholesterol (LDLC) at $\mathrm{T} 2$ and the Difference between $\mathrm{T} 1$ and $\mathrm{T} 2$ 82

Table 9. Experimental Effect on the Scores for Functional Capacity at T2 and the Differences between $\mathrm{T} 1$ and $\mathrm{T} 2$

Table 10. Experimental Effect on the Scores for Poor Perceived Health at T2 and the Differences between $\mathrm{T} 1$ and $\mathrm{T} 2$ 83

Table 11. Experimental Effect on Practice at T2 via Knowledge and Attitude at T2 86

Table 12. The Net Effect of Experimental Status and Differences in Knowledge, Attitude, and

Practice on Difference in $\mathrm{A} 1 \mathrm{C}$ at $\mathrm{T} 2$ 91

Table 13. The Net Effect of Experimental Status and Differences in Knowledge (DK), Attitude (DA), and Practice (DP) on Difference in low-density lipoprotein cholesterol (DLDLC) .. 92 
Table 14. The Net Effect of Experimental Status and Differences in Knowledge (DK), Attitude (DA), and Practice (DP) on Difference in Poor Perceived Health (DPPH). 93

Table 15. The Net Effect of Experimental Status and Differences in Knowledge (DK), Attitude (DA), and Practice (DP) on Difference in Functional Capacity (DFC) 


\section{LIST OF ABBREVIATIONS}

ADA

AMOS

BSE

CAD

CFI

$\mathrm{CHF}$

CITI

CKD

DAS

DKT

DMPA

EQ-5D

EQ VAS

EuroQol

GOF

HBM

IRB

ICD9

KAP

KAP-O

LDLC
American Diabetes Association

Analysis of Moment Structures

Breast Self-Exam

Coronary Artery Disease

Comparative Fit Index

Congenital Heart Failure

Collaborative Institutional Training Initiative

Chronic Kidney Disease

Diabetes Attitude Scale

Diabetes Knowledge Test

Diabetes Mellitus Patient Attitude Test

European Quality, Five Dimensions

European Quality, Visual Analogue Scale

European Quality of Life

Goodness-of-fit

Health Belief Model

Institutional Review Board

International Classification of Diseases Ninth Revision

Knowledge, Attitude, Practice

Knowledge, Attitude, Practice, Outcome

Low Density Lipoprotein Cholesterol 
PAID

PPBG

RMSEA

RCT

SDSCA

SPSS

SEM

UKPDS

UCF
Problem Areas in Diabetes

Postprandial Blood Glucose

Root Mean Square Error Approximate

Randomized Control Trial

Summary of Diabetes Self-Care Activities

Statistical Package for the Social Sciences

Structural Equation Modeling

United Kingdom Prospective Diabetes Study

University of Central Florida 


\section{CHAPTER ONE: INTRODUCTION}

Diabetes is a chronic metabolic disease with no cure (Fradkin, 2012). Although health education is an essential component of chronic disease management (Horn, 1997), educational interventions to improve the self-care by diabetes patients have had mixed results. Studies have shown improvements in some health care outcomes (Adepu, Rasheed, \& Nagavi, 2007; Cranor, Bunting, \& Christensen, 2003; Hogue, Babamoto, Jackson, Cohen, \& Laitinen, 2003; Korhonen et al., 1983; Malathy, Narmadha, Ramesh, Alvin, \& Dinesh, 2011; Tilly, Belton, \& McLachlan, 1995), but for other outcomes no improvement has been shown (Bloomgarden et al., 1987; Ozmen \& Boyvada, 2002).

\section{The Study Purpose}

This research studies the causal mechanisms leading to better adherence by diabetes patients to management of their disease and to better health care outcomes for them, as well as how to improve the success of educational interventions for such patients.

\section{Background on Diabetes}

Diabetes causes a disruption of the body's metabolism of sugar. All cells of the body need sugar to function; it is insulin that makes sugar available to muscle and fat cells. The two major types of diabetes are Type I, when the insulin production is deficient, and Type 2, when insulin action meets with resistance (Fradkin, 2012). Since 90-95\% of all the United States diabetes patients have Type 2 diabetes (Fradkin, 2012), this research examines the management of Type 2 diabetes. In Type 2 diabetes, the body cells fail to respond to the normal action of insulin, so sugar is not taken up and remains in the blood. High sugar levels in the blood damage 
small and large blood vessels, nerves, and organs and eventually can cause blindness, kidney diseases, strokes and heart attacks, as shown by the United Kingdom Prospective Diabetes Study (UKPDS).

Type 2 diabetes and its complications are a huge economic burden. However, the disease can be controlled with medication to lower blood sugar and blood pressure, as demonstrated in the UKPDS trial (Leslie, 1999). Moreover, the threat of diabetes has been shown to be forestalled by a $7 \%$ weight loss and 150 minutes of weekly exercise, in the Diabetes Prevention trial (Knowler et al., 2002). Other trials with pre-diabetics in Sweden, China and Finland also have reported that lifestyle changes reduced the incidence of Type 2 diabetes by $31 \%$ to $63 \%$ (Delahanty \&Wylie-Rosette, 2006). Thus studies have shown that Type 2 diabetes is preventable. Such complications of diabetes as kidney failure, heart attack, and stroke can be avoided or treated (Fradkin, 2012).

\section{Prevalence, Risk Factors and Costs}

According to the Centers for Disease Control and Prevention (2011), Type 2 is a chronic condition that affects $8.3 \%$ of the US population and $26.7 \%$ of those aged sixty-five or older (www.cdc.gov/nchs). This high prevalence of Type 2 makes diabetes a national threat; patients die prematurely from the resulting complications (Fradkin, 2012). The prevalence of diabetes Type 2 has been increasing steadily, particularly in younger age groups (Fradkin, 2012).

Risk factors for developing Type 2 diabetes are: genetics, first-degree relatives with diabetes, obesity, sedentary lifestyle, high-carbohydrate diet, low socioeconomic status, and lack of access to primary care and to nutritious food, ethnicity, and history of gestational diabetes or delivery of a baby heavier than 9 lbs., and polycystic ovary syndrome (www.cdc.gov/nchs). 
Direct health care costs for diagnosed diabetes and lost productivity in 2012 totaled 245 billion dollars. The costs would be higher if indirect costs were included, according to a report by Yang et al. (2013) for the American Diabetes Association.

Diabetes is asymptomatic in its early stages, but screening for elevated blood sugar and/or glycated hemoglobin (A1C) in the fasting state can diagnose both pre-diabetes and diabetes. A better outlook for diabetes patients has been achieved by research that has improved clinical outcomes and patients' quality of life. Patients' economic burden can be reduced if they control their diabetes, by complying with a medication regimen, self-monitoring blood sugar and meeting appointments for screening and laboratory tests.

To delay the complications from diabetes also requires controlling blood sugar, blood pressure, and cholesterol through medications (Fradkin, 2012). The American Diabetes Association (ADA), in the Executive Summary: Standards of Medical Care in Diabetes (2011), recommends screening for blood sugar with the glycated hemoglobin (A1C) test, screening cholesterol, and laboratory tests for kidney disease as well as measurement of blood pressure at clinic visits. The results of laboratory tests guide the provider in deciding about drug therapy. Diabetic patients also should be monitored by other medical specialists to avoid and treat complications.

Physicians follow professional guidelines for the best therapy and also counsel patients on incorporating regular exercise and healthy diet. However, a physician's plan will not be effective unless the patient makes regular office visits and keeps appointments for tests and screening.

Because Type 2 diabetics have reduced response to insulin, they need to self-monitor blood glucose to assess the effects of different types and quantities of foods in raising blood 
sugar, and then must adjust food intake to avoid both high and low blood sugar. Self-monitoring their blood glucose empowers patients to assess how it is affected by their food intake, physical activity and medication (Austin, 2005).

A randomized control trial with more than 5,000 Type 2 diabetics conducted by Pi Sunyer et al. (2007) showed that weight loss through reduced food intake and increased physical activity complemented a medication regimen so that patients had better clinical outcomes and needed less medication to control their blood sugar, blood pressure and cholesterol. Since much of such management depends on the patients, it is important to educate patients. The ADA (2012) drew on clinical evidence to recommend empowering diabetics with the knowledge and ability needed for self-care, through self-management education. The curriculum for diabetes self-management educates patients about the disease process, healthy eating, physical activity, medication adherence, self-monitoring of blood sugar, self-monitoring of food and activity, goal setting, problem solving, healthy coping, adherence to medications and having follow-up visits to reassess health outcomes.

Health education available from popular periodicals or internet search engines may not be evidence-based. Health educational interventions should be theoretically grounded and empirically validated in order to incorporate causal mechanisms that lead to effective adherence to a regimen and so to better health care outcomes.

Randomized control trials of self-management education have focused mostly on measuring specific clinical and other health care outcomes and noting those that health education may improve. However, such studies fail to demonstrate any dose-response relationship between the amount of health education and the degree of outcome improvement with the exception of glycated hemoglobin (A1C) as described by Norris, Lau, Smith, Schmid and Engelgau (2002). 
Furthermore, the shortcomings of research on controlling diabetes through health education are compounded by the failure to consider variation in their study design (Norris, Engelgau, \& Narayan, 2001).

The purpose of the present study is to identify the causal mechanisms responsible for improved knowledge, attitude, practice and outcomes, so that, educational interventions can be tailored efficiently and effectively to the groups of patients who are most likely to benefit from self-care management.

\section{Significance of the Study}

The knowledge-attitude-practice-outcome (KAP-O) framework as proposed by Wan (2014) is used to understand the causal path of educational interventions and changing health care outcomes through the mediation by the variables of knowledge, attitude, and practice. The study aims to evaluate whether educational interventions affect outcomes directly or have indirect effects on outcomes through knowledge, attitude and practice since prior research has not examined the causal relationships among KAP-O components.

\section{Conceptual or Theoretical Import}

The behavioral sciences literature suggests that attitudinal and behavioral changes can be explained by health beliefs (Rosenstock, 1960 as cited in Glanz et al., 2002, p. 47), cognitive learning (Malathy et al., 2011), motivational therapy (Williams, Freedman, \& Deci, 1998), behavioral economics (Farina, 2013), and cultural sensitivity (Baradaran, Knill-Jones, Wallia, \& Rodgers, 2006). However, these studies fail to demonstrate how health education works. This study addresses this deficiency by using a framework composed of knowledge, attitude, practice and outcomes (KAP-O) proposed by Wan (2014) in the International Journal of Public Policy. 
This study measures the structural or causal relationships among the components of the KAP-O framework in a health behavioral system model.

\section{Methodological Rigor}

This study delineates the possible causal paths of educational intervention (an exogenous, or independent, variable) in producing the intervention's direct influence as well as its presumed indirect influence on a series of self-reported and clinical outcomes, variables dependent on changes in patients' knowledge, attitude, and behavior. Outcomes can be either subjective (i.e. self-reported perceptions of poor health and functional capacity as measured by reliable, validated survey instruments) or objective such as glycated hemoglobin (A1C) (UKPDS Trial, 2002) and low- density lipoprotein cholesterol (Zyskind, Jones, Pomerantz, \& Barker, 2009).

Because medical practices' approaches to diabetes control vary, this study aims to eliminate that confounding factor by examining the practice of a single medical group with a single provider. Socioeconomic factors may contribute to the variation in health care outcomes (Manabe et al., 2011; Morales, Lara, Kington, Valdez, \& Escarce, 2002). This study examines a relatively homogeneous patient population served by a single medical practice with a single provider in St. Augustine and Palm Coast, Florida. A randomized trial for the evaluation of a health educational intervention has been conducted.

\section{Practical Application}

It is very expensive to impart diabetes education in a study of diabetes control. The continued monitoring and observation of patients' clinical outcomes is complicated because it requires the support of clinical and other staff in a medical practice. Fortunately, full cooperation from the St. Augustine and Palm Coast practices' physician and staff enabled this randomized 
trial. A set of assessment instruments was well identified and evaluated for the implementation of this empirical study.

\section{Policy Relevance}

Diabetes is not only a major clinical problem, but a serious public health issue as well. Type 2 diabetes is increasingly prevalent in younger age groups (www.cdc.gov/nchs), and is associated with the rising rates of obesity and physical inactivity (King, Aubert, \& Herman, 1998). It is important to promote changes toward a healthy lifestyle and greater physical activity if we are to combat this serious public health problem. In addition, public health officials could promote healthy outcomes using cost-effective strategies such as health education.

\section{Research Questions}

This research studies the causal mechanisms leading to better adherence by diabetes patients to management of their disease and to better health care outcomes for them, as well as how to improve the success of educational interventions with such patients. Research questions pertaining to the KAP-O model were formulated.

Although the reviewed literature assumes that the outcome indicators used here are related, empirical evidence is lacking to show that these outcome indicators constitute a single dimension of a theoretical construct: health care outcomes.

Evidence demonstrating the causal mechanisms for improving diabetes patients' knowledge, attitude, and practice, and, hence the outcome of diabetes care is also needed. Health education may directly affect knowledge, attitude, practice, and subjective and objective outcomes. Health educational interventions also may exert indirect effects on practice through changes in knowledge and attitude. Thus an empirical investigation of health education's effects 
could be conducted to answer the first research question: Does health education directly affect knowledge, attitude, practice of self-care, and health care outcomes? The second research question: Based on the KAP model, what is the effect of health education on knowledge, attitude, and practice? Based on the theoretical specification of KAP-O model, it is expected that health educational intervention may indirectly influence outcome variables via improved knowledge, attitude, and practice. Thus the third research question: Does health education affect health care outcomes indirectly through improved changes in knowledge, attitude and self-care practice?

\section{Study Design}

The study's classic experimental design used pre- and post- tests of the KAP-O components for a randomly selected patient population from a single medical practice with a single provider. The pre- and post- test study used randomization in which the researcher was an active agent, and not a passive observer. A thorough literature review revealed a gap in the potential causal mechanism of the effects of educational intervention on preventive practice and outcomes. This study attempts to fill the research gap.

The study design was experimental pre-post, with patients randomized to test and control groups, which is the most powerful method for testing any hypothesis relating to cause and effect relationships between variables. The experimental group was given access to interactive selfpaced web-based tutorials supplemented with a printout, using the Healthy Tutor (Dickeson \& Scheel, 2014). The control and experimental groups both received usual customary care. The experiment attempted to delineate whether it was the experimental intervention that caused KAPO changes in the experimental group. 
The study employed a pre- and post- test design. Knowledge, attitude, practice, functional capacity and poor perceived health were measured at two time points before and after intervention, using reliable, validated instruments. Baseline and post-intervention glycated hemoglobin (A1C) and low-density lipoprotein cholesterol (LDLC) were the objective outcomes. The researcher had no control over the follow-up appointments of patients therefore the two time points before and after intervention varied for each patient.

\section{Consideration of the Framework for the Study}

In this study the diabetic patient is the unit of analysis, and variation in self-care or preventive practice is the focus. Hence theories of human health behavior were reviewed. The five theories considered were the health belief model, the theory of planned behavior, the social cognitive theory, the trans-theoretical model, and the patient empowerment model. None of those

five theories were applicable, for the following reasons: The health belief model concerns with such determinants of health behavior as perceived costs and perceived benefits, but not the measurement of behavior. The theory of planned behavior assumes that behavioral intention is the only prerequisite for actual behavior; however, intention does not always result in behavioral change. Social cognitive theory regards self-efficacy or the ability to enact behavior as the most important determinant of behavior, but does not focus on the actual behavior. The transtheoretical model is a therapeutic model applicable to intentional behavioral changes, whereas this study measures both intentional and non-intentional behaviors. Finally, the patient empowerment model's emphasis on goal setting and the plan of actions to achieve a goal is not applicable to this study. 
The study framework is based on behavioral science, in particular on social psychological theory of cognition, attitude, behavior, and outcomes. Cognition and attitude are interrelated constructs. The study focuses on actual practice, not behavioral intention that may or may not result in healthy behavior.

\section{Health Educational Intervention}

According to Simmonds (1976), health education aims at inducing individuals, groups or large populations to adopt healthy behavior that will promote present and future health and, to eliminate behaviors that have adverse effects on health (as cited in Glanz et al., 2002, p.8). A variety of educational products could be used to design an intervention for diabetes patients, for example, diabetes conversation map created for Merck \& Co., Inc., a learning map module called Managing Your Journey (Garrett et al., 2005).

\section{Knowledge, Attitude, Preventive Practice, and Outcomes (KAP-O) Framework}

The literature review suggested that educational interventions improve knowledge and attitude, and that improved knowledge enhances self-care practice. Improved attitude improves practice, and improved practice leads to improved outcomes. Therefore the knowledge-attitude-

practice -outcome framework (KAP-O model of behavioral change) as proposed by Wan (2014) forms the ideal theoretical basis for the study's examination of the underlying mechanism by which educational intervention may improve health care outcomes. Application of KAP-O in a pre- and post- test study may reveal the relative importance of predictors for the variation in diabetes outcomes. 


\section{Measurement of Knowledge, Attitude, Practice, and Subjective and Objective Outcomes}

Following is a list of instruments used in this study. The Diabetes Knowledge Test (DKT) instrument was formulated by the researcher to measure knowledge of causes of diabetes, signs of disease, complications of diabetes, and preventive behaviors for diet, exercise, foot care, high blood pressure, cholesterol, and meal planning. Thirty-eight questions from a pool of questions embedded in the seven core tutorials of Healthy Tutor 2010 (Dickeson \& Scheel, 2014) formed the DKT instrument used to measure knowledge.

Diabetes Attitude: The researcher also formulated a scale for Diabetes Type 2 Patient Attitude (DMPA) to measure gradational levels of attitude ranging from like (favor) to dislike (disfavor). Thirty questions were developed to cover the three domains of attitude: cognitive, affective and behavioral.

Preventive Practice: Summary of Diabetes Self-Care Activities (SDSCA) is a known available instrument that measures the practices of following a healthy diet, exercising, testing blood sugar, checking blood pressure, taking care of feet and avoiding smoking.

\section{Instruments to Measure Subjective Outcomes}

Two subjective outcomes are: 1) Functional Capacity, the degree of ability for mobility, selfcare, usual activities, pain/discomfort, anxiety/depression, (EuroQol, 2009) as well as the dimensions for sleep, memory/concentration, energy, seeing and hearing, and contact with others (Perneger \& Courvoisier, 2011) was measured by a composite instrument of EQ-5D-5L with five additional dimensions as proposed by Perneger and Courvoisier in 2011; and 2) Poor Perceived Health: a single index value for health status, which is self-reported with the EQ VAS analog scale. 


\section{Measurement of Objective Outcomes}

Two clinically assessed outcomes are: 1) Glycated Hemoglobin (A1C), a lab test that shows the average level of blood glucose over the previous 3 months, indicating the extent of control of diabetes over a period of time (ADA, 2012). Glycated Hemoglobin (A1C) is tested by a sample of blood from a vein. 2) Low Density Lipoprotein Cholesterol (LDLC): low density lipoprotein, which transports cholesterol within the blood, can deposit inside blood vessels and thus obstruct them. Low Density Lipoprotein Cholesterol (LDLC) is tested in a sample of blood from a vein.

\section{Sampling}

The Type 2 diabetic patients in a single multi-site medical practice located in St. Johns County and Flagler County, Florida, comprised the sampling frame, since the focus of the study is not provider performance, but the variation in self-care management by Type 2 diabetic patients. Patients were randomized into the experimental and the control groups to avoid systematic bias in the groups.

\section{Analysis Plan}

A Pearson correlation was used to detect whether the groups were comparable in terms of personal characteristics that could, simultaneously with intervention, influence knowledge, attitude, and practice (proximal outcomes), and outcome measures (distal outcomes). A correlation analysis of the outcome variables was needed so that the formation of a single latent endogenous variable (i.e. the diabetes care outcome) could be determined by confirmatory factor analysis. 
Multiple independent samples t-tests were needed to detect the differences in baseline and values at $\mathrm{T} 2$ of the endogenous variables, in terms of knowledge, attitude, practice, and outcome measures. The key outcome variables for detecting whether group differences existed at T1 and T2 were: glycated hemoglobin (A1C), low density lipoprotein cholesterol (LDLC), functional capacity (FC), and poor perceived health (PPH).

A causal model was posited with explanatory linkages assumed among health educational intervention, knowledge, attitude, practice and outcomes in a panel design, as shown in figure 1 below.

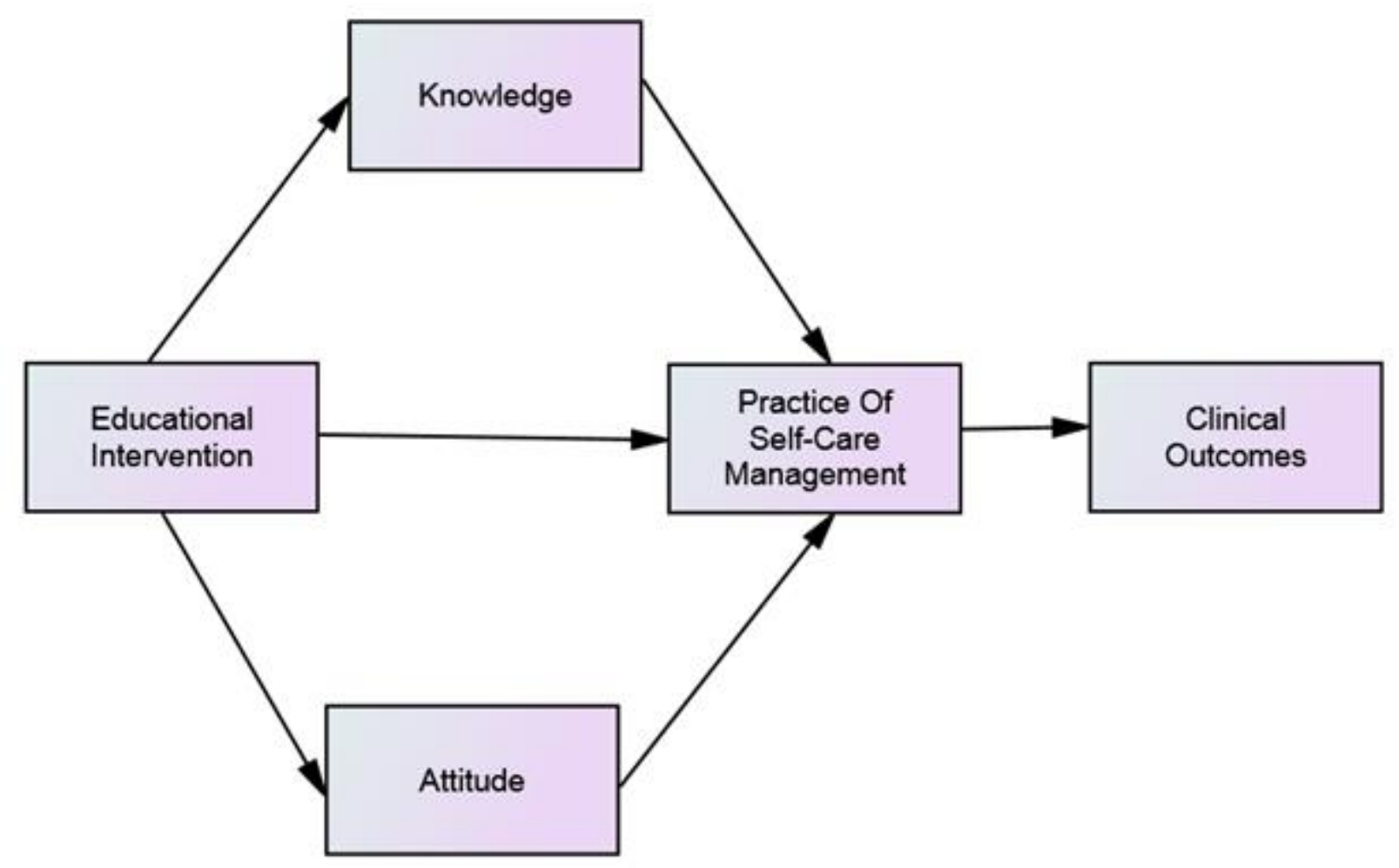

Figure 1. Relationships of KAP-O Components in the Experiment

This model was tested to discover whether the hypothesized pathways (direct and indirect causal paths) specified by the causal model were consistent with the data. Structural equation 
modeling (SEM) with path analysis tested the causal hypotheses concerning direct and indirect causal effects of health educational intervention on proximal knowledge, attitude, practice and distal outcomes of diabetes control. Those techniques enable the researcher to remove the potential confounding effects of variables other than the intervention variable. Analysis of Moment Structures (AMOS) 21 was used to run the models at a statistical significance level of 0.05 .

\section{Challenges of the Study}

Conducting random trials is costly and challenging. The key challenges of a randomized control trial are related to obtaining adequate sample size, duration of the study (if the study period is too short, the researchers are not able to elicit changes in outcomes. If the study lasts too long, the sample dropout rate is high). In longitudinal studies the number of study participants dwindles over time due to their mobility, the difficulty in locating the participants, and death or disability in a high-risk population (Polit \& Hungler, 1995). Additional difficulties in the conduct of the experiment were as follows:

1. Recruiting of study participants face-to-face was a challenge; many diabetic patients declined to participate. (Monetary incentives, which have been shown to increase participation, were not possible, since there was no financial backing).

2. Conducting the study was tedious and laborious due to the lack of manpower. One researcher did all the tasks: recruiting patients, which involved time-consuming conversations to convince them to participate by explaining the benefits of the research; qualifying patients' eligibility; showing patients in the intervention group how to access the online web tutorials; providing lab orders for tests; sending 
reminders to patients about complying with tests and completing tutorials; locating hard-to-reach patients, entering clinical data into the computer from electronic charts; and contacting labs for test results.

3. Some study participants of low socioeconomic status declined to participate, saying that they did not have access to computers or were not computer literate.

4. The selection of educational material involved choosing an appropriate number of modules, selecting modules that were relevant to self-care and choosing questions specific to the knowledge provided by the educational modules. The existing instruments to measure knowledge, attitude and preventive practice are not very standardized. Researchers use a variety of different instruments.

5. A suitable instrument was lacking to test the three components of attitude: cognition, affect and behavioral tendency. Construction of an attitude instrument to test these three domains of attitude became necessary.

6. Appropriate instruments to test health literacy, practice of preventive behavior, functional capacity and poor perceived health had to be identified.

The above challenges of the research were overcome by the following actions:

1. Persistence in recruiting despite some earlier resistance from patients paid off eventually. Evincing concerns for the patients and attending to their needs with appropriate help, as well as being a member of a health care team enabled the researcher to enroll about two hundred participants. Informing participants that the study was endorsed by the University of Central Florida created trust and assured patients of confidentiality. 
2. Persistence in accomplishing all relevant tasks enabled data collection. All data entries for the survey instruments were checked thoroughly.

3. Participation was made convenient for all participants by providing computer access on large screen monitors and providing private rooms or a conference room where survey questionnaires could be completed. The researcher sat down with willing participants and showed them how to access the tutorials. Every possible patient was approached to participate unless he/she met exclusion criteria or failed the literacy assessment test. Because the explanations to diabetes patients were very timeconsuming, however, some patients left the clinic before they could be approached.

4. Selection of educational material that would provide information clearly to patients and empower them to control their disease was essential. A curriculum of ten modules was reduced to seven core tutorials accessible to patients with varying educational levels. Thirty-eight questions specific to the content of the modules were chosen from a pool of more than one hundred questions.

5. Since no existing instruments measure all three of the components of attitude: cognition, affect, and behavioral tendency, the researcher drew on the literature review, and consultation with professionals who treat diabetes patients in order to pinpoint areas of concern for diabetics and create a useful instrument to measure attitude.

6. The researcher consulted with experts in the field to select appropriate instruments; their guidance was invaluable. 


\section{Overview of the Chapters}

The dissertation has five chapters. The literature review and theoretical framework constitutes Chapter 2. The methodology, comprising the study design, sampling, measurements, and analytical design, is in Chapter 3. The findings for each research question are presented in Chapter 4. Finally, Chapter 5 presents the implications of the major findings, conclusions, and future research directions. 


\section{CHAPTER TWO: LITERATURE REVIEW AND THEORETICAL FRAMEWORK}

Patients diagnosed with diabetes, a progressive chronic condition, need to be engaged in behavioral change. According to the American Diabetes Association (2011), the goals of behavioral change as described in standards of medical care in diabetes are: avoid complications, ensure good control of blood sugar through adherence to medications, self-monitor blood sugar, develop healthy eating, perform 150 minutes of physical exercise weekly, and follow up with medical appointments.

This chapter focuses on selected behavioral theories relevant to changing diabetes patients' behaviors: the health belief model, the theory of planned behavior, social cognitive theory, the trans-theoretical model of stages of change, and the patient empowerment model. These theories seek to identify the determinants of health behavior. This chapter also reviews studies that measured knowledge, attitude, and practice, and proposes the theoretical framework and hypotheses.

\section{Review of Conceptual/Theoretical Perspectives}

The health belief model (Becker, 1974; Hochbaum, 1958; Janz \& Becker, 1984; Kirscht, 1974; Rosenstock, 1960 as cited in Glanz et al., 2002) is one of the oldest theories seeking to explain human health behavior. An individual will perform a preventive behavior if the individual believes that he/she is vulnerable to a disease or problem (susceptibility), that the after-effects of the disease or problem are serious (perceived risk for the severity of illness), that the prescribed action to deal with the problem is helpful (perceived benefits of action), and that the action entails more advantages than costs (perceived costs). 
The health belief model (HBM) has several limitations. One is the fact that habitual behavior such as smoking tends not to be influenced by active accounting of costs and benefits. HBM, which attempts to predict human behavior by considering differences in individual beliefs and attitudes, would predict that Type 2 diabetes patients, to avoid complications of diabetes by controlling their blood sugar, would be likely to have a healthy diet and exercise regularly. The HBM model thus identifies as an initial predisposing factor the desire to avoid complications of diabetes; but the model does not consider factors responsible for enabling and maintaining preventive behavior over time (Janz, Champion, \& Strecher, 2002). Moreover, the Health Belief Model deals only with personal perceptions such as perceived risk and perceived cost and thus is too subjective for application in this study. This model does not consider the interaction effects of a complex set of behavioral determinants. Although HBM identifies potential predictors of adherence to medical regimens, its contribution to understanding the causal mechanisms of adherence is limited.

The theory of planned behavior (Ajzen, 1991; Ajzen \& Driver, 1991; Azjen \& Madden, 1986 as cited in Glanz et al., 2002) states that a person's behavior is determined by his/her intention to perform that behavior. The intention is formed by his/her attitudes toward that behavior, his/her beliefs about what others think he/she should do, his/her motivation to comply with the wishes of others and perceived behavioral control. If the individual evaluates the behavior as beneficial, and significant others approve of the behavior, then the individual has more intention to carry out the behavior and is more likely to do so (Montano \& Kasprzyk, 2002). Nevertheless, behavioral intention does not always lead to actual behavior, because environmental and contextual constraints come into play. The theory of planned behavior does not consider such interaction effects. The theory of planned behavior traces logical sequence, but 
human behavior is not always logical. In any case, the current study measures self-care behaviors as actual actions reported by patients, not just their intentions to act.

Social cognitive theory (SCT) (Bandura 1986, 1997, 2001 as cited in Glanz at el., 2002, p. 165-184) offers a complex global theory of behavioral change. Determinants of health behavior are described by the key elements of reciprocal determination, observational learning, outcome expectancy, and self-efficacy (Baranowski, Perry, \& Parcel, 2002). However, SCT lacks a causal framework linking those components of the theory.

Reciprocal determination denotes that behavior and environment interact and influence one another. The theory postulates that change results from the interactions between individuals and their environments as a reciprocal process (Baranowski et al., 2002). Observational learning is the capacity to learn from observing the behavior of others (Baranowski et al., 2002). Outcome expectancy refers to a person's assessment that a given behavior will result in certain beneficial outcomes (Baranowski et al., 2002). Self-efficacy is the degree of assurance in one's own ability to make a change or perform a behavior (Baranowski et al., 2002).

Social cognitive theory recognizes that environmental influence, social norms, cues, and self-efficacy influence health behavior (Baranowski et al., 2002). The theory implies that health can be promoted by modifying the social environment and fostering skills that empower individuals to make healthy behavioral changes (Baranowski et al., 2002). However, this theory lacks a framework linking the causal components of behavioral change, and it is also resource intensive. For those reasons it was not used in this study.

The trans-theoretical model (Prochaska \& DiClemente, 1983) explains behavioral change as a cyclical process involving five stages of change. Individuals have varying degrees of readiness to change and may vacillate between the stages of pre-contemplation, contemplation, 
preparation, action and maintenance (Prochaska, Redding, \& Evers, 2002). Therefore the implementation of that research framework entails providing individual psychotherapy. As a model that would require monitoring a large number of study participants as well as the assistance of licensed therapists, therefore, the trans-theoretical model was not a feasible choice for this study.

Patient empowerment theory (Funnell, Anderson, \& Arnold 1991; Funnell \& Anderson 2003 as cited in Mensing, 2006, p.46) postulates that decisions about lifestyle changes cannot be dictated to patients. Patients should be in charge of their self-care. The theory reasons that since self-care first of all benefits patients themselves, they should be the primary decision makers about it (Funnell, Anderson, \& Tang, 2006). The patient empowerment model guides educators and health professionals in recognizing a patient's wishes to manage and then tailoring a patientdirected plan for behavioral change (Funnell et al., 2006). This labor-intensive and timeconsuming approach was not feasible for a single researcher.

In summary, the likely human health behavioral theories or models either do not measure actual health behavior or are very labor- and resource-intensive and time-consuming. Therefore the Knowledge-Attitude-Practice (KAP) framework was used.

\section{The Knowledge, Attitude, Practice Framework}

The KAP behavioral system framework captures both the predisposing factors of attitudes and knowledge about diabetes control, and actual behavior. It is more complete in its causal specifications of determinants of preventive practice and outcomes. Knowledge about and attitudes towards a health disorder are important predictors of adherence to a prescribed regimen. Although the KAP framework cannot address provider behavior, it is still advantageous when 
compared to other models in its logical formulation for causal sequences among the determinants of health behavior and outcomes. The following section briefly reviews the use of the KAP model in research.

\section{History of KAP Surveys}

KAP surveys were first developed in the 1950s. After 1960 KAP surveys were extensively used in many countries to research family planning practice. The KAP studies are more cost-effective and conserve resources more than other social research methods, because they are tightly focused and limited in scope (Eckman \& Walker, 2008). This theoretical framework has been widely used in the health education field and in the developing world for family planning, and as a guide to understanding the mechanisms of health education for patient behavioral changes and patient health outcomes (Jaccard, Dittus, \& Gordon, 1996). KAP surveys are now a widely used methodology for studying human behavior when affected by a problem or disease.

\section{KAP Survey Methodology}

"K" stands for knowledge of the problem or disease, "A" for attitude towards the problem or disease, and " $\mathrm{P}$ " for practice or preventive behavior to protect against the problem or disease. Researchers assume that knowledge, attitude, and practice are related, and that knowledge and attitude directly influence preventive practice. Surveys are used to measure what individuals know about the disease or health problem. Attitude instruments measure the feelings and beliefs of survey participants about the disease or problem, and information on practice measures the preventive behaviors that individuals follow to avoid a problem or disease. 
Researchers choose a sample of participants that is representative of the population. The constructs of knowledge, attitude and practice are further defined below.

\section{Definitions of Constructs}

Knowledge: Knowledge is the acquisition, retention, and use of information or skills (Badran, 1995). Cognition through which knowledge is acquired is a process of understanding and is distinguished from the experience of feeling. Knowledge accrues from both education and experience. Knowledge possessed by diabetics refers to their comprehension of the disease, its progression, and self-care practice necessary for keeping diabetes under control.

Attitude: Eagly and Chaiken (1993) in "The Psychology of Attitude" define attitude as "a psychological tendency that is expressed by evaluating a particular entity with some degree of favor or disfavor". Attitude has three components: cognition, affect, and behavior, as discussed by Katz \& Stotland, 1959; Krech \& Crutchfield, 1948; and Rosenberg \& Hovland, 1960 as cited in Eagly \& Chaiken, 2007. Cognition comprises true and false beliefs about the attitude object; health education may change such beliefs. Thus there may be overlap between knowledge and attitude. For example, some diabetic patients may have beliefs that they may not live healthy, long lives, because of having heard about older relatives dying at an early age from such complications of diabetes as heart attack, stroke, or kidney failure; they assume that the same fate may befall them. The affective component of attitude is the whole gamut of emotions toward every aspect of the attitude object. Some diabetic patients may have a set of varying attitudes towards self-care management of diabetes. They may love to exercise, as it makes them feel good, but hate self-monitoring their blood sugar because they are averse to pricking their skin. The behavioral components of attitude are the proneness to act in particular ways with reference 
to the attitude object. Thus some diabetes patients may follow through all recommendations by physicians, while other patients may not. In summary, attitude toward diabetes refers to any preconceived ideas about diabetes and its management, patients' feelings/emotions towards aspects of diabetes and diabetes care, and the aptness to behave in particular ways about diabetes and its management.

Practice: Practice demonstrates the acquisition of knowledge (increased understanding of a problem/disease) and any change in attitude caused by the removal of misconceptions about problems or disease that translates into preventive behaviors. Thus that demonstration may reflect a reciprocal relationship between knowledge and attitude. Practice is behaviors or actions that can avert a disease or delay its progression. In diabetes, practice would involve healthy eating, increased physical activity, adherence to medications, overcoming the barriers to weight loss and sedentary lifestyle, avoidance of overeating or inactivity as responses to stress, followup with physicians, and participation in tests to reassess health outcomes. Those practices are the seven self-care behaviors strongly advocated by the American Association of Diabetes Educators and the American Diabetes Association.

\section{Objectives of KAP Surveys}

KAP surveys have three objectives. The first objective of KAP surveys is to assess in samples of a population the knowledge, attitudes and practices about an epidemic problem. The knowledge comprises what members of the sample know about symptoms, transmission and treatment of the disease. Attitudes towards the disease include sample members' awareness of the seriousness of the disease, fear of being infected, and willingness to protect them from the disease. Practice refers to preventive behavior to avoid harm. The KAP survey can guide the 
prioritization of resources to populations with very poor KAP scores. Several of the studies reviewed in the literature assess KAP in either a randomly selected or a convenience sample of a population with regard to a health problem or a disease. Such assessments are usually crosssectional, since those are cheaper to conduct and less time-consuming.

A second objective of KAP study is to enable researchers to identify gaps in knowledge, attitude and practice and to design an intervention to close those gaps. A third objective of KAP surveys is to evaluate interventions or programs, noting the differences in knowledge, attitude and practice scores after an intervention by using the same group in a pre- and post-design.

Some KAP studies explore the relationships of socio-demographic variables to the variables of knowledge, attitude, and preventive behavior. A number of researchers have evaluated diabetes programs using the KAP approach. The findings of KAP studies both on diseases other than diabetes and on diabetes are described.

\section{Non-Diabetes Studies Using KAP Survey Methodology}

General studies using KAP survey methodology that assume that knowledge and attitude are related and that knowledge and attitude affect preventive practice, are cross-sectional and descriptive; hence they do not enable researchers to generate causal inferences. These studies lack a strong theoretical framework. Many studies use convenience samples. Most of the studies lack control or comparison groups. Findings for these studies are discussed below.

A community-based descriptive KAP study in 2012 of a convenience sample of 600 women in Iran (Nafissi, Saghafinia, Motamedi, \& Akbari, 2012) that examined knowledge of, attitude toward, and practice of breast self-examination showed that $30.8 \%$ knew the necessity of breast self-examination and about $60 \%$ knew how to do breast self-examination, but only 
$12.9 \%$ carried out the preventive practice of breast self-examination regularly. It was assumed that poor attitude was responsible for the low use of preventive practice.

In 2012, a KAP survey assessed the reporting of adverse effects of drugs to government agencies by Indian physicians (Kharkar \& Bowalekar, 2012). Knowledge about and a positive attitude toward reporting adverse effects were found in about $55 \%$ of the group. However, only $18.5 \%$ of the physicians reported adverse drug effects. Reasons for that low rate of reporting were that physicians were wary of government agencies, needed a simple reporting procedure, had no toll-free number available for reporting and disliked or lacked access to electronic submission for reporting.

A KAP comparison study of two environmentally different Vietnam communities: an urban community unaffected by the H5N1 flu virus in 2012 and a rural group affected by H5N1 during that outbreak, was conducted in 2012 (Manabe et al., 2012). The study demonstrated that the highly educated, affluent urban group exposed to media had more knowledge and a better attitude, and obtained health care if they had flu symptoms. The rural group affected by the 2010 H5N1 outbreak did not know about or practice precautions in handling sick poultry, as a consequence of their poverty and illiteracy.

In 2005, pregnant women in Rwanda from areas with prevalent malaria both knew about the adverse consequences of malaria for pregnancy and had good attitudes yet only $8.3 \%$ used an insecticide-treated bed net. The unaffordability of the bed nets made the preventive practice impossible for most of the women (Van Geertruyden et al., 2005).

A 2006 cross-sectional study of randomly selected tuberculosis patients discharged from a hospital in Romania investigated their limited adherence to medication regimens. Eighty-one percent of the patients knew that medications had to be continued despite the absence of 
tuberculosis symptoms and had a good attitude toward doing so, but still some of the patients failed to continue taking their medications because they could not afford them (Berger \& Bratu, 2006).

A convenience sample of women from a clinic in Brazil (Vasconcelos, Pinheiro, Casteol, Costa, \& Oliveira, 2011) was assessed with KAP for use of the pap test. The preventive practice of pap testing was undertaken by $67 \%$, even though only $40.4 \%$ of the women had adequate knowledge scores and only $28 \%$ had good attitude scores. The preventive practice was nevertheless frequent because the clinic was accessible to patients and many lived with a partner. Failure to have pap tests for the rest of the women was due to their negative attitudes toward cervical examination.

A pre- and post- KAP comparison study of the test and control groups in two rural Vietnam communities that had experienced an H5N1 flu outbreak was conducted in 2011 to assess the impact of educational intervention. The difference in the groups' knowledge, attitude, and practice scores between the pre- and post-tests was not significant. The authors acknowledge the difficulty of changing the unhealthy behaviors and customs of people in a poor rural area regarding poultry. Study participants reported touching and eating dead or sick poultry at both KAP_Time 1 and KAP_Time 2. The questionnaires comprised mostly of closed-ended or multiple choice questions (Manabe et al., 2011).

In 2013, Wahed et al. did a cross-sectional KAP assessment of urban slum dwellers of Bangladesh regarding cholera prevention. The sample of 2,830 families was randomized to three arms: one-third of the families were allocated as control, a third received only vaccine, and the remaining families received vaccine as well as intervention messages about hygiene and behavior change. In the majority of the participants, KAP scores for knowledge about cholera 
were poor and attitude scores were high. Preventive practices were few, however, due to environmental and economic difficulties. Participants with good knowledge of preventive measures against cholera could not practice preventive behavior adequately because of the scarcity of water, gas supply, sanitation and a proper drainage system.

A cross-sectional, telephone KAP survey study conducted in China in 2011 about the knowledge, attitudes and practices relating to the H1N1 pandemic has limitations. The rate of immunization against $\mathrm{H} 1 \mathrm{~N} 1$ was $10.8 \%$ among the respondents, although $69.9 \%$ believed that vaccine had few adverse effects and the vaccine was available free from state agencies (Lin et al., 2011).

In summary, the general KAP surveys widely used in non-experimental social research are correlational (ex post facto) and descriptive. They verify correlations, i.e. whether a tendency for a variation in one variable is related to the variation in another variable. The studies attempt to understand the relationships among knowledge of, attitude toward, and preventive behavior against a naturally occurring phenomenon (e.g., an influenza epidemic), using a randomly selected sample and no research intervention. Some researchers studied the association of sample attributes with KAP scores for knowledge, attitude and preventive practice. Such studies are limited to correlational rather than causal analysis. A researcher conducting an ex post facto study lacks any control over the independent variables that have already confounded the association between the independent variable and the dependent variable. As a result, causal relationships cannot be ascertained due to the inability to accurately manipulate the independent variable (s). However, correlations may serve as starting points for generating hypotheses or developing theories. The stronger the association between two variables, the more likely it is to eventually find a causal link between them, though not in the associative study. 
These studies indicate that knowledge and attitude influence preventive practice. However, several studies have shown that lack of money is a serious barrier to preventive practice. Preventive behavior is encouraged by personal support and accessibility to medical care.

\section{Diabetes KAP Studies}

A review of KAP studies involving diabetic patients shows that most studies are crosssectional, using convenience samples or randomly selected participants. The studies aim to assess scores for knowledge, attitude, and preventive practice as well as clinical outcomes, or to determine associations between socio-demographic factors and knowledge, attitude and practice. A few studies have used single-group convenience samples with a pre- and post- intervention assessment of changes in knowledge, attitude, and practice scores. Other studies have used randomly assigned participants to test and control groups with a pre- and post- intervention assessment of changes in knowledge, attitude, and practice scores.

\section{Cross-Sectional KAP Assessments Using Convenience Samples}

Using a convenience sample of 75 patients with Type 2 diabetes at an urban center for diabetes care in Malaysia, Ng et al. (2012) assessed KAP scores for knowledge, attitude and practice about diabetes. Although KAP scores were satisfactory, outcomes for glycated hemoglobin (A1C) and fasting blood sugars were not. Eighty-six percent of the participants had significantly poor clinical test outcomes in spite of adequate knowledge and positive attitudes about diabetes. Fewer than $50 \%$ of the participants reported exercising regularly. There was a strong association between knowledge and attitude, and between knowledge and practice. The attitude questionnaire did not differentiate the three components of attitude: cognition, affect and 
behavior. This study has limited generalizability, since it was a cross-sectional study of a small, urban, convenience sample of 75 patients whose responses were collected on a self-reported questionnaire.

Raj \& Angadi (2010) used KAP to assess preventive practice of diabetes in a convenience sample of 730 Type 2 diabetic patients treated at a hospital in Karnataka, India. This was a cross- sectional study. A high number of the respondents had good knowledge and positive attitudes about diabetes, yet had poor practices; $60 \%$ considered diabetes to be a serious disease; but only $40 \%$ took precautions while travelling, $51 \%$ did not monitor blood glucose regularly, and $60 \%$ did not exercise at all. The cross-sectional, hospital-based study used an 8item, descriptive KAP instrument that could not examine causality among the KAP components.

A convenience sample of 238 Type 2 diabetes patients from 3 hospital clinics in Saurashtra, Gujrat India were assessed using KAP by Shah V., Kamdar, \& Shah N., (2009). About $46 \%$ of the patients knew about the causes and complications of diabetes. Most patients in the study had positive attitudes toward self-care. However, they relied more on dietary modifications than on exercise to manage their diabetes. The study's findings are limited in generalizability.

KAP scores and demographic details for 162 newly diagnosed diabetics from an outpatient clinic in Nepal were assessed by Upadhyay, Mohamed, Alurkar, Mishra, and Palaian (2012) in a cross-sectional study. Eighty-two percent had no family history of diabetes. Their knowledge, attitude and practice scores were very low. The attitude instrument consisted of four questions. The sample population was newly diagnosed and was limited to one hospital from one region, so generalizability of the findings is very limited. 
Abubakari et al. (2011) assessed the associations among knowledge, illness perceptions, self-management and clinical outcomes in a convenience sample of 359 Type 2 diabetic patients from the London Diabetes Clinics. This study was cross-sectional, using Leventhal's (1980) common- sense, self-regulating model and hypothesis. The findings show that perceiving severe consequences of diabetes was associated with poor self-management in patients of both African and European origins. Perceptions of personal control were associated with better selfmanagement in patients of African origin. After controlling for demographic and disease characteristics, self-management of diabetes did not predict metabolic outcomes in any ethnic group. The study used psychometric instruments. Since data for this study were collected at one time point, it was not feasible to determine the direction of the relationships between determinants and outcomes or to investigate causal relationships. The limitations of the study were: self-reported data on self-management with concern-for- social-desirability bias, and memory and recall biases. Face-to-face administration of the questionnaires may have introduced interviewer bias. Selection bias due to convenience sampling, however, was minimized by the high participation rate. The authors acknowledged that the sample from the London Diabetes clinics was not representative, and findings cannot be generalized to other settings.

Venkataraman et al. (2012) studied the relationships among personal, disease and treatment-related factors, and diabetes control in a convenience sample of 507 hospital patients diagnosed with Type 2 diabetes in a cross-sectional survey. Self-efficacy positively influenced mental attitudes. Self-efficacy was the single most important determinant of current diabetes control. The findings of this study need further validation by a longitudinal study design. A purposive convenience sample of 100 diabetics among Mexican American and Mexican-Native volunteers was recruited from a large Catholic church in north central Texas 
(Melancon, Oomen-Early, \& del Rincon, 2009). KAP surveys were conducted to assess diabetes knowledge, attitudes, disease management, and self-efficacy. Factors promoting or deterring diabetes prevention and management were identified, using Airihenbuwa's PEN-3 Model by Melancon et al. (2009). Eighty- two volunteers completed quantitative surveys and 18 participated in qualitative focus groups. Knowledge and perceived psychosocial impact scores for the study participants were significantly lower than those from national samples. Since the sample was not truly representative and data were subject to participants' recall and feelings at one point in time, the results from this study cannot be generalized to all Mexican Americans and Mexican Native adults in the United States with Type 2 diabetes.

\section{Cross-Sectional Studies Using Random or Stratified Samples}

A cross-sectional study of 125 randomly selected, low- income- minority patients in South Carolina with Type 2 diabetes was conducted by Bains and Edgede in 2011, using psychometrically validated instruments. Health literacy was significantly associated only with diabetes knowledge. Diabetes knowledge and perceived health status were significantly associated with glycemic control; health literacy was not associated with glycemic control. Since this was a cross-sectional study, it was not possible to infer any causality. Furthermore, as this study was conducted at a single academic center, the findings were not generalizable. The study did not include either the duration of diabetes or comorbidities as confounding factors. No theoretical framework guided the analysis.

Another cross-sectional study, by Walker et al. (2012), of 378 consecutively scheduled primary care patients with Type 2 diabetes in southeastern US examined the impact of diabetes fatalism on self-care behaviors and medication adherence. Fatalism was defined as a belief that 
"all events are predetermined and therefore inevitable" and as a psychological state characterized by perceptions of despair, hopelessness and powerlessness. In the linear regression model, fatalism was significantly associated with extents of medication adherence, diabetes knowledge, diet, exercise, and blood sugar testing. This association was further confirmed once depression was statistically controlled for. Since this was a cross-sectional study, causal directions of the associations could not be assumed. In addition, findings may not be generalizable to other populations or geographical regions.

KAP assessment using a cross-sectional survey of 575 randomly selected diabetic patients of two hospital clinics by Al-Maskari et al. (2013) found that $31 \%$ had poor knowledge about diabetes, $72 \%$ had negative attitudes towards diabetes, $57 \%$ had poor glycemic control and $10 \%$ admitted noncompliance with medications. There was a weak but statistically significant correlation between the level of knowledge and practice $(r=0.320, p=0.001)$ and also between attitudes and practice $(r=0.270, \mathrm{p}=0.001)$. Similarly there was a weak but statistically significant association between knowledge and attitude scores $(\mathrm{r}=0.115, \mathrm{p}=0.006)$. Correlations between glycated hemoglobin (A1C) and knowledge, attitude and practice scores did not reach statistical significance. In this study, there was no correlation between the level of knowledge and glycemic control. No theoretical framework guided the research.

Khandekar, Harby, Harthy, and Lawatti (2010), in a cross-sectional study, examined KAP relationships in a randomly selected sample of 750 diabetics from seven regions of Oman regarding eye complications and self-care for diabetes. This study, with 5 questions on knowledge, 3 on attitude and 3 on practice, found diabetes knowledge to be satisfactory; however, attitude and practice were less than satisfactory. 
An empirical study, using KAP assessment, of 1982 randomly selected diabetics and nondiabetics from Kenya areas with high prevalence of diabetes was conducted in 2011 (Maina, Ndegwa, Njenga, \& Muchemi, 2011). The study examined how knowledge influenced attitudes and practices about the prevention and control of diabetes, and used KAP assessments to develop prevention programs. About $70 \%$ of all respondents from each of four regions had poor knowledge about diabetes. There was a direct relationship between level of education and knowledge. Forty-nine percent of the respondents had a positive attitude toward diabetes and forty-one percent demonstrated good practices toward diabetes. The KAP assessment in this study indicated the need for diabetes education.

Ardena et al. (2010) assessed KAP and developed an educational program in a stratified sampling of 156 rural persons with Type 2 diabetes in the Philippines. The associations between patient factors and knowledge, attitudes, and practices about diabetes were explored. The overall mean percentage score on knowledge was $43 \%$. Older patients had lower knowledge scores. Ten percent believed in tight glucose control; only one percent believed that diabetes was a serious disease. College graduates had better attitudes than less educated people did. Only $23 \%$ did regular A1C checks and $34 \%$ examined feet for abnormalities; $25 \%$ continued to smoke despite medical advice.

\section{Pre- and Post- Test with a Single Group}

Pre- and post- intervention evaluation of an educational program for a single group of 67 patients with Type 1 diabetes who were receiving free monthly supplies of human insulin at the outpatient clinic of a tertiary care hospital in Pondicherry, India was undertaken by Vimalavathini, Agarwal and Gitanjali (2008), using a KAP survey. The KAP questionnaire 
consisted of 22 questions, of which four were about attitude. This was a prospective interventional study using a convenience sample. Knowledge and attitudes about diabetes improved after the educational intervention. Only marginal improvement in practice scores was observed; patients cited financial reasons for non-adherence to the insulin regimen. The practice of storing insulin vials at home did show significant improvement $(\mathrm{p}<0.0001)$. It was concluded that knowledge, attitude and some aspects of practice improved after the educational intervention, though some patients were unable to consistently follow an insulin regimen because they could not afford transportation to the clinic.

In a single-group, prospective pre- and post -intervention study using a postal questionnaire for 97 diabetic women in Ireland (Type 1, n = 89; Type 2, n = 8), Holmes et al. (2012) evaluated use of an educational DVD to evaluate whether or not knowledge and attitudes about preconception care and reproductive health, and behavior changed. The study found a significant positive change in women's perceived benefits of, and their personal attitudes about receiving preconception care and using contraception. There was a significant improvement in self-efficacy, that is, the self-confidence to use contraception and to access preconception care. Viewing the DVD significantly increased the women's knowledge about pregnancy planning and pregnancy-related risks and significantly reduced perceived barriers to preconception care. Knowledge, attitude and self-efficacy all improved as a result of the intervention. This study has limitations, and its findings cannot be generalized. Only $26 \%$ of the women contacted participated in the study. The sample women were relatively upper class, and there was a lower percentage of Type 2 diabetics than that in the general population ( $9 \%$ vs. $17 \%$ ). The study did not measure behavior or practice. More motivated and more highly educated individuals, who acknowledged having earlier received preconception advice, responded and participated in the 
study. Since there was no comparison control group, the improvement in knowledge and attitude cannot be accurately attributed to the intervention alone.

A single-group, pre- and post- education, correlational study of a convenience sample of 168 urban, newly diagnosed Type 2 diabetics attending diabetes group education in Ireland was conducted by Clarke (2009). The study found that attitude about diabetes was not related to adoption of diabetes self-care behavior. The study findings were not generalizable since the sample was not representative of the population.

\section{KAP Studies with a Test-Control, Random-Assignment and Pre-Post Design}

Malathy et al. (2011) evaluated a custom-designed counseling program, assessing the effects of counseling on knowledge and practice in the test group, in a randomized sample of 207 Type 2 diabetes patients in South India, having an intervention group $(n=137)$ and a control group $(\mathrm{n}=70)$. KAP scores of the test-group patients improved significantly, in the postintervention assessment $(\mathrm{p}<0.0001)$ especially for knowledge and attitude. The practice scores did not show any improvement $(\mathrm{p}<0.06)$; the baseline practice scores had been relatively high. No significant changes in KAP scores for the control group were observed. The postprandial blood glucose levels decreased significantly in the test group; there were no significant changes in the control group. The study used a questionnaire of 25 questions with only three questions on attitude. The study did not examine glycated hemoglobin (A1C), which is an important biomedical marker of blood sugar control over time. Post-prandial blood glucose was assessed at a single point in time.

A multi-site, prospective study of randomly selected diabetic Asians living in Scotland,

by Baradaran et al. (2006) evaluated an educational intervention tailored for South Asians, using 
a group comparison of changes in diabetes knowledge between the test group and the ethnic and the white control groups. The final study sample was 101 patients. The test group had low baseline KAP scores. In the intervention group scores improved significantly for knowledge $(+12.5 \%)$, serious attitudes $(+13.5 \%)$, and practice $(+20.0 \%)$. There were no significant differences in KAP improvement between the members of the two control groups (white \& ethnic).

Evaluation of the effectiveness of a diabetes educational intervention with a small group was undertaken by Garrett et al. (2005). Volunteers were randomly assigned to an intervention group $(\mathrm{n}=382)$ or to a control group $(\mathrm{n}=382)$. The intervention group used a book explaining self-care. After accounting for demographic differences between the groups, significant changes were found in diabetes knowledge, feeling of control and self-management behavior between the intervention and the control group. Although the study used a randomly selected sample, the pool of volunteers had higher motivation than in the general population, which may introduce selection bias. Hence the study findings had limited generalizability.

In a randomized, prospective study of Type 2 diabetics in India, Adepu et al. (2007) evaluated the effect of pharmacist- provided counseling on patients' perceptions about disease management and quality of life. A total of 60 Type 2 diabetes patients were randomly allocated to the test group $(n=32)$ or the control group $(n=28)$. In the test group, knowledge, attitude and practice scores markedly improved; mean capillary blood glucose levels fell ( $\mathrm{p}<0.05$ ), and mean quality-of-life scores rose $(\mathrm{p}<0.05)$. In the test group, a highly significant correlation was found between the capillary blood glucose levels and the quality-of-life scores $(\mathrm{p}<0.05)$. The control group showed a reduction in the quality-of-life scores $(\mathrm{p}<0.05)$. 
In summary, some of these studies indicate that even though patients had good knowledge and positive attitude they had poor preventive practices and poor clinical outcomes. In one study lack of money was a serious barrier to preventive practice.

\section{Review of the Methodological Rigor of Previous Research}

In order to improve the integrity of research, the methodological rigor of previous studies is assessed. The following section describes the methodological problems of previous studies.

\section{Problem with the Measurement Instrument}

Studies used either a composite questionnaire including questions on knowledge, attitude, and practice, or separate questionnaires to measure knowledge, attitude and practice. Researchers may not have clearly defined the constructs of knowledge, attitude and practice. The questionnaires had closed-ended questions or multiple choice questions. The response to a closed question does not guarantee that the study subject has fully understood the question as intended by the researcher. Open-ended questions are preferred on KAP surveys. When KAP studies used a variety of instruments to assess a particular topic, it is harder to compare their results.

Sometimes KAP survey instruments have to be developed to study a specific subject, for lack of existing valid instruments. The Diabetes Attitude Scale (DAS) (Anderson, Fitzgerald, Funnell, \& Grupen, 1998) questionnaire, which has been used in some studies, does not assess the affective component of attitude. There is a paucity of questionnaires to assess health attitude. Several researchers have created their own questionnaires; however, those assess only one component of attitude, the cognitive.

Since in previous studies with KAP the researchers did not use psychometrically validated KAP questionnaires, the results cannot be considered reliable or valid. 


\section{Problem of Research Design - Cross-sectional}

The KAP studies reviewed were cross-sectional, using data collected at one point in time. Because cross-sectional studies describe relationships among phenomena only at a fixed point in time, they do not enable causal inferences. The previous studies lack strong theoretical frameworks. The lack of temporal sequence or specification restricts the ability of those studies to confirm the mechanisms of behavioral change. Moreover, the findings of those KAP studies differed about the relationships among knowledge, attitude, and practice.

\section{Lack of Control Group}

To assess maturation effects, the change in a dependent (i.e. outcome) variable in the experimental group receiving treatment is compared to the change in that dependent variable in the control group that does not receive treatment. Some previous studies lacked a control group, so it is difficult to separate the effects of maturation from those of the treatment.

\section{Problem of Non-random Assignment of Participants to Groups}

In the random assignment of participants into either experimental or control groups, every participant has an equal chance of being assigned to any group. As a result there is more likelihood that the groups are equivalent to begin with in regard to any attributes that may affect the dependent variable under investigation. The lack of randomization in many studies detracts from the credibility of the interpretation of their findings. 


\section{Problem of Lack of Theoretical Grounds}

Previous KAP studies failed to generate testable hypotheses with clear causal specifications. A majority of the studies reviewed were not theoretically grounded and lacked the causal hypotheses deduced from specific assumptions that are needed for a causal inquiry.

\section{Reformulation of Theoretically Informed, Causal Model of KAP-O with Health Educational Intervention}

Health education is known to improve health care outcomes, although not all interventions are effective. Most of the studies reviewed suggested that educational intervention leads to positive changes in outcomes or predictive outcomes. A few examples of such studies are discussed below to frame the causal associations of the KAP-O model.

\section{Study Examples}

In 2001, Norris et al. reviewed 72 studies evaluating the effectiveness of selfmanagement education lasting for a period of six months or less. The authors found that the interventions improved knowledge and glycemic control; however, they had variable effects on lipids.

In 2002, Norris et al. with other researchers found that there was a drop of one percent in glycated hemoglobin (A1C) for every additional 23.6 hours of contact time between educator and patient. Tilly et al. (1995) evaluated a diabetes educational program by collecting data on health status, glycemic control (A1C), diabetes-related quality of life, and general health-related quality of life at multiple time points over a period of 15 months. The authors found significant improvement in all four health outcomes. 
A study by Hogue et al. (2003) of a community pharmacy-based diabetes educational program with 381 participants, based on the American Diabetes Association Standards, found improvements in Hemoglobin A1C results, fasting blood glucose levels, lipid levels, blood pressure measurements, and diabetes knowledge scores. Similarly, Cranor et al. (2003) studied the outcomes for the five years following the initiation of community-based, pharmaceutical care services for patients with diabetes. The study, with a quasi-experimental, longitudinal, pre-post cohort design, found improvements in all categories of outcomes and a decrease in the mean for total direct medical costs per patient per year.

Korhonen et al. (1983) studied the effect of patient education on diabetic control in insulin-treated diabetic adults in a randomized trial. One group received intensive education and the second group received printed material. A significant improvement in diabetic control was observed in both groups immediately after the educational programs, which however returned to the original level of control later.

A systematic review of other research literature has shown either mixed results or no improvement in clinical care outcomes attributable to diabetes education. Three of those studies are summarized below.

Bloomgarden et al. (1987), in a randomized trial involving adults with insulin-treated diabetes, found that for most, patient education was not as efficacious as therapeutic intervention. Beeney and Dunn (1990) assessed knowledge and glycated hemoglobin pre- and postintervention of 558 patients attending one of five diabetes education programs. There was an increase in $18 \%$ in knowledge scores; however, that improvement in knowledge scores was not correlated with changes in glycated hemoglobin (A1C). 
However, Ozmen and Boyvada (2002) provided diabetes education to 359 patients who were then split into two groups: A and B. Group A received a glucometer and an additional two hours of education and Group B group received no glucometer and no additional education. There was no change in A1C in the control group (B), and only some patients in the test group (A) had improvement in A1C.

The studies summarized above did not investigate causal mechanisms or specifications. The educational interventions are most likely to have influenced the outcomes through the mediation of changes in knowledge, attitude, and practice, rather than directly. It is important to explore which of the two factors, knowledge or attitude, may have a more dominant influence on preventive practice and thus on diabetes care outcomes. The relative importance of the factors influencing diabetes care outcomes can guide educational programs to target specific knowledge or attitudinal components of the behavioral system. Thus research could improve practice and outcomes.

Because previous KAP studies failed to develop causal specifications of the behavioral components of preventive practice and outcomes, their results were inconclusive and inconsistent. The present KAP-O study is designed to test causal specifications and identify the dominant mediating and moderating factors that influence the preventive practice and health care outcomes of diabetes care. The KAP-O model was subjected to empirical validation with a rigorous research design.

\section{Studies Supporting the Concept that Educational Intervention Directly Improves Diabetics' Knowledge}

Norris et al.'s (2001) review, cited earlier, of 72 studies focusing on the effectiveness of self-management education for a period of six months or less found that self-management 
education improves diabetics' knowledge. The Hogue et al. (2003) study, cited earlier, of community, pharmacy-based diabetes education based on the American Diabetes Association Standards with 381 participants found improvements in diabetes knowledge scores, as well as in glycated hemoglobin (A1C) results, fasting blood glucose levels, lipid levels, and blood pressure measurements.

Evaluation of the effect of an educational KAP program, through a single-group, prospective pre- and post-intervention study of 67 Type 1 diabetic patients receiving free monthly supplies of human insulin at the outpatient clinic of a tertiary care hospital, in Pondicherry, India was undertaken by Vimalavathini et al. (2008). The study used a convenience sample. Diabetes knowledge improved after the intervention.

Holmes et al. (2012), as described earlier, conducted in Ireland a single-group, prospective, pre- and post-intervention study by postal questionnaire of 97 women with diabetes (Type $1, \mathrm{n}=89$; Type $2, \mathrm{n}=8$ ) who were aged $18-40$ years. The purpose was to evaluate whether an educational DVD increased their knowledge about diabetes and changed their attitudes towards preconception care and reproductive health behavior. After viewing the DVD, the women's knowledge about pregnancy planning and pregnancy-related risks had increased significantly.

Malathy et al. (2011), in evaluating a custom-designed counseling program as described earlier, assessed the effects of counseling on diabetes knowledge and practice in a test group (n $=137)$ versus a control group $(n=70)$ in a randomized sample of Type 2 diabetes patients in South India. The knowledge scores of the test group patients improved significantly $(\mathrm{p}<0.0001)$. There was no statistically significant change in the knowledge scores of the control group. 
In other research cited earlier, a multi-site, prospective study of randomly selected South Asian diabetes patients in Scotland, by Baradaran et al. (2006), evaluated a custom tailored, educational intervention by comparing the change in diabetes knowledge among the test, ethnic control and white control groups. The study sample comprised of 101 Type 2 patients. The test group had low KAP at baseline and significant improvement in the scores for diabetes knowledge after the intervention.

As described earlier, evaluation of the effectiveness of a small group, diabetes educational intervention was undertaken by Garrett et al. (2005), using volunteers randomly assigned to either an intervention group $(\mathrm{n}=382)$ that participated in the small-group learning activity or a control group $(\mathrm{n}=382)$ that received a diabetes self-care book. Adjusting for demographic differences between the groups, there was a significant change in diabetes knowledge in the intervention group as compared to the control group.

In a randomized, prospective study of Type 2 diabetics in India, Adepu et al. (2007), cited earlier, evaluated the effect of pharmacist- provided counseling on patients' perceptions about disease management and quality of life. A total of 60 Type 2 diabetes patients were randomly allocated to the test group $(n=32)$ or the control group $(n=28)$. In the test group, knowledge, scores markedly improved.

In the studies discussed above, health educational interventions led to increases in knowledge. This evidence led to hypothesis. H1: Health educational intervention directly improves knowledge. 


\section{Studies Supporting the Concept that Educational Intervention Directly Improves Attitude}

The evaluation by Vimalavathini et al. (2008) of an educational program, cited above, found that diabetic patients' attitudes toward self-care improved after educational intervention.

The study conducted by Holmes et al. (2012) in Ireland using educational DVD improved diabetes knowledge and also the diabetic women's attitudes towards preconception care, reproductive health attitudes and behavior. At post-intervention, there was a significant positive change in women's perceived benefits of, and their personal attitudes to receiving preconception care and using contraception.

A one- group, pre- and post- education, correlational study in Ireland of a convenience sample of 168 urban, newly diagnosed Type 2 diabetics who were attending diabetes group education was conducted by Clarke (2009) to assess their changing perceptions about diabetes from attending the group education. The patients' attitude about the seriousness of diabetes continued to increase over time.

Malathy et al. (2011), previously cited, evaluated a custom-designed KAP counseling program in South India and found that the scores of the test group improved significantly $(\mathrm{p}<0.0001)$, for attitude about diabetes at post-intervention. There were no significant changes in the attitude scores of the control group.

A multi-site, prospective study of 101 South Asian diabetic patients in Scotland by Baradaran et al. (2006) cited previously, compared changes in diabetes knowledge between the test and the ethnic control and the white control groups. The test group had low KAP scores at baseline and significantly improved in scores for attitudes toward the seriousness of diabetes after the intervention. 
Adepu et al. (2007), cited earlier, evaluated the effects of pharmacist- provided patient counseling for Type 2 diabetes patients from two community pharmacies in Calicut, Kerala, India. The test group scores for attitude about diabetes markedly improved.

The studies discussed above using health educational interventions found resulting improvements in attitude. This evidence led to hypothesis H2: Health educational intervention directly improves attitude.

\section{Studies Supporting the Concept that Educational Intervention Directly Improves Preventive Practice}

In an evaluation of the effectiveness of a small-group intervention, described earlier, by Garrett et al. (2005), there were significant changes in behavior related to self-management of diabetes in the intervention group as compared to the control group, which had simply received a diabetes self-care book. The study adjusted for demographic differences between the two groups.

A multi-site, prospective study of randomly selected diabetic Asians living in Scotland, by Baradaran et al. (2006) evaluated an educational intervention tailored for South Asians, using a group comparison of changes in diabetes knowledge between the test group and the ethnic and the white control groups. The final study sample was 101 patients. The test group had low baseline KAP scores. In the intervention group practice scores improved significantly $(+20.0 \%)$.

In a randomized, prospective study of Type 2 diabetics in India, Adepu et al. (2007) evaluated the effect of pharmacist- provided counseling on patients' perceptions about disease management and quality of life. A total of 60 Type 2 diabetes patients were randomly allocated to the test group $(\mathrm{n}=32)$ or the control group $(\mathrm{n}=28)$. In the test group practice scores markedly improved. 
These studies suggested that health educational intervention directly increased preventive practice. This evidence led to the development of the third hypothesis, H3: Health educational intervention directly improves preventive practice.

\section{Studies Supporting the Concept that Health Educational Intervention Improves Health Care Outcomes}

In 2001, Norris et al. reviewed 72 studies evaluating the effectiveness of selfmanagement education lasting for a period of six months or less. The authors found that the interventions improved knowledge and glycemic control; however, they had variable effects on lipids.

In 2002, Norris with other researchers found that there was a drop of one percent in glycated hemoglobin (A1C) for every additional 23.6 hours of contact time between educator and patient. Tilly et al. (1995) evaluated a diabetes educational program by collecting data on health status, glycemic control (A1C), diabetes-related quality of life, and general health-related quality of life at multiple time points over a period of 15 months. The authors found significant improvement in all four health outcomes.

A study by Hogue et al. (2003) of a community pharmacy-based diabetes educational program with 381 participants, based on the American Diabetes Association Standards, found improvements in Hemoglobin A1C results, fasting blood glucose levels, lipid levels, blood pressure measurements, and diabetes knowledge scores. Similarly, Cranor et al. (2003) studied the outcomes for the five years following the initiation of community-based, pharmaceutical care services for patients with diabetes. The study, with a quasi-experimental, longitudinal, pre-post cohort design, found improvements in all categories of outcomes and a decrease in the mean for total direct medical costs per patient per year. This evidence led to the development of the fourth 
hypothesis, H4: Health educational intervention directly improves diabetes health care outcomes which is further detailed by the following hypotheses, $\mathrm{H} 4_{1}$ : Health educational intervention directly lowers glycated hemoglobin (A1C), $\mathrm{H}_{2}$ : Health educational intervention directly lowers low density lipoprotein cholesterol (LDLC), $\mathrm{H}_{3}$ : Health educational intervention directly improves functional capacity (FC), $\mathrm{H}_{4}$ : Health educational intervention directly decreases poor perceived health $(\mathrm{PPH})$.

\section{Studies Supporting the Concept that Educational Intervention Indirectly Improves Practice via Knowledge and Attitude}

The previously described study by Vimalavathini et al. (2008) evaluated the effects of an educational program on the diabetes knowledge, attitude and practices of 67 Type-1 patients receiving free monthly supplies of human insulin at the outpatient clinic of a tertiary care hospital in India. Patients were of low socioeconomic status, either illiterate or with primary school education, and had longstanding diabetes. Their diabetes knowledge and attitudes improved after the intervention. The improvement in practice scores, though significant, was marginal. The practice of storing insulin vials at home showed significant improvement $(<$ 0.0001), but patients cited financial reasons for not adhering to their insulin regimens.

Baradaran et al. (2006), cited earlier, conducted a multi-site, prospective study of 101 South Asian diabetes patients in Scotland, and compared KAP scores between the test group and the ethnic and white control groups. The test group had low KAP scores at baseline; their scores post-intervention improved significantly for knowledge $(+12.5 \%)$ and serious attitudes toward diabetes $(+13.5 \%)$, and for practice $(+20.0 \%)$, as well.

The studies discussed above suggested that health educational intervention indirectly improves preventive practice via knowledge and attitude. This evidence led to hypothesis H5: 
Health educational intervention also indirectly improves preventive practice via knowledge and attitude.

\section{Studies Supporting the Concept that Educational Intervention Indirectly Affects Outcomes, Mediated via Knowledge, Attitude, and Practice}

Adepu et al. (2007) previously cited, evaluated the effect of pharmacist-provided patient counseling in India on Type 2 diabetes patients' perceptions about disease management and quality of life. In the test group patients $(n=32)$, knowledge, attitude and practices scores were markedly improved post-intervention, mean capillary blood glucose levels was reduced $(\mathrm{P}<$ $0.05)$ and the mean scores for quality of life improved $(\mathrm{P}<0.05)$. The correlation between the capillary blood glucose levels and quality of life scores was also found to be highly significant in the test group $(\mathrm{r}=0.955)$.In the control group $(\mathrm{n}=28)$ quality of life score was reduced $(\mathrm{P}<$ $0.05)$.

Malathy et al. (2011) previously cited, assessed the effect of custom-designed counseling on knowledge and practice for test group $(n=137)$ and control group $(n=70)$ of 207 Type 2 diabetes patients in South India. Post-intervention KAP scores of test group patients, especially knowledge and attitude, improved significantly $(\mathrm{p}<0.0001)$. Practice scores showed no improvement $(\mathrm{p}<0.06)$, since baseline practice scores were high. The control group showed no significant changes in KAP score. The outcome for postprandial blood glucose (levels, improved significantly in the test group.

Norris et al. (2002) found that self-management education improves the outcome of glycated hemoglobin (A1C) levels at immediate follow-up and that improvement in glycated hemoglobin (A1C) levels increases if the education continues for a longer time. The benefit of improved outcome of glycated hemoglobin (A1C) was sustained for 1-3 months after cessation 
of the intervention. This suggests that knowledge and attitude continue to influence practice and outcome even after the self-management education ends.

The studies discussed above suggested that influence of health education on clinical outcomes is not direct but is mediated via knowledge, attitude, and practice. This evidence leads to hypothesis H6. The influence of health education on diabetes health care outcomes is not direct, but is mediated via knowledge, attitude, and practice.

The hypotheses are listed below:

H1: Health educational intervention directly improves knowledge.

H2: Health educational intervention directly improves attitude.

H3: Health educational intervention directly improves preventive practice.

$H 4_{1}$ : Health educational intervention directly lowers glycated hemoglobin (AlC).

$\mathrm{H}_{2}$ : Health educational intervention directly lowers low density lipoprotein cholesterol $(L D L C)$.

$\mathrm{H}_{3}$ : Health educational intervention directly improves functional capacity $(F C)$

H44: Health educational intervention directly decreases poor perceived health (PPH).

H5: Health educational intervention also indirectly improves preventive practice via knowledge and attitude.

H6: The influence of diabetes health education on health care outcomes is not direct, but is mediated via knowledge, attitude, and practice.

The hypotheses were empirically tested using a pre-post design, with participants randomly assigned into experimental and control groups. The following chapter details how the overall model was validated and the hypotheses tested, using structural equation modeling. 


\section{CHAPTER THREE: METHODOLOGY}

\section{Introduction}

The goal of this research study was to examine the causal mechanisms of diabetes education's effects on knowledge, attitude, practice and health care outcomes using the knowledge-attitude-practice-outcome (KAP-O) framework. As discussed in the literature review, few experimental studies have been done using the KAP-O framework and a pre- posttest-control design with random assignment of diabetic participants.

Previous studies lacked theoretical grounding with causal specifications implied in the hypotheses. The descriptive studies failed to define the constructs of knowledge, attitude, and practice clearly or to measure changes in those constructs. Most of the questionnaires used composite scores for mainly knowledge-based questions about specific health conditions. The questions on attitudes did not consider the affective component of attitude, were not comprehensive, and lacked demonstrable psychometric properties.

The present study used an experimental design with pre- post- assessments of diabetes patients who had been randomized into experimental and control groups. The rationale for choosing a randomized clinical trial was to explore the causal relationship between health educational intervention and knowledge, attitude, practice, clinical outcomes and subjective outcomes. Randomization of participants to experimental and control groups avoided both biased selection and any influence from differences in previous characteristics on clinical and subjective outcomes. The experimental design using experimental and control groups enabled ruling out any changes in the KAP measures and clinical outcomes due to the maturation effect. The study employed psychometrically validated tools to enhance validity and reliability of the data gathered and tailored an attitudinal instrument comprising the cognitive, affective, and 
behavioral components. This chapter details the research design, sampling, power analysis, classification of study variables and their measurements, analytical methods including t-tests and structural equation modeling, and the logical flow of a multi-phase analysis of the KAP-O model of health educational intervention.

\section{Preparation for a Randomized Controlled Experiment}

\section{Preliminary Steps}

1. The researcher secured permission from a study site to conduct research.

2. The researcher undertook a refresher online course for Human Research Curriculum through the Collaborative Institutional Training Initiative (CITI) as a prerequisite for University of Central Florida, Institutional Review Board (UCF IRB) approval of the study.

3. The researcher secured approval for a human research study by online application to UCF IRB.

4. The researcher identified diabetes patients via the medical practice's electronic data base and mailed copies of a letter from the physician inviting patients to participate in the study.

5. The researcher generated the patient sample and obtained patients' informed consents for the study.

6. The researcher created a layout of how the research findings would be presented without any numbers. 


\section{Description of Intervention and Implementation}

The researcher viewed "Introduction to Healthy Tutor" and selected the educational program for the present study from Healthy Tutor (www.healthytutor.com). That health educational material is readable by people with at least sixth grade education. A mantra of health providers seeking to avert the complications of diabetes is "control the ABCs of diabetes: A1C (an indicator of average blood sugar for 3 months), blood pressure, and cholesterol." That mantra guided the selection of seven tutorials: introduction, meal planning, exercising for a healthy life, high blood pressure, managing cholesterol, foot care, and hypoglycemia.

Healthy Tutor utilizes evidence-based, interactive, self-paced, web-based health education tutorials produced by the Patient Education Institute in Coralville, Iowa marketed under the X-Plain trademark. X-Plain tutorials and their associated illustrated hard copy texts, are suitable for sixth grade readers. To the X-Plain tutorials, Healthy Tutor added pre-tests and post-tests using patented algorithms. These tutorials are available on the National Library of Medicine website http://www.nlm.nih.gov/medllineplus/diabete.html . A special permission was granted by Healthy Tutor for use of their educational materials in this study. Thakurdesai, Kole, \& Pareek (2004) evaluated web-based educational material for diabetes patients according to the Health Summit Working Group (HSWG) criteria and for coverage of core educational concepts. From 53 viable web educational programs the authors formulated a list of the 10 best websites for online diabetes education. They ranked the National Library of Medicine's website second.

\section{Choice of Instruments to Test Literacy, Knowledge, Attitude, Practice and Outcomes}

The study instruments listed below were selected after consultation with experts and as supported by the literature review. 
1. LAD - literacy assessment of diabetes (Nath, Sylvester,Yasek, \& Gunel, 2001)

2. SDSCA - summary of diabetes self-care activities (Toobert, Hampson, \& Glasgow, 2000)

3. Functional Capacity - EQ-5D-5L (2009), with additional items as used by Perneger and Courvoisier (2011).

4. Perceived Poor Health - European Quality Visual Analogue Scale (EQ-VAS), (EuroQolOrg, 2009).

5. Knowledge Instrument - thirty-eight questions specific to the seven core diabetes tutorials (Healthy Tutor, 2010) (Dickeson \& Scheel, 2014).

6. Attitude Instrument - An extensive literature review revealed that existing attitude instruments such as the diabetes attitude scale (DAS) (Anderson et al., 1998) and problem areas in diabetes (PAID) (Polonsky et al., 1995) do not test the affect component of attitude. Interactions with patients and a review of current diabetes instruments pinpointed areas of concern by diabetic patients about the disease, its complications and its care. Certain questions were adapted or borrowed from psychometric instruments assessed by Eigenmann, Colagiuri, Skinner, and Trevena (2009), to develop an instrument to measure attitude that covered all three components of attitude, namely cognitive, affective, and behavioral tendency. After pilot testing of the instruments for clarity before the research started, some questions were reworded to improve clarity. 


\section{Setting}

The project site for the study was Medical Specialists, a two-site internal medicine and nephrology practice that serves a medically underserved population of 6,176 patients, of whom $62 \%$ are insured by Medicaid. Medical Specialists has been operating since 1983. The medical practice has at least 500 diabetes patients.

\section{Recruitment of Participants}

The electronic charts of patients on the daily appointment schedule were checked to identify Type 2 diabetes patients. The electronic charts of walk-in patients were reviewed to see whether they had Type 2 diabetes and met the inclusion criteria. Participation in the study was voluntary. Research subjects could opt out of the study at any time. Confidentiality was ensured by assigning a unique identifier to each subject's record.

The researcher made sustained efforts to recruit potential participants from the clinic patients through face-to-face recruitment. The prospective participants were told that the researcher is a doctoral student of the University of Central Florida, and that the findings of the research were expected to benefit Type 2 diabetes patients and their families. The researcher offered to provide all participants with a summary report if they were interested in the findings of the study. No financial incentive to participate was offered.

The research had to be explained to patients to gain their participation. At first many declined, which discouraged the researcher, who knew the study would go nowhere without their participation. The patients were assured of the research integrity: that the data would be used only for scientific inquiry. The patients' confidence in the study also was boosted when they were told that it was endorsed by the University of Central Florida. Participation was made as 
convenient as possible for patients by rescheduling appointments and at times arranging for transportation through the Council on Aging. For participants who did not have computers, large screen computers were made available to view tutorials in one to two examination rooms. The researcher sat with many patients and showed them how to access the tutorials online.

Patients, who agreed to participate, signed informed consent forms. Each potential participant was assessed for his/her health literacy level. Participants then filled out questionnaires while waiting to be seen by the physician. Each was given a lab order requisition for a stat glycated hemoglobin (A1C) and lipid profile. Shortly after enrollment, patients in the experimental group were reminded in person and by phone to review the tutorials and/or complete the questionnaires. All patients were asked to fill out the questionnaires again during follow-up visits at 3 months or 6 months and to have blood tests then for A1C and lipid profile. Patients were requested to respond to the questionnaires by mail if they could not come to the office.

\section{Definitions of Constructs}

The aim of this research is to examine the relationship of a health educational intervention to diabetes knowledge, attitude, self-care practice, and clinical outcomes. Knowledge, attitude, and practice, the KAP components, were measured by patient responses to pre-and post-questionnaires. Objective outcomes: Glycated hemoglobin (A1C), a measure of blood sugar; and lipid profile were measured by clinical laboratory blood tests. Subjective outcomes: Functional capacity was determined by the survey questionnaires: EQ-5D-5L (EuroQol Org 2009, and five additional items as used by Perneger \& Courvoisier, 2011). 
Poor Perceived health status was determined by visual analogue scale: EQ-VAS (EuroQol/org 2009).

Knowledge is the acquisition, retention and use of information or skills (Badran, 1995). Acquiring knowledge through cognition is a process of understanding and is distinguished from an experience of feeling. Knowledge about health accrues as a result of health education or experience. Health knowledge possessed by diabetics refers to their comprehension of the disease and its progression, and self-care practice necessary for keeping diabetes under control.

Attitude: Eagly and Chaiken in "The Psychology of Attitude" define attitude as "a psychological tendency expressed by evaluating a particular entity with some degree of favor or disfavor" (Eagly \& Chaiken, 1993, p.1 as cited in Eagly and Chaiken, 2007). Attitude encompasses three basic components of cognition, affect, and behavioral tendency as discussed by Katz \& Stotland (1959), Krech \& Crutchfield (1948) and Rosenberg \& Hovland (1960) as cited in Eagly and Chaiken, 2007. Cognitions are true and false beliefs about the attitude object. Health education may change such cognitive perceptions. There may be some overlap of knowledge and attitude. Some diabetic patients may have preconceived ideas that they may not live long lives, from having heard about relatives dying at an early age from heart attacks. Some patients are afraid of disabilities from stroke, limb amputation or kidney failure. The affective component includes the whole gamut of feelings/emotions about every aspect of the attitude object. Some patients may have various attitudes towards self-care management of their diabetes. They may love to exercise because it makes them feel good, but hate self-monitoring of blood sugar because they are averse to pricking their skin. The behavioral component in attitudes is the proneness to act in particular ways with reference to the attitude object. Some diabetes patients may be apt to follow through every recommendation by physicians. Others may not. In 
summary, attitude toward diabetes refers to any preconceived ideas about diabetes and its management and feelings/emotions towards certain aspects of diabetes and diabetes care, any of which may carry an aptness to behave in a particular way regarding diabetes and managing its care.

A patient's health practice manifests the level of understanding of health problems/diseases and her/his attitude toward them. A change in attitude caused by removal of misconceptions about health problems or disease can translate into preventive behavioral practices such as self-care. Practice is thus a cluster of actual behaviors or actions that avert a disease condition or delay its progression. For diabetics, self-care or preventive behavioral practice involves healthy eating, increased physical activity, adherence to medications, overcoming barriers to weight loss and active lifestyle, avoidance of responding to stress by overeating or inactivity, timely follow-up with physicians, and participation in tests to reassess health outcomes. These seven self-care behaviors are strongly advocated by the American Association of Diabetes Educators.

The experimental (exogenous) variables, endogenous outcome variables and control variables of this study are described below.

\section{Measurement of the Variables}

1. The experimental or exogenous variable was a self-management educational intervention delivered by online tutorials or reading a printout of the tutorials. The experimental group was coded 1 and the control group was coded 0.

2. Endogenous variables: The KAP-O framework was the guide for the development and selection of endogenous variables as consequences of the health educational 
intervention. Knowledge (K) was assessed by scoring a questionnaire of 38 items covering the tutorial content. Attitude toward diabetes and its self-management was assessed by a questionnaire of 30 items to determine the affective, cognitive, and behavioral components of the participants' attitudes. The summary of diabetes selfcare activities was used to evaluate practice. Outcome measures of the Healthy Tutor 2010 (Dickeson \& Scheel, 2014) intervention program were laboratory results: glycated hemoglobin (A1C) and low density lipoprotein cholesterol (LDLC), and subjective outcomes: functional capacity as evaluated by the questionnaire EuroQol (EQ-5D-5L) supplemented with 5 items from the Perneger and Courvoisier study in 2011 and poor perceived health as evaluated by European Quality Visual Analog Scale (EQ-VAS).

3. Control variables or confounders were considered since they might pose potential threats to the internal validity of the KAP-O model.

4. The pre- and post- tests generated time-specific changes in knowledge, attitudes and health behavioral practice.

The instruments used to collect the data are described in detail below.

\section{Measurement Instruments Used}

LAD (Literacy Assessment for Diabetes): The control of diabetes requires self-care by patients. Because diabetes patients often have to read instructions and menus, they need adequate literacy. The Literacy Assessment for Diabetes (Nath et al., 2001) assesses literacy in adult patients with a words recognition test in which patients read out loud and pronounce the words on 3 lists. Low word recognition scores suggest low comprehension skill, whereas the ability to 
read all 60 words predicts successful comprehension of pamphlets and menus. The LAD (Nath et al., 2001) has shown high concurrent validity and high test-retest reliability.

EQ-5D: (European Quality, Five Dimensions), by the EuroQol Group, is a standardized measure of health status. EQ-5D has two components, a descriptive EQ-5D and an EQ - visual analogue scale (EQ VAS). EQ-5D covers the five dimensions of health status. Five dimensions were added to EQ-5D as tested by Perneger and Courvoisier (2011) to produce a more comprehensive tool for a multi-attribute assessment of health ability. A completed EQ-5D provides a descriptive indication of functional capacity. A completed EQ-VAS provides a single index value for health status. The EQ-5D and EQ-VAS comprise reliable and valid instruments.

SDSCA (Summary of Diabetes Self-Care Activities): A summated scale of diabetes selfcare activities, measuring multiple preventive and self-care practice behaviors, was used. It is a brief, reliable and valid measure of diabetes self-management (Toobert et al., 2000). Patients report on the frequency of each of the seven health habits or behavioral practices promoted by the American Diabetes Association and physicians.

DMPA (Diabetes Mellitus Patient Attitude Test): Since no comprehensive instrument to measure attitudes toward a specific illness (e.g., diabetes) was available, the researcher created a 30-item questionnaire for the attitude instrument, based on the literature review. Thirty items cover all three attitude domains: cognition (patient's perception of diabetes), affective domain (likes and dislikes of specific aspects of diabetes and diabetes care), and behavioral tendency, the predisposition to act. The presence of a specific attitude is scored 1, otherwise 0 . A summated score was developed for the attitudinal scale toward diabetes and diabetes care.

DKT (Diabetes Knowledge Test): Thirty-eight questions specific to the tutorial content were chosen to form the knowledge-based instrument for diabetes and diabetes care, since all 
experimental group participants had access to all seven core modules and print material pertaining to the tutorials. Each of these questions was open- ended; participants could choose from four possible responses. A summated scale of diabetes knowledge was developed.

Table 1. Description of Constructs and Their Measurement

\begin{tabular}{|c|c|c|c|}
\hline Construct & Conceptual Definition & Operational Definition & $\begin{array}{c}\text { Instrument/Process to } \\
\text { Measure Variable }\end{array}$ \\
\hline $\begin{array}{l}\text { Health } \\
\text { Literacy }\end{array}$ & $\begin{array}{l}\text { Health Literacy is defined as } \\
\text { " the degree to which } \\
\text { individuals have the capacity } \\
\text { to obtain, process, and } \\
\text { understand basic health } \\
\text { information and services } \\
\text { needed to make appropriate } \\
\text { health decisions." (IOM) as } \\
\text { cited in Bains and Egede } \\
\text { (2011). }\end{array}$ & $\begin{array}{l}\text { Subjects pronounce } 60 \\
\text { words. Subject scores } \\
\text { plus (+) for each } \\
\text { correctly pronounced } \\
\text { word, zero (0) for each } \\
\text { mispronounced word, } \\
\text { and a minus (-) for a } \\
\text { word not attempted. A } \\
\text { word that the patient } \\
\text { self-corrects is counted } \\
\text { as correct and scored } \\
\text { plus (+).The total score } \\
\text { is converted to a } \\
\text { reading grade level } \\
\text { using the conversion } \\
\text { table on the score sheet. }\end{array}$ & $\begin{array}{l}\text { LAD - The Literacy } \\
\text { Assessment for } \\
\text { Diabetes (LAD) is } \\
\text { administered one-on- } \\
\text { one to assess an adult } \\
\text { patient's ability to read } \\
\text { ordinary nutritional and } \\
\text { medical terms, and } \\
\text { terms specific to } \\
\text { diabetes. }\end{array}$ \\
\hline $\begin{array}{l}\text { Diabetes } \\
\text { Knowledge }\end{array}$ & $\begin{array}{l}\text { Knowledge of causes of } \\
\text { diabetes, signs of diabetes, } \\
\text { complications of diabetes, } \\
\text { preventive behavior } \\
\text { regarding diet, exercise, foot } \\
\text { care, high blood pressure, }\end{array}$ & $\begin{array}{l}\text { Correct answer was } \\
\text { scored one and wrong } \\
\text { answer scored zero. }\end{array}$ & $\begin{array}{l}\text { DKT- (Diabetes } \\
\text { Knowledge Test) - } 38 \\
\text { questions from a pool } \\
\text { of questions embedded } \\
\text { in } 7 \text { core modules on } \\
\text { diabetes. }\end{array}$ \\
\hline
\end{tabular}




\begin{tabular}{|c|c|c|c|}
\hline Construct & Conceptual Definition & Operational Definition & $\begin{array}{l}\text { Instrument/Process to } \\
\text { Measure Variable }\end{array}$ \\
\hline & $\begin{array}{l}\text { cholesterol, and meal } \\
\text { planning. }\end{array}$ & & \\
\hline $\begin{array}{l}\text { Diabetes } \\
\text { Attitude }\end{array}$ & $\begin{array}{l}\text { Attitudes are gradational } \\
\text { evaluations of an entity, } \\
\text { ranging from like (favor) to } \\
\text { dislike (disfavor). Attitudes } \\
\text { are beliefs, feelings, and } \\
\text { aptness to behave regarding } \\
\text { diabetes and its } \\
\text { management. }\end{array}$ & $\begin{array}{l}\text { Scored using Likert } \\
\text { scale ranging (1-5) } \\
\text { from strongly disagree } \\
1 \text { to strongly agree } 5 \text {. }\end{array}$ & $\begin{array}{l}\text { DMPA (Diabetes } \\
\text { Mellitus Type } 2 \text { Patient } \\
\text { Attitude) - } 30 \text { questions } \\
\text { developed to cover the } \\
3 \text { domains of attitude: } \\
\text { cognition, affective and } \\
\text { behavioral. }\end{array}$ \\
\hline $\begin{array}{l}\text { Preventive } \\
\text { Practice }\end{array}$ & $\begin{array}{l}\text { Follow a healthy diet, } \\
\text { exercise, test blood sugar, } \\
\text { check blood pressure, use } \\
\text { foot care and avoid smoking. }\end{array}$ & $\begin{array}{l}\text { The number of days } \\
\text { from none to } 7 \text { per } \\
\text { week that preventive } \\
\text { practice was carried } \\
\text { out. }\end{array}$ & $\begin{array}{l}\text { SDSCA- the Summary } \\
\text { of Diabetes Self-care } \\
\text { Activities. }\end{array}$ \\
\hline $\begin{array}{l}\text { Functional } \\
\text { Capacity }\end{array}$ & $\begin{array}{l}1 \text { Degree of ability regarding } \\
\text { mobility, self-care, usual } \\
\text { activities, pain/discomfort, } \\
\text { anxiety/depression } \\
2 \text { Degree of ability for sleep, } \\
\text { memory/concentration, } \\
\text { fatigue/energy, seeing and } \\
\text { hearing, and contact with } \\
\text { others. }\end{array}$ & $\begin{array}{l}\text { Scoring for items: } \\
\text { No problems }=1 . \\
\text { Slight problems }=2 . \\
\text { Moderate problems = } \\
3 . \\
\text { Severe problems }=4 . \\
\text { Unable to, or extreme } \\
\text { problem }=5 .\end{array}$ & $\begin{array}{l}1 \text { EQ-5D-5L } \\
\text { EuroQol (2009) } \\
2 \text { Perneger \& } \\
\text { Courvoisier (2011) }\end{array}$ \\
\hline $\begin{array}{l}\text { Poor } \\
\text { Perceived } \\
\text { Health }\end{array}$ & $\begin{array}{l}\text { A single index value for } \\
\text { health status. }\end{array}$ & $\begin{array}{l}\text { Self-perception of } \\
\text { health by choosing a } \\
\text { number on a scale } 0 \text { to } \\
100 \text { where } 0=\text { worst }\end{array}$ & EQ VAS \\
\hline
\end{tabular}




\begin{tabular}{|c|c|c|c|}
\hline Construct & Conceptual Definition & Operational Definition & $\begin{array}{c}\text { Instrument/Process to } \\
\text { Measure Variable }\end{array}$ \\
\hline & & $\begin{array}{l}\text { health and } 100=\text { best } \\
\text { health. }\end{array}$ & \\
\hline $\begin{array}{l}\text { Glycated } \\
\text { Hemoglobin } \\
\text { (A1C) }\end{array}$ & $\begin{array}{l}\text { HbA1C is a lab test that } \\
\text { shows the average level of } \\
\text { blood sugar over the } \\
\text { previous } 3 \text { months. It } \\
\text { assesses the control of } \\
\text { diabetes. (American } \\
\text { Diabetes Association, 2012). }\end{array}$ & $\begin{array}{l}\text { Normal: Less than } \\
5.7 \% \\
\text { Pre-diabetes: } 5.7 \% \text { to } \\
6.4 \% \\
\text { Diabetes: } 6.5 \% \text { or } \\
\text { higher. } \\
\text { (American Diabetes } \\
\text { Association, 2012). }\end{array}$ & $\begin{array}{l}\text { A sample of blood } \\
\text { from a vein is tested in } \\
\text { a clinical laboratory. }\end{array}$ \\
\hline $\begin{array}{l}\text { Low Density } \\
\text { Lipoprotein } \\
\text { Cholesterol } \\
\text { (LDLC) }\end{array}$ & $\begin{array}{l}\text { Lipoprotein transports } \\
\text { cholesterol within blood. It } \\
\text { can deposit inside blood } \\
\text { vessels and narrow the blood } \\
\text { vessel. }\end{array}$ & $\begin{array}{l}\text { Goal for most people is } \\
\text { LDLC level below } 130 \\
\mathrm{mg} / \mathrm{dl} \text {. }\end{array}$ & $\begin{array}{l}\text { A sample of blood } \\
\text { from a vein is tested in } \\
\text { a clinical laboratory. }\end{array}$ \\
\hline
\end{tabular}

In addition to the construct variables the main attributes of the participants were age, ethnicity, gender and comorbidities. These were coded as follows: age (years), ethnicity $(0=$ other, $1=$ white $)$, gender $(0=$ female, $1=$ male $)$, and comorbidities $(0=$ absence of comorbidities, 1 = presence of comorbidities).

\section{Validity and Reliability of Measurement: Knowledge, Attitude, Practice, and Outcome Measures}

Data for knowledge, attitude, and practice and the outcome measures of functional capacity and poor perceived health were collected after participants had completed the 
questionnaires described. The glycated hemoglobin (A1C) and low density lipoprotein cholesterol (LDLC) were obtained through blood tests.

For quantitative measures, instrument reliability and validity must be evaluated. The reliability of an instrument is the degree of consistency or accuracy with which it measures the attribute it is supposed to measure. The reliability of an instrument is specific to the sample and conditions (Polit \& Hungler, 1995). Reliability coefficients, which are an important indicator of the quality of quantitative measures, range from 0.00 to 1.00 (Polit \& Hungler, 1995). The higher values indicate increased reliability or increased accuracy (Polit \& Hungler, 1995). For group-level comparisons, a coefficient around 0.7 may be sufficient (Polit \& Hungler, 1995). Coefficients of 0.8 or greater are highly desirable (Polit \& Hungler, 1995). The reliability coefficients were computed and are as follows: the alpha for scale reliability of knowledge instrument $=0.788$, the alpha for scale reliability for the attitude instrument is 0.695 , the alpha for scale reliability for the practice measure is 0.801 , the alpha for scale reliability for the functional capacity measure is 0.871 .

Validity of an instrument refers to how adequate it is in measuring what it is supposed to measure. Does the resultant score measure the construct? Researchers have more confidence in the validity of an instrument when it has demonstrated in several previous studies that it measured what it was supposed to measure (Polit \& Hungler, 1995). The outcome measures of glycated hemoglobin (A1C) and low density lipoprotein cholesterol (LDLC), as objective measures obtained from certified laboratories, are relatively unlikely to be distorted. 


\section{Sampling and Power Analysis}

Established Type 2 diabetic patients of the medical practice sites were eligible to be recruited according to the inclusion and exclusion criteria given below.

Inclusion criteria: Patients older than age 18, diagnosed with diabetes Type 2 as indicated by one of the International Classification of Diseases Ninth Revision (ICD9) codes 249.00 250.99 , or who have been told by health practitioners that they have high blood sugar, who take Metformin, or who present to the clinic with classic symptoms of hyperglycemia and random plasma glucose of $>200 \mathrm{mg} / \mathrm{dl}$. Exclusion criteria are: Patients with Type 1 diabetes, patients who had completed more than 2 hours of diabetes education within the past 6 months, patients having reading ability below the sixth grade level as determined by the health literacy survey instrument, and patients less than eighteen years of age. Diabetic patients with complications such as kidney stage IV failure (i.e. glomerular filtration rate of $30 \%$ or less) or legal blindness from diabetic retinopathy were excluded. Patients in very poor health and unable to participate were excluded. Patients with mental impairment were excluded.

Patients were randomly assigned to experimental and control groups. Recruitment period of subjects for the study was from October 2011 to April 2012. There were three waves of recruitment. The first wave of recruitment of the subjects for the experimental group occurred in October 2011, followed by recruitment of the control subjects in November 2011. The pattern of recruitment was repeated three more times for a total of six months ending in April 2012. The study was explained to participants in person in the offices of the medical practice and patient questions were answered. 


\section{Sample Size}

Initially, the researcher attempted to recruit one hundred participants for both experimental and control groups to accommodate potential attrition and dropout. One hundred eighty- two patients were recruited. Only 141 patients completed the study with all the information necessary for analysis. The full KAP-O model has five variables $(\mathrm{P}=5)$ to be estimated and 4 residual terms (zetas) to be estimated. Thus the total number of parameters to be estimated by SEM is 9: five parameters and 4 residual terms. The known information is: (p* $(\mathrm{P}+1)$ divided by $2=30 / 2=15$. Thus, total degree of freedom is $6(15-9)$. To estimate 9 parameters in SEM, a minimum of 90 cases was required. In addition, a priori sample size calculation for anticipated effect size 0.1 , desired statistical power level of 0.8 , and probability level of 0.05, recommended a minimum sample size of 100 (Cohen, 1988; Soper, 2014; \& Westland, 2010). In addition, the study had 141 participants and satisfies this requirement.

\section{Power Analysis}

Power is the ability of a research design to detect relationships among variables when the null hypothesis is false; i.e. the ability to ascertain that this relationship between variables is not due to chance or sampling fluctuations.

The power of a study increases with large sample size, use of precise measuring tools, and a research design that controls extraneous variables. The probability of a type II error is termed beta. The complement of beta (1- $\beta)$ is the probability of obtaining a significant result, also referred to as the power of a statistical test.

Power analysis is a method for reducing the risk of type II error (wrongly accepting a false null hypothesis). To perform power analysis, four components are necessary: the level of 
significance or alpha; sample size; effect size, which refers to the strength of the relationship among variables (or the salience of the treatment compared to the noise in measurement), and power $(1-\beta)$, i.e. the probability of rejecting the null hypothesis. Power analysis was used to estimate sample size. In addition, the adequacy of the model can be estimated by a significance level of 0.05 , a sample size of 141 with 4 degree of freedom provides a power of 0.67 to detect the RMSEA ranging between 0 and 0.127 .

\section{Internal Validity}

Internal validity refers to the extent to which it is possible to make an inference that the independent variable truly influences the dependent variable and that this relationship is authentic (Campbell \& Stanley, 1963 as cited in Polit \& Hungler, 1995, p. 227). This study used an experimental design where participants were randomly assigned to intervention group and control group. Alternative explanations for resultant outcomes are referred to as threats to internal validity.

\section{History Threat}

The history threat refers to external events that occur simultaneously with the intervention and can affect the outcome (viz: participants may watch a documentary on diabetes on TV). However, since this is a randomized control trial (RCT), the researcher can assume that external events are likely to affect the experimental group and the control group equally.

\section{Maturation Threat}

Maturation refers to changes that occur in an individual with the passage of time, including aging and developmental changes, independent of the intervention. Maturation threat is 
not applicable since the two groups, intervention and control, were evaluated for a short period of six months.

\section{Testing Effects}

Answering pre-test questions may affect participants' performance on a post-test. However, since this is an experimental study with random assignment to test-control groups, this effect would be expected to be equal in both groups.

\section{Multiple Group Threats: “Social Interaction” Threats to Internal Validity}

Diffusion or imitation of treatment occurs when controls learn about the intervention from the intervention group. Since patients were assigned to the intervention group in month one and to the control group in month two, and that pattern was repeated; and since the follow- up appointments were three months from the date of the initial visit, it was unlikely that the two groups would interact.

The study used a randomized experimental pre- and post- test design. The unit of analysis was the diabetic patient. The patients were randomized to an experimental group of patients who received usual diabetes care such as prescriptions and referrals for tests and specialists and also education via the web-based program called Healthy Tutor supplemented with print-outs of the educational modules, and a control group that received simply usual care. The knowledge, attitude and self-management practice of both experimental and control groups were evaluated at baseline and post-intervention. The experimental group members, who also watched the online tutorials and/or read the printouts, were expected to have higher scores on the post-test than on pre-test, indicating an increase in knowledge. 
The provider variation is constant since the site is a single practice with a single provider. The researcher was the only staff responsible for the data collection, analysis, and results of this study. All participants answered a set of questionnaires at two time points, baseline and post intervention (three to six months after enrollment in the study). Random assignment of participants to the test and the control group is likely to yield equivalent groups vis- a- vis similar attributes that may affect the dependent variables. The performance of the control group on dependent variables forms a basis for comparing the performance of the experimental group on the same dependent variable to separate the effects of maturation from those of exposure to the intervention, i.e. diabetes self-care education.

Thirty-eight patients could not participate for various reasons: mental impairment, extreme illness, or having failed the literacy test. The researcher had recruited 182 participants, but only 141 were available for analysis. The attrition from 182 was accounted for as follows: 1) two patients underwent gastric bypass surgery after they had filled out the first set of questionnaires; 2) two patients were dismissed from the practice; 3) two patients died; 4) three patients left the state; 5) one patient, admitted to the hospital with a stroke had decline in mental functioning; and 6) thirty-one patients either changed providers soon after recruitment or failed to provide complete questionnaires.

\section{Data Collection and Management}

The pre-analysis steps were as follows: A data analysis plan was created. Each subject's completed responses were placed in a folder. The folders for the interventional group and the control groups were filed separately and alphabetically by last name. The questionnaires were reviewed for completeness and legibility. Steps were taken to retrieve missing information on 
questionnaires or missing clinical outcome measures of glycated hemoglobin (A1C) and low density lipoprotein cholesterol (LDLC). Research data was transformed into numbers by coding to enable computer analysis. A code book was prepared. Each subject was assigned a unique identification number.

The software package known as the Statistical Package for the Social Sciences (SPSS) 21 was used for data entry and analysis. Data entries were visually verified. Data were cleaned by checking for improbable values and replaced with correct values. The data were checked for consistency. Data were transformed as follows: scoring of items was reversed if they were negatively worded; individual variables were combined to form composite scores; dichotomous variables were created for multivariate analysis. Missing values on knowledge items were scored as zero. There were very few missing Likert scale items. The missing Likert scale items were replaced with mean for the item, to create a more complete data set. Cases with less than eight percent missing information were retained.

\section{Data Management}

All data were managed and stored by the investigator. The survey results were entered into SPSS 21 for analysis.

\section{Statistical Analysis Plan}

Structural equation modeling is an appropriate statistical methodology to analyze the data to determine causal relationships between the educational intervention of Healthy Tutor, knowledge, attitude, practice of self-care and clinical/self-reported outcomes.

This KAP-O model was tested to determine whether the hypothesized direct and indirect causal pathways from the cause to the effect were consistent with the data. 
The hypothesized relationships constitute the following testable hypotheses:

H1: Health educational intervention directly improves knowledge.

H2: Health educational intervention directly improves attitude.

H3: Health educational intervention directly improves preventive practice.

H4 ${ }_{1}$ : Health educational intervention directly lowers glycated hemoglobin (AlC).

$\mathrm{H}_{2}$ : Health educational intervention directly lowers low density lipoprotein cholesterol

$(L D L C)$.

H4 $4_{3}$ : Health educational intervention directly improves functional capacity $(F C)$.

$\mathrm{H}_{4}$ : Health educational intervention directly decreases poor perceived health (PPH).

H5: Health educational intervention also indirectly improves preventive practice via

knowledge and attitude.

H6: The influence of health education on health care outcomes is not direct, but is

mediated via knowledge, attitude, and practice.

Initially, from the perspective of the intention-to-treat analysis, the assumed direct causal effects were empirically tested using a pre-post design, with participants randomly assigned into experimental and control groups. The statistical analysis plan indicating how each of the six hypotheses was tested is shown below. 


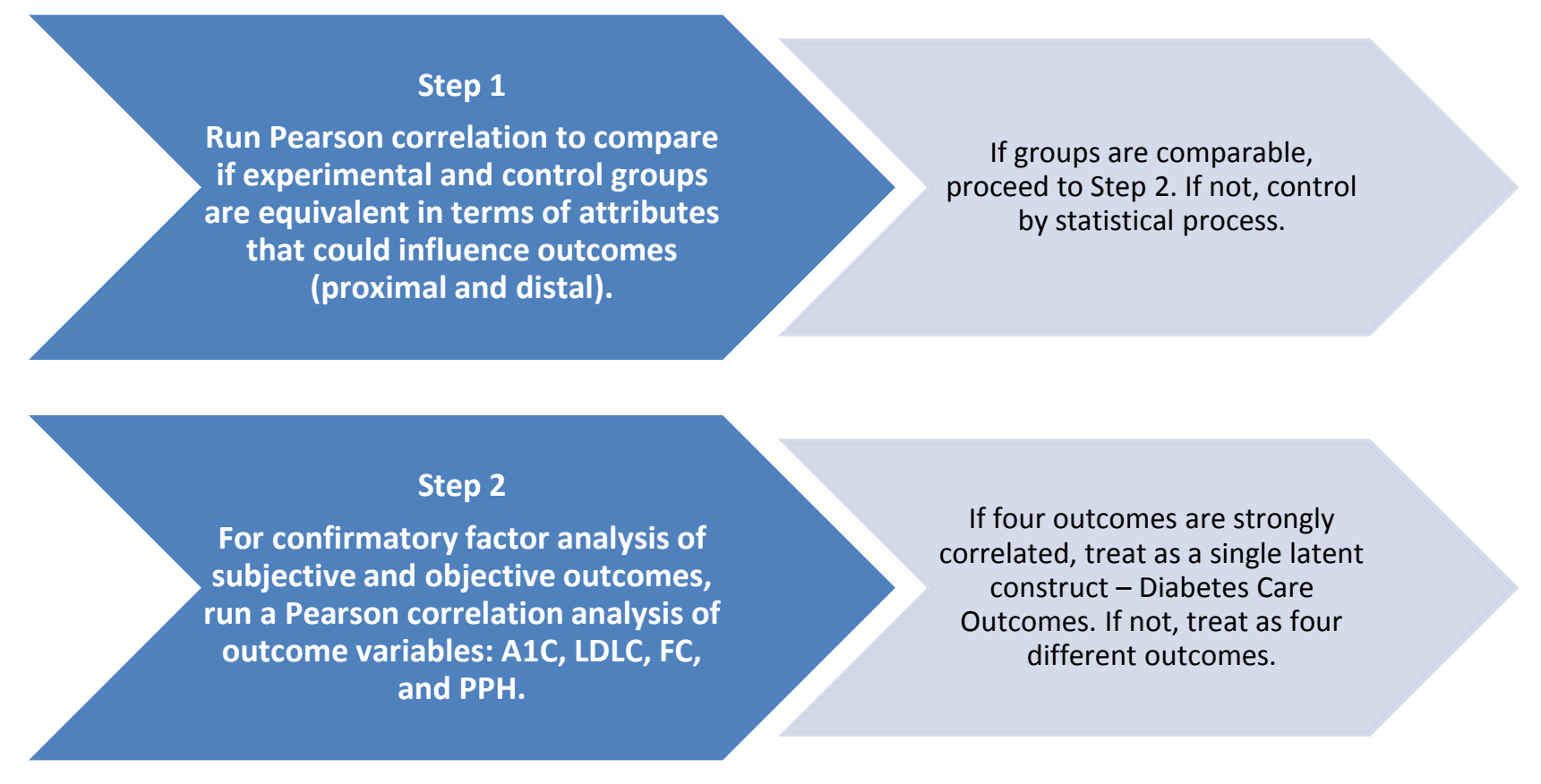

Figure 2. Statistical Analysis Plan 


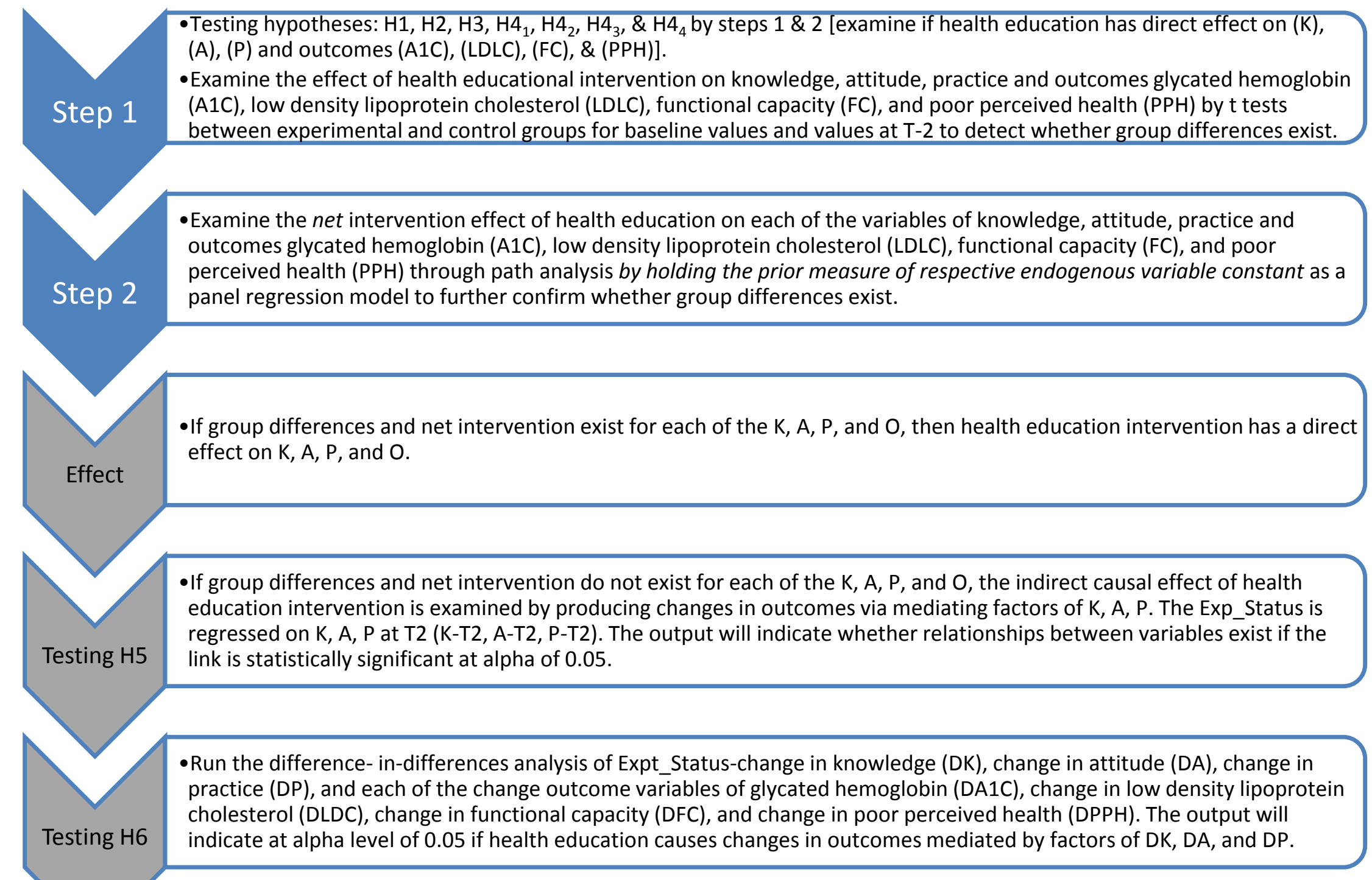

Figure 3. Intention to Treat Analysis Plan 
Fit indices and their acceptable thresholds as detailed in Hooper, Coughlan, and Mullen (2008) are absolute fit indices and incremental fit indices.

Absolute fit indices are: 1) Chi-Square $\chi 2,2)$ Relative $\left.\chi^{2}\left(\chi^{2 / d f}\right), 3\right)$ Root Mean Square Error of Approximation (RMSEA) and; Incremental Fit Indices are NFI, NNFI, and CFI.

1. Absolute fit indices:

a. Chi-Square $\chi^{2}-$ an acceptable threshold level is low $\chi^{2}$ relative to degrees of freedom with an insignificant $p$ value $(\mathrm{p}>0.05)$ (Barrett, 2007 as cited in Hooper et al., 2008).

b. Relative $\chi^{2}$ ( $\left.\chi^{2 / d f}\right)$ (Kline, 2005; Tabachnik and Fidell, 2007 as cited in Hooper et al., 2008) adjusts for sample size.

c. Root Mean Square Error of Approximation (RMSEA) - acceptable values are less than 0.07 (Steiger, 2007 as cited in Hooper et al., 2008). RMSEA has a known distribution and favors parsimony. Values less than 0.03 represent excellent fit.

2. Incremental fit indices:

a. NFI - acceptable values are greater than 0.95. NFI assesses fit relative to a baseline model which assumes no covariances between the observed variables. NFI has a tendency to underestimate fit for samples less than 200 (Mulaik et al, 1989; Bentler, 1990 as cited in Hooper et al. 2008), and is thus not recommended to be solely relied on (Kline, 2005 as cited in Hooper et al., 2008).

b. NNFI (TLI) - acceptable values are greater than 0.95. TLI favors parsimony.

c. CFI - acceptable values are greater than 0.95 . 


\section{CHAPTER FOUR: FINDINGS}

\section{Introduction}

The study used a randomized, experimental pretest-posttest design. The unit of analysis was the diabetic subject. The original plan to have 100-150 subjects each in the intervention and control groups was not feasible. Thirty eight patients either refused to participate, or were mentally impaired, were extremely ill, or failed the literacy test. The researcher recruited 182 patients for the study, of whom 141 with complete information were available for the analysis.

The attrition from 182 was accounted for as follows: 1) two patients underwent gastric bypass surgery after they had filled out the first set of questionnaires; 2) two patients were dismissed from the practice; 3) two patients died; 4) three patients left the state; 5) one patient, admitted to the hospital with a stroke had decline in mental functioning; and 6) thirty-one patients either changed providers soon after recruitment or failed to provide complete questionnaires.

\section{Descriptive and Correlation Analysis}

\section{Comparison of the Experimental and Control Groups}

The main attributes of the experimental group $(\mathrm{N}=87)$ and the control group $(\mathrm{N}=52)$ were obtained from electronic patient charts. Those attributes were: 1) age, ethnicity, and gender; 2) comorbid conditions of atherosclerosis, coronary artery disease (CAD), congestive heart failure $(\mathrm{CHF})$, chronic kidney disease (CKD), eye problems, myocardial infarction, stroke, neuropathy and osteoarthritis. A Pearson correlation to confirm the associations between normally distributed variables of the experimental and the control group gave the results shown in Table 2. 
Table 2. Pearson Correlations of Age, Ethnicity, Gender, and Comorbidities with Experimental Status

\begin{tabular}{|c|c|c|}
\hline \multicolumn{2}{|l|}{ Attributes } & Exp_Status \\
\hline \multirow[t]{2}{*}{ Age } & Pearson Correlation & -.098 \\
\hline & Sig. (2-tailed) & .246 \\
\hline \multirow[t]{2}{*}{ Ethnicity } & Pearson Correlation & -.097 \\
\hline & Sig. (2-tailed) & .253 \\
\hline \multirow[t]{2}{*}{ Gender } & Pearson Correlation & -.001 \\
\hline & Sig. (2-tailed) & .990 \\
\hline \multirow[t]{2}{*}{ CAD } & Pearson Correlation & -.048 \\
\hline & Sig. (2-tailed) & .572 \\
\hline \multirow[t]{2}{*}{ CKD } & Pearson Correlation & .036 \\
\hline & Sig. (2-tailed) & .674 \\
\hline \multirow[t]{2}{*}{$\mathrm{CHF}$} & Pearson Correlation & -.003 \\
\hline & Sig. (2-tailed) & .970 \\
\hline \multirow[t]{2}{*}{ MI } & Pearson Correlation & .022 \\
\hline & Sig. (2-tailed) & .792 \\
\hline \multirow[t]{2}{*}{ STROKE } & Pearson Correlation & -.041 \\
\hline & Sig. (2-tailed) & .630 \\
\hline \multirow[t]{2}{*}{ OSTEO } & Pearson Correlation & -.120 \\
\hline & Sig. (2-tailed) & .157 \\
\hline \multirow[t]{2}{*}{ NERVES } & Pearson Correlation & -.005 \\
\hline & Sig. (2-tailed) & .957 \\
\hline \multirow[t]{2}{*}{ EYE } & Pearson Correlation & .011 \\
\hline & Sig. (2-tailed) & .899 \\
\hline \multirow[t]{2}{*}{ Atherosclerosis } & Pearson Correlation & -.086 \\
\hline & Sig. (2-tailed) & .311 \\
\hline
\end{tabular}

* Correlation is significant at the 0.05 level (2-tailed).

** Correlation is significant at the 0.01 level (2-tailed). (experimental group $=1$, control group $=0$ ). 
The experimental group $(\mathrm{N}=87)$ and the control group $(\mathrm{N}=52)$ were comparable in terms of age, ethnicity, gender and major diagnoses.

The next consideration was to determine whether there were correlations among the four distal health outcomes- glycated hemoglobin (A1C), low density lipoprotein cholesterol (LDLC), functional capacity $(\mathrm{FC})$, and poor perceived health $(\mathrm{PPH})$ in order to formulate a single outcome construct as a latent variable of health outcomes for diabetes care.

\section{Correlation of Outcome Variables}

A correlation matrix of outcome variables at T1 (baseline) is presented in Table 3.

Table 3. Correlation Analysis of Four Outcome Variables: A1C, LDLC, PPH, and FC

\begin{tabular}{|l|l|l|l|l|l|}
\hline Outcome Variables & A1C-T1 & LDLC-T1 & PPH-T1 & FC-T1 \\
\hline \multirow{5}{*}{ A1C-T1 } & Correlation & 1 & & & \\
\cline { 2 - 6 } & Sig. (2-tailed) & & & & \\
\hline PPH-T1 & Correlation & $.196^{*}$ & 1 & & \\
\cline { 2 - 6 } & Sig. (2-tailed) & .024 & & & \\
\hline FC-T1 & Correlation & .058 & .091 & 1 & \\
\cline { 2 - 6 } & Sig. (2-tailed) & .512 & .302 & & \\
\cline { 2 - 6 } & Correlation & .041 & -.074 & $-.657^{* *}$ & 1 \\
\hline
\end{tabular}

* Correlation is statistically significant at the 0.05 level (2-tailed).

** Correlation is statistically significant at the 0.01 level (2-tailed).

Correlations among these four outcome variables were relatively weak, with the exception of moderate correlations between LDLC-T1 and A1C-T1 and FC-T1 and PPH-T1. Thus the four outcome variables did not constitute a single common factor or construct enabling 
the development of one common factor measurement model for the outcome evaluation. Therefore each outcome variable was treated as an endogenous variable in the analysis.

\section{The Intention-to-Treat Analysis: T-Tests}

This analysis was performed in 2 steps. First, the experimental effect of health educational intervention was analyzed using t-tests for each of the seven variables: Knowledge $(\mathrm{K})$, attitude (A), practice $(\mathrm{P})$, and four outcome variables \{ glycated hemoglobin (A1C), lowdensity lipoprotein cholesterol (LDLC), functional capacity (FC), and poor perceived health $(\mathrm{PPH})\}$. Analyses were performed for Time-1 (T1) and Time-2 (T2) separately without controlling for the effects of other predictors. Second, the intention-to-treat analysis was performed by regression analysis to determine the net experimental effect of health educational intervention on each of the seven study variables (K, A, P, AIC, LDLC, FC and PPH) at T2, holding the respective prior measure of the variable constant.

\section{Experimental Effect of Health Educational Intervention on Knowledge Scores (H1)}

An independent samples t-test was conducted to compare the knowledge scores for the experimental and the control group. At T1 there was not a statistically significant difference between the mean knowledge scores for the experimental group and those for the control group. At T2, the mean knowledge score of the experimental group improved; there was a statistically significant difference between the mean knowledge scores for the experimental group and those for the control groups $(\mathrm{p}<0.05)$. The difference between the T1 and T2 scores for the experimental group showed no statistically significant difference from those of the control group. 
Table 4. Experimental Effect on Knowledge Scores at T2 and Differences between T1 and T2

\begin{tabular}{|l|l|l|l|l|l|}
\hline \multirow{2}{*}{ Variables } & \multicolumn{2}{|l|}{ Control Group N = 52 } & \multicolumn{2}{l|}{ Experimental Group N = 87 } & \multirow{2}{*}{ P-value } \\
\cline { 2 - 5 } & Mean & SD & Mean & SD & \\
\hline Knowledge-T1 & 29.38 & 4.47 & 30.24 & 5.11 & 0.319 \\
\hline Knowledge-T2 & 29.56 & 5.18 & 31.44 & 5.30 & $\mathbf{0 . 0 4 3}$ \\
\hline Difference between T2 and T1 & 0.17 & 3.89 & 1.20 & 3.83 & 0.133 \\
\hline
\end{tabular}

*Statistically significant at 0.05 or lower level.

Hypothesis H1: Health educational intervention directly improves knowledge about diabetes is supported.

\section{Experimental Effect of Health Educational Intervention on Attitude Scores (H2)}

An independent samples t-test was conducted to compare the scores for attitude towards diabetes for the experimental and the control groups. At T1 there was not a statistically significant difference in the mean scores for attitude toward diabetes between the experimental and the control group. At T2 there was not a statistically significant difference in the mean scores for attitude toward diabetes between the experimental and the control group $(p>0.05)$. The difference between the T1 and T2 scores for the experimental group showed no statistically significant difference from those of the control group.

Table 5. Experimental Effect on the Scores for Attitude toward Diabetes at T2 and Differences between $\mathrm{T} 1$ and $\mathrm{T} 2$

\begin{tabular}{|l|l|l|l|l|l|}
\hline \multirow{2}{*}{ Variables } & \multicolumn{2}{|l|}{ Control Group N=52 } & \multicolumn{2}{l|}{ Experimental Group N=87 } & \multirow{2}{*}{ P-value } \\
\cline { 2 - 5 } & Mean & SD & Mean & SD & \\
\hline Attitude-T1 & 20.63 & 4.22 & 20.23 & 4.22 & 0.585 \\
\hline Attitude-T2 & 20.40 & 4.01 & 20.48 & 3.81 & 0.908 \\
\hline Difference between T2 and T1 & -0.23 & 3.55 & 0.25 & 3.75 & 0.454 \\
\hline
\end{tabular}

*Statistically significant at 0.05 or lower level. 
Hypothesis H2: Health educational intervention directly improves attitude towards diabetes is not supported.

\section{Experimental Effect of Health Educational Intervention on Preventive Practice Scores (H3)}

An independent samples t-test was conducted to compare the preventive practice scores

for the experimental and the control groups. At T1 there was not a statistically significant difference in the mean preventive practice scores for the experimental and the control group. At $\mathrm{T} 2$ there was not a statistically significant difference in the mean preventive practice scores for the experimental and the control group $(\mathrm{p}>0.05)$. The difference between the T1 and T2 scores for the experimental group showed no statistically significant difference from those of the control group.

Table 6. Experimental Effect on the Scores for Preventive Practice at T2 and the Differences between $\mathrm{T} 1$ and $\mathrm{T} 2$

\begin{tabular}{|l|l|l|l|l|l|}
\hline \multirow{2}{*}{ Variables } & \multicolumn{2}{|l|}{ Control Group N=52 } & Experimental Group N=87 & \multirow{2}{*}{ P-value } \\
\cline { 2 - 5 } & Mean & SD & Mean & SD & \\
\hline Practice-T1 & 46.85 & 18.43 & 43.92 & 17.78 & 0.356 \\
\hline Practice-T2 & 51.21 & 16.22 & 51.44 & 16.55 & 0.938 \\
\hline Difference Between T2 and T1 & 4.37 & 12.12 & 7.52 & 14.48 & 0.190 \\
\hline
\end{tabular}

*Statistically significant at 0.05 or lower level.

Hypothesis H3: Health educational intervention directly improves preventive practice is not supported.

\section{Experimental Effect of Health Educational Intervention on A1C Measures $\left(\mathrm{H}_{1}\right)$}

An independent samples t-test was conducted to compare the A1C measures for the experimental and the control groups. At T1 there was no statistically significant difference 
between the $\mathrm{A} 1 \mathrm{C}$ scores for the experimental and the control groups. At $\mathrm{T} 2$ there was no statistically significant difference between the mean A1C measures for the experimental and the control groups $(\mathrm{p}>0.05)$. The difference between the $\mathrm{T} 1$ and $\mathrm{T} 2$ scores for the experimental group showed no statistically significant difference from those of the control group.

Table 7. Experimental Effect on the A1C Measures at $\mathrm{T} 2$ and Differences between $\mathrm{T} 1$ and $\mathrm{T} 2$

\begin{tabular}{|l|l|l|l|l|l|}
\hline \multirow{2}{*}{ Variables } & \multicolumn{3}{|l|}{ Control Group N =45 } & Experimental Group N = 85 & \multirow{2}{*}{ P-value } \\
\cline { 2 - 5 } & Mean & SD & Mean & SD & \\
\hline A1C-T1 & 8.14 & 2.212 & 8.06 & 2.566 & 0.863 \\
\hline A1C-T2 & 8.2578 & 2.37396 & 7.5941 & 1.98190 & 0.113 \\
\hline Difference Between T2 and T1 & 0.1222 & 1.50905 & -0.4635 & 1.66389 & 0.051 \\
\hline
\end{tabular}

*Statistically significant at 0.05 or lower level.

$\mathrm{H} 4_{1}$ : Health educational intervention directly lowers glycated hemoglobin (A1C) is not supported.

\section{Experimental Effect of Health Educational Intervention on Low-Density Lipoprotein Cholesterol (LDLC) Measures $\left(\mathrm{H}_{2}\right)$}

An independent samples t-test was conducted to compare the low- density lipoprotein cholesterol (LDLC) measures for the experimental and the control group. For both T1 and T2, there was no statistically significant difference in the mean low density lipoprotein cholesterol (LDLC) measures between the two groups ( $\mathrm{p}>0.05)$. The difference between the $\mathrm{T} 1$ and $\mathrm{T} 2$ scores for the experimental group showed no statistically significant difference from those of the control group. 
Table 8. Experimental Effect on the Measures of Low- Density Lipoprotein Cholesterol (LDLC) at T2 and the Difference between T1 and T2

\begin{tabular}{|l|l|l|l|l|l|}
\hline \multirow{2}{*}{ Variables } & Control Group N =45 & \multicolumn{2}{l|}{ Experimental Group N =78 } & P-value \\
\cline { 2 - 6 } & Mean & SD & Mean & SD & \\
\hline LDLC-T1 & 103.37 & 49.44 & 107.75 & 37.945 & 0.583 \\
\hline LDLC-T2 & 90.91 & 36.813 & 100.99 & 36.509 & 0.144 \\
\hline Difference between T2 and T1 & -12.4633 & 38.59645 & -6.7577 & 37.13258 & 0.420 \\
\hline
\end{tabular}

*Statistically significant at 0.05 or lower level.

$\mathrm{H}_{2}$ : Health educational intervention directly lowers low density lipoprotein cholesterol (LDLC) is not supported.

\section{Experimental Effect of Health Educational Intervention on Functional Capacity $\left(\mathrm{H}_{3}\right)$}

An independent samples t-test was conducted to compare the functional capacity scores for the experimental and the control group. For both $\mathrm{T} 1$ and $\mathrm{T} 2$, there were no statistically significant differences between the mean functional capacity scores for the experimental and the control group ( $\mathrm{p}>0.05)$. The difference between the $\mathrm{T} 1$ and $\mathrm{T} 2$ scores for the experimental group showed no statistically significant difference from those of control group.

Table 9. Experimental Effect on the Scores for Functional Capacity at T2 and the Differences between $\mathrm{T} 1$ and $\mathrm{T} 2$

\begin{tabular}{|l|l|l|l|l|l|}
\hline \multirow{2}{*}{ Variables } & \multicolumn{3}{|l|}{ Control Group N =52 } & \multicolumn{3}{l|}{ Experimental Group N =88 } & P-value \\
\cline { 2 - 6 } & Mean & SD & Mean & SD & \\
\hline FC-T1 & 38.5769 & 6.55997 & 37.0114 & 8.14593 & 0.216 \\
\hline FC-T2 & 37.8269 & 7.31831 & 37.5227 & 7.85351 & 0.821 \\
\hline $\begin{array}{l}\text { Difference between T2 } \\
\text { and T1 }\end{array}$ & -0.7500 & 4.35158 & 0.5114 & 4.78982 & 0.122 \\
\hline
\end{tabular}

*Statistically significant at 0.05 or lower level. 
$\mathrm{H} 4_{3}$ : Health educational intervention directly improves functional capacity $(\mathrm{FC})$ is not supported.

\section{Experimental Effect of Health Educational Intervention on Poor Perceived Health Scores $\left(\mathrm{H}_{4}\right)$}

An independent samples t-test was performed to compare the poor perceived health scores for the experimental and the control groups. For both T1 and T2, no statistically significant differences were found in the mean scores for poor perceived health between the experimental and the control group ( $\mathrm{p}>0.05)$. The difference between the $\mathrm{T} 1$ and $\mathrm{T} 2$ scores for the experimental group showed no statistically significant difference from those of the control group.

Table 10. Experimental Effect on the Scores for Poor Perceived Health at T2 and the Differences between $\mathrm{T} 1$ and $\mathrm{T} 2$

\begin{tabular}{|c|c|c|c|c|c|}
\hline \multirow{2}{*}{ Variables } & \multicolumn{2}{|c|}{ Control Group N = 52} & \multicolumn{2}{|c|}{ Experimental Group $\mathrm{N}=89$} & \multirow[t]{2}{*}{ P-value } \\
\hline & Mean & SD & Mean & SD & \\
\hline PPH-T1 & 30.7500 & 21.05630 & 34.1910 & 24.44654 & 0.398 \\
\hline $\mathrm{PPH}-\mathrm{T} 2$ & 32.1731 & 21.57679 & 34.6292 & 22.92447 & 0.532 \\
\hline $\begin{array}{l}\text { Difference between } \mathrm{T} 2 \\
\text { and } \mathrm{T} 1\end{array}$ & 1.4231 & 20.34732 & 0.4382 & 22.19795 & 0.794 \\
\hline
\end{tabular}

*Statistically significant at 0.05 or lower level.

$\mathrm{H}_{4}$ : Health educational intervention directly decreases poor perceived health (PPH) is not supported. 


\section{Intention-to-Treat Analysis with Statistical Control of the Prior Score}

To examine the net experimental effect at $\mathrm{T} 2$ of health educational intervention on each respective variable: knowledge, attitude, practice, and outcome variables, holding the prior measure of the study variable at T1 constant, a regression analysis was performed. See Figure 4 below for the net effect of experimental status on K-T2. The intention-to-treat analysis with statistical control of the prior score of knowledge K-T1, attitude A-T1, or preventive practice PT1enabled partial examination of the causal model of Exp_Status-K-T2, A-T2, or P-T2.

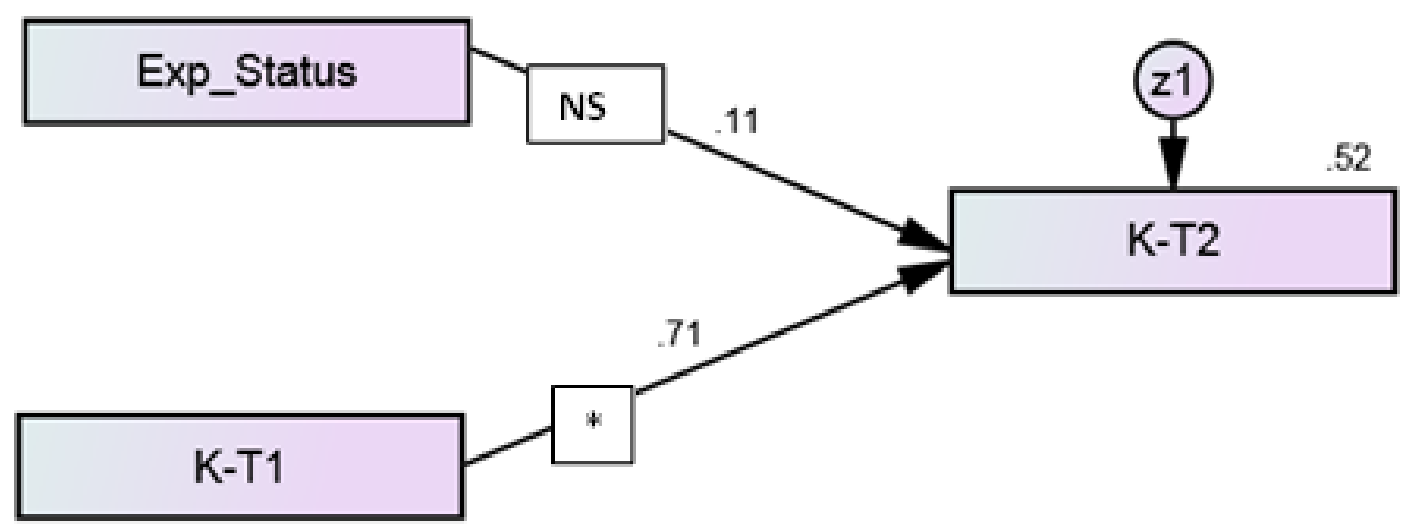

$\mathrm{NS}=$ Not statistically significant at 0.05 or lower level

*Statistically significant at 0.05 or lower level Goodness-of-fit Statistics: Chi Square $=0.981$ with DF $=1, \mathrm{P}=0.322, \mathrm{CFI}=1, \mathrm{TLI}=1.001, \mathrm{RMSEA}=0.00, \mathrm{R}^{2}=$ 0.52 .

Comments on Model Fit: Non significant Chi square value and value close to zero indicates a close fit; and RMSEA less than 0.05 indicates an excellent fit.

Figure 4. The Net Effect of Experimental Status on Knowledge at T2 (K-T2)

Figure 4 shows that experimental status does not statistically affect knowledge at T2 (K-T2) while prior level K-T1 is controlled. Knowledge at T2 is relatively constant, with beta $=0.7$. This is a partial examination of the causal model. The $\mathrm{R}^{2}$ for the experimental variable is $3 \%$. Thus the 
experimental status accounts for very little variation in K-T2, i.e. experimental status does not have much direct influence on knowledge. Similarly, experimental status accounts for very little variation in attitude at T2 (A-T2) or in practice at T2 (P-T2). The results for these two submodels are shown in Appendix K. Health educational intervention has little influence in changing any of the KAP components. These analyses of the net effects of experimental status on knowledge, attitude, and practice found that knowledge and practice scores were strongly related to their prior levels $\mathrm{K} 1, \mathrm{P} 1$ and relatively stable over time, while attitude scores at $\mathrm{T} 1$ and T2 were moderately associated.

Since the intention-to-treat analysis with statistical control of the prior score using regression analysis showed that health educational intervention has little direct causal influence on each of the variables: knowledge $(\mathrm{K})$, attitude $(\mathrm{A})$, and practice $(\mathrm{P})$, the concomitant effect of experimental status, knowledge and attitude on practice was examined by analyzing the model $\{($ Exp_Status)-(K-T2)-(A-T2)-(P-T2) $\}$ in SEM. 


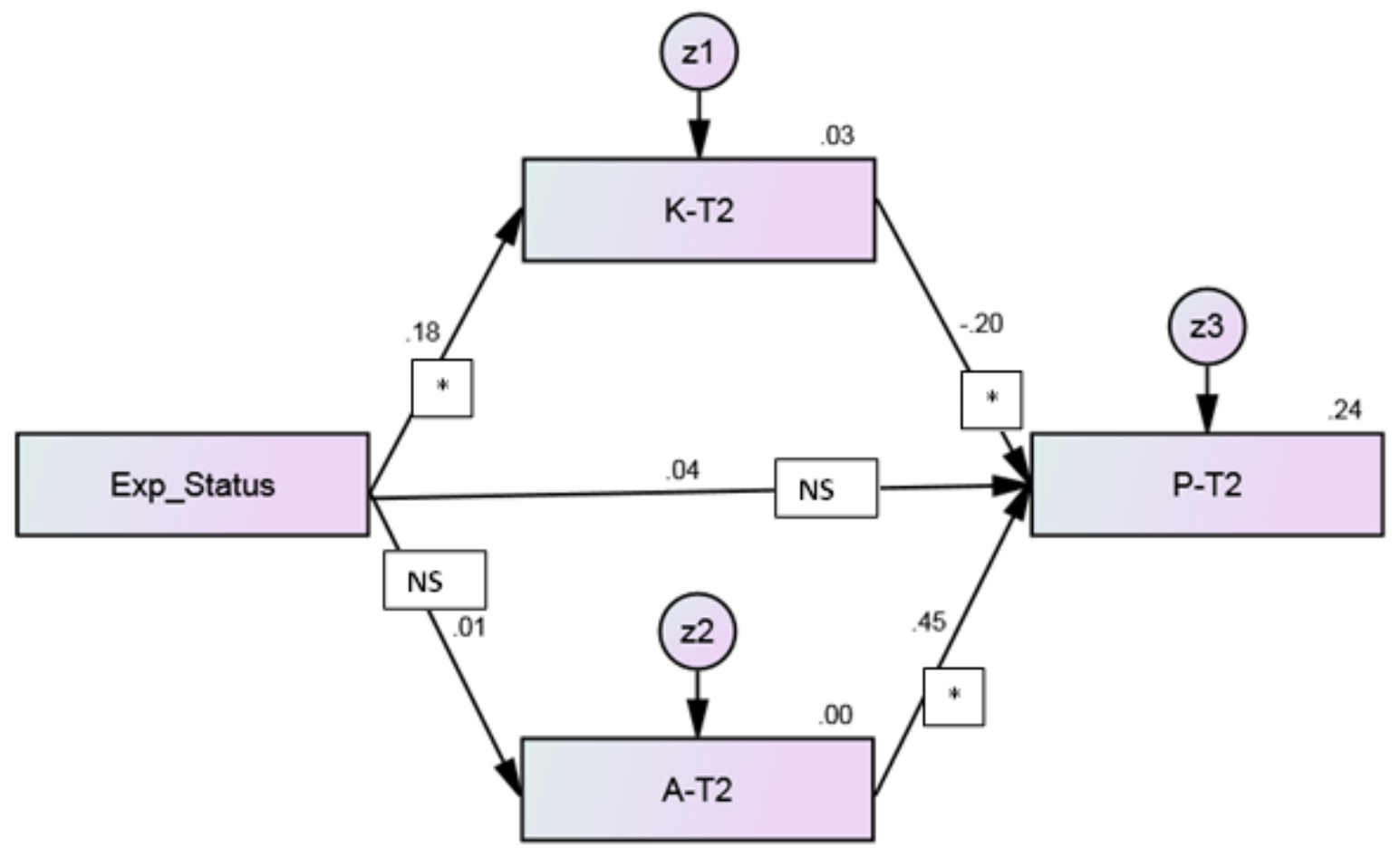

Goodness-of-fit Statistics: Chi Square $=3.274$, with DF $=1, P=0.070$, CFI $=0.930$, TLI $=0.302$, RMSEA $=0.127$, $\mathrm{R}^{2}=0.24$,

Comments on Model Fit: Chi square/DF $=3.274(<4) \mathrm{p}=0.070$ suggests that the model fit reasonably well.

Figure 5. Experimental Status, Knowledge (K-T2), Attitude (A-T2), and Practice (P-T2) at T2 Model

Table 11. Experimental Effect on Practice at T2 via Knowledge and Attitude at T2

\begin{tabular}{|l|l|l|l|l|}
\hline \multicolumn{1}{|c|}{ Indicator/Item } & \multicolumn{1}{|c|}{$\begin{array}{c}\text { Standardized } \\
\text { Parameter or Factor } \\
\text { Loading }\end{array}$} & $\begin{array}{c}\text { Unstandardized } \\
\text { Factor Loading }\end{array}$ & $\begin{array}{c}\text { Standard } \\
\text { Error (S.E) }\end{array}$ & $\begin{array}{c}\text { P value/ } \\
\text { Significance }\end{array}$ \\
\hline $\begin{array}{l}\text { K-T2 <--- } \\
\text { Exp_Status }\end{array}$ & .175 & 1.922 & .915 & $.036^{*}$ \\
\hline $\begin{array}{l}\text { A-T2 <--- } \\
\text { Exp_Status }\end{array}$ & .006 & .046 & .672 & .946 \\
\hline $\begin{array}{l}\text { P-T2<--- } \\
\text { Exp_Status }\end{array}$ & .039 & 1.336 & 2.545 & .599 \\
\hline P-T2<--- K-T2 & -.204 & -.635 & & .233 \\
\hline P-T2<--- A-T2 & .449 & 1.924 & .315 & $* * *$ \\
\hline
\end{tabular}

NS = Not statistically significant at 0.05 or lower level.

*Statistically significant at 0.05 or lower level. 
Figure 5 illustrates the model of experimental status, knowledge, attitude, and practice at T2. This is not a full examination of the model, since prior levels are not controlled. The model shows the concomitant effects of experimental status, knowledge and attitude, on practice. The experimental status has no direct impact on the practice of preventive self-care, controlling for knowledge and attitude at T2. The experimental variable has an indirect effect on self-care practice through knowledge. Knowledge at $\mathrm{T} 2$ has a negative impact on self-care practice that is statistically significant, with $\beta=-0.204$. The impact of the experimental variable on attitude at T2 is not statistically significant. The impact of attitude at T2 (A-T2) on practice at T2 (P-T2) is positive and statistically significant, with $\beta=0.449$. The impact of attitude (A-T2) is more dominant than the impact of knowledge. Positive attitude increases the practice of selfmanagement and vice versa.

H5: Health educational intervention also indirectly improves preventive practice via knowledge is supported.

Next, the net experimental effect on each of the four outcome variables at T2, holding the prior measure constant, was examined by regression analysis. The net effect of experimental status on $\mathrm{A} 1 \mathrm{C}$ at $\mathrm{T} 2$, holding $\mathrm{A} 1 \mathrm{C}$ at $\mathrm{T} 1$ constant, is shown in Figure 6 below. 


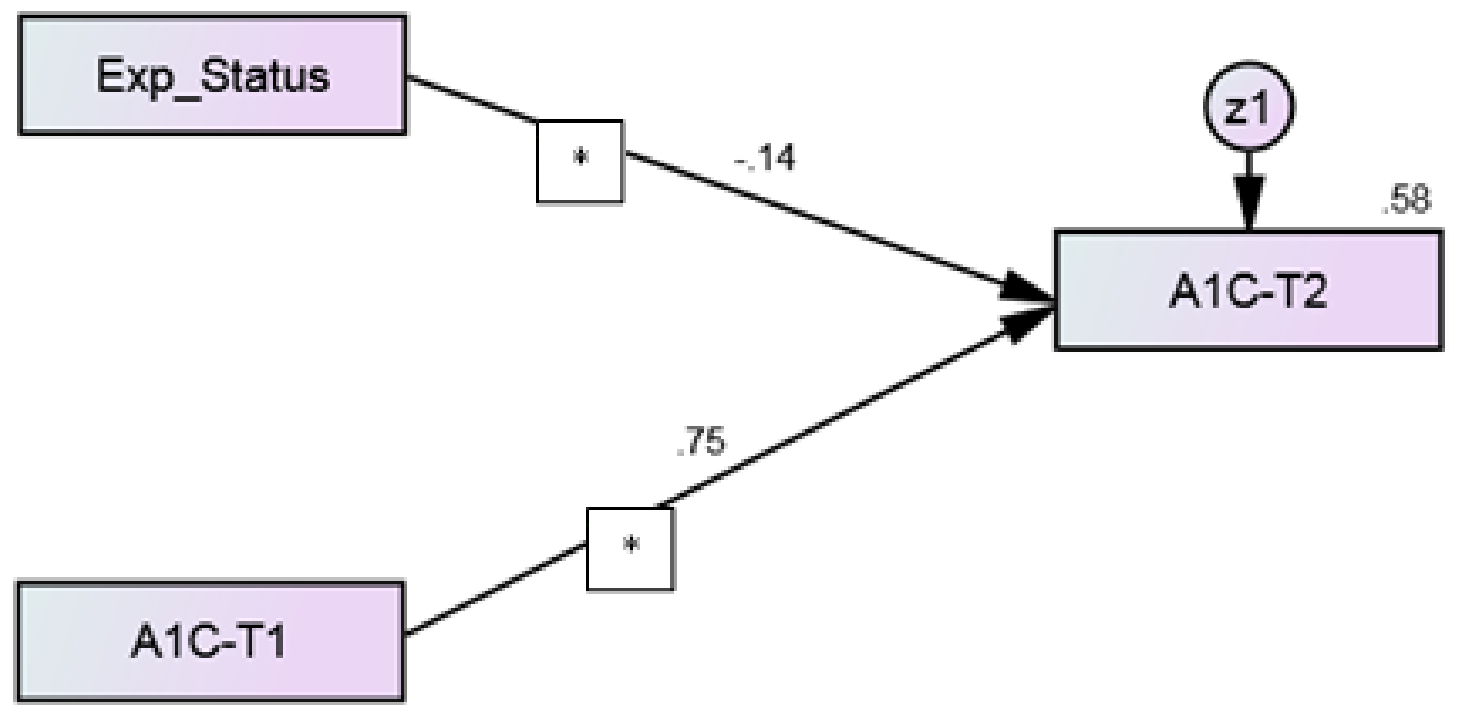

$\mathrm{NS}=$ Not statistically significant at 0.05 or lower level

*Statistically significant at 0.05 or lower level

Goodness-of-fit Statistics:

Chi Square $=0.037$ with $\mathrm{DF}=1, \mathrm{P}=0.848, \mathrm{CFI}=1, \mathrm{TLI}=1.053, \mathrm{RMSEA}=0.00, \mathrm{R}^{2}=0.58$.

Comments on Model Fit: Chi square/DF $=0.037(<4) \mathrm{p}=0.848$ suggests that the model fit reasonably well. RMSEA is less than 0.05 indicates an excellent fit.

Figure 6. The Net Effect of Experimental Status on Glycated Hemoglobin (A1C) at T2

The impact of experimental status on $\mathrm{A} 1 \mathrm{C}$ at $\mathrm{T} 2$ (A1C-T2), holding prior $\mathrm{A} 1 \mathrm{C}$ constant, is statistically significant $(\mathrm{p}<0.05)$. There is a direct effect of experimental status on A1C.The impact of $\mathrm{A} 1 \mathrm{C}$ at $\mathrm{T} 1$ on $\mathrm{A} 1 \mathrm{C}$ at $\mathrm{T} 2$ is statistically significant, with $\beta=0.75 . \mathrm{H} 4_{1}$ : Health educational intervention directly lowers glycated hemoglobin (A1C) is supported.

The net effect of experimental status on each of these outcomes: low-density lipoprotein cholesterol, functional capacity, and poor perceived health at $\mathrm{T} 2$, holding their respective prior levels constant, was not statistically significant and is illustrated in figures 13,14 and 15 in appendix $\mathrm{K}$. The impact of LDLC at T1 on LDLC at $\mathrm{T} 2$ is statistically significant, $\beta=0.56$. The impact of functional capacity (FC) at $\mathrm{T} 1$ on functional capacity at $\mathrm{T} 2$ is statistically significant, 
with $\beta=0.82$. The influence of poor perceived health at $\mathrm{T} 1$ on poor perceived health at $\mathrm{T} 2$ is statistically significant, with $\beta=0.557$.

These analyses examining net effect of the experimental variable on each of the four outcome variables when holding prior levels constant demonstrated there is no direct effect of experimental status on outcome variables, with the sole exception of the direct effect on glycated hemoglobin (A1C). Thus an indirect causal effect of health education mediated via the change variables of DK, DA, and DP on outcome variables is assumed in the difference-in-differences analysis. A difference-in-differences analysis of Expt_Status, change in knowledge (DK), change in attitude (DA), change in practice (DP), and each of the change outcome variables: change in glycated hemoglobin (DA1C), change in low- density lipoprotein cholesterol (DLDLC), change in functional capacity (DFC), and change in poor perceived health (DPPH) was conducted.

\section{Difference-in-Differences Analysis}

The causal model of experimental status and differences in knowledge, attitude, practice and outcomes over time (T2-T1) is an acceptable fit. This model enabled examination of the direct or indirect effects of health educational intervention on outcome indicators.

\section{Effect of Experimental Status and Differences in Knowledge, Attitude, and Practice on Difference in $A 1 C$ at $T 2$}

Table 12 below shows that the effects of the experimental variable on change in knowledge (DK), on change in attitude (DA), and on change in practice (DP) are not statistically significant. Change in knowledge (DK) and change in attitude (DA) do not have statistically significant effects on change in practice (DP). 
Change in practice (DP) has a statistically significant effect on change in the outcome for A1C (DA1C). Change in practice (DP) has no statistically significant effect on change in any of the other outcome variables, DLDLC, DPPH, and DFC, as illustrated in Figures 8, 9, and 10 and the accompanying tables.

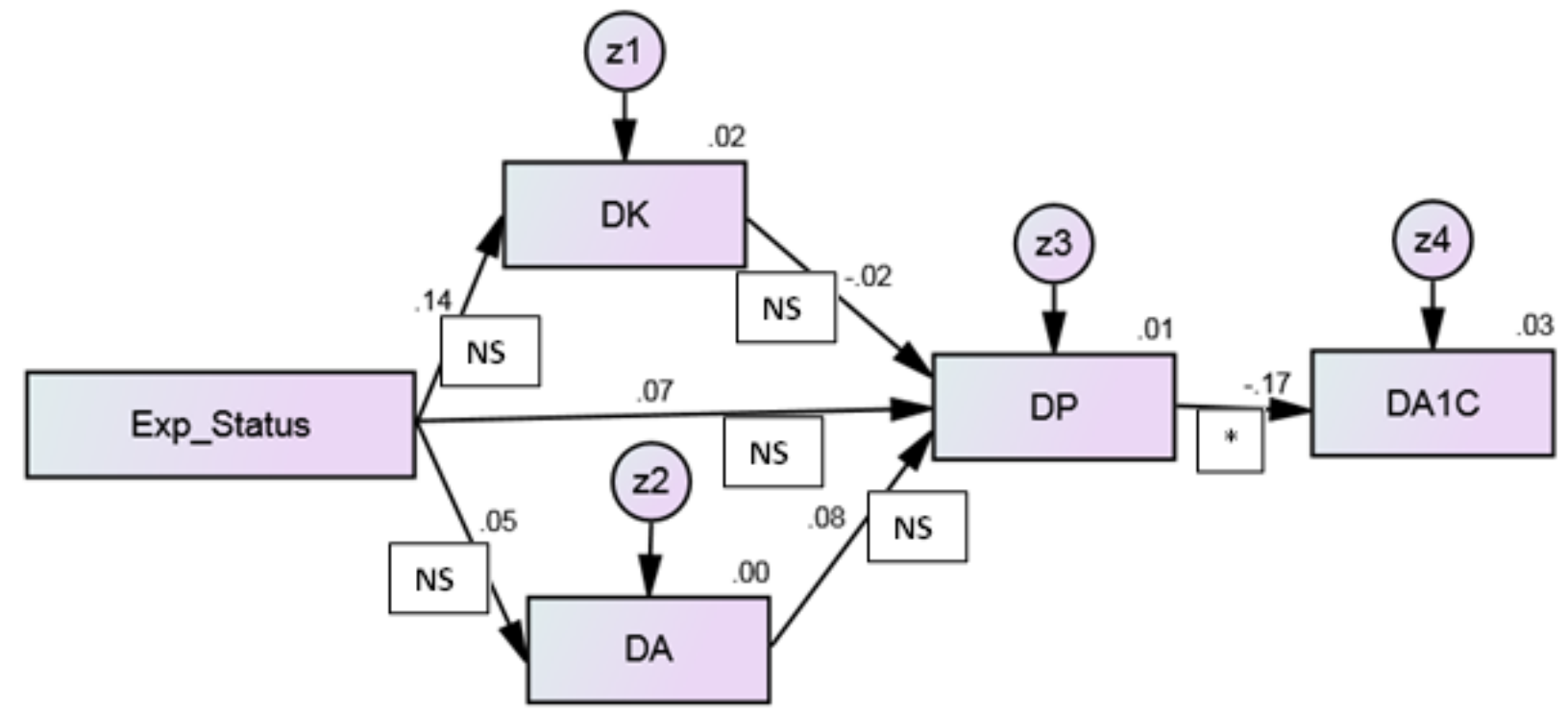

$\mathrm{NS}=$ Not statistically significant at 0.05 or lower level

*Statistically significant at 0.05 or lower level

Goodness of Fit Statistics: Chi Square $=5.338$ with $\mathrm{DF}=4, \mathrm{P}=0.254, \mathrm{TLI}=4.247, \mathrm{RMSEA}=0.051, \mathrm{R}^{2}=0.52$.

Comments on Model Fit: Non significant Chi square value and Chi Square/DF= 1.355, $p=0.254$ suggests that the model fit reasonably well; RMSEA less than 0.08 indicates a close fit.

Figure 7. The Net Effect of Experimental Status and Differences in Knowledge (DK), Attitude (DA), and Practice (DP) on Difference in Glycated Hemoglobin (DA1C) 
Table 12. The Net Effect of Experimental Status and Differences in Knowledge, Attitude, and Practice on Difference in A1C at T2

\begin{tabular}{|l|l|l|l|l|}
\hline Indicator/Item & $\begin{array}{l}\text { Standardized } \\
\text { Parameter or } \\
\text { Factor Loading }\end{array}$ & $\begin{array}{l}\text { Unstandardized } \\
\text { Factor Loading }\end{array}$ & $\begin{array}{l}\text { Standard } \\
\text { Error (S.E) }\end{array}$ & $\begin{array}{l}\text { P Value/ } \\
\text { Significance }\end{array}$ \\
\hline DK <---Expt_Status & .139 & 1.137 & .714 & .111 \\
\hline DA <--- Expt_Status & .046 & .357 & .675 & .597 \\
\hline DP <--- Expt_Status & .072 & 2.109 & 2.578 & .413 \\
\hline DP <--- DK & -.023 & -.083 & .316 & .793 \\
\hline DP <--- DA & .080 & .304 & .331 & .358 \\
\hline DA1C <--- DP & -.173 & -.020 & .010 & $.047^{*}$ \\
\hline
\end{tabular}

NS = Not statistically significant at 0.05 or lower level.

*Statistically significant at 0.05 or lower level.

H6: The influence of health education on health care outcomes is not direct, but is mediated via knowledge, attitude, and practice is not supported. 


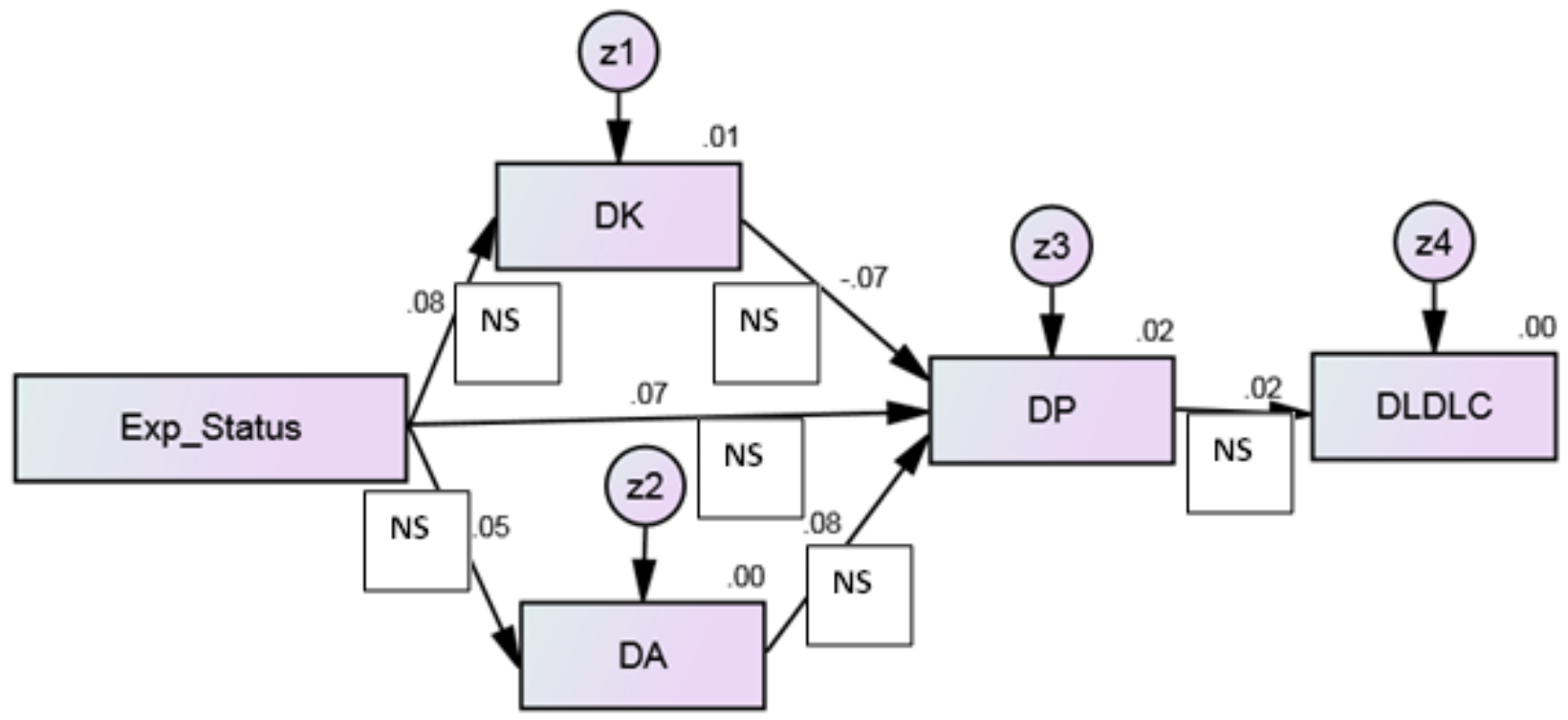

$\mathrm{NS}=$ Not statistically significant at 0.05 or lower level

*Statistically significant at 0.05 or lower level

Goodness of Fit Statistics: Chi Square $=4.329$ with DF $=4, \mathrm{P}=0.363, \mathrm{TLI}=1.164, \mathrm{RMSEA}=0.025, \mathrm{R}^{2}=0.00$.

Comments on Model Fit: Non significant Chi square value and Chi Square/DF=1.082, $p=0.363$ suggests that the model fit reasonably well; RMSEA less than 0.05 indicates an excellent fit.

Figure 8. The Net Effect of Experimental Status,and Differences in Knowledge (DK), Attitude (DA), and Practice (DP) on Difference in Low-Density Lipoprotein Cholesterol (DLDLC)

Table 13. The Net Effect of Experimental Status and Differences in Knowledge (DK), Attitude (DA), and Practice (DP) on Difference in low-density lipoprotein cholesterol (DLDLC)

\begin{tabular}{|l|l|l|l|l|}
\hline Indicator/Item & $\begin{array}{l}\text { Standardized } \\
\text { Parameter or Factor } \\
\text { Loading }\end{array}$ & $\begin{array}{l}\text { Unstandardized } \\
\text { Factor Loading }\end{array}$ & $\begin{array}{l}\text { Standard } \\
\text { Error(S.E) }\end{array}$ & $\begin{array}{l}\text { P Value/ } \\
\text { Significance }\end{array}$ \\
\hline DK <--- Exp_Status & .079 & .629 & .707 & .374 \\
\hline DA <--- Exp_Status & .049 & .366 & .665 & .582 \\
\hline DP <--- Exp_Status & .068 & 1.967 & 2.559 & .442 \\
\hline DP <--- DK & -.065 & -.236 & .321 & .462 \\
\hline DP <--- DA & .081 & .313 & .339 & .356 \\
\hline DLDLC <--- DP & .024 & .065 & .247 & .793 \\
\hline
\end{tabular}

NS = Not statistically significant at 0.05 or lower level.

*Statistically significant at 0.05 or lower level. 


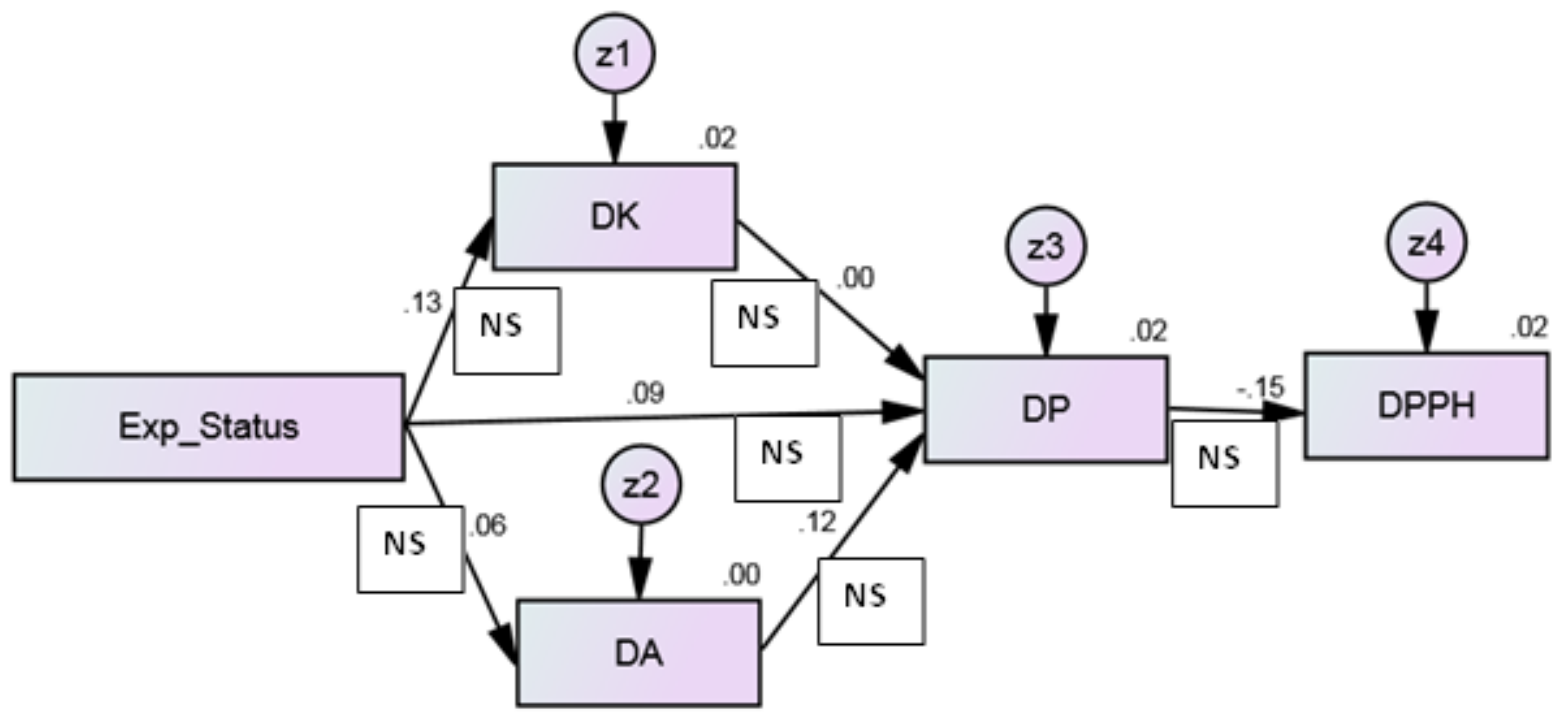

$\mathrm{NS}=$ Not statistically significant at 0.05 or lower level

*Statistically significant at 0.05 or lower level

Goodness of Fit Statistics: Chi Square $=3.984$ with DF $=4, \mathrm{P}=0.408$, TLI $=0.966$, RMSEA $=0.00, \mathrm{R}^{2}=0.02$.

Comments on Model Fit: Non significant Chi square value and Chi Square/DF $=0.996, p=0.408$, suggests that the model fit reasonably well. CFI greater than 0.95 is good; RMSEA less than 0.05 indicates an excellent fit.

Figure 9. The Net Effect of Experimental Status and Differences in Knowledge (DK), Attitude (DA), and Practice (DP) on Difference in Poor Perceived Health (DPPH)

Table 14. The Net Effect of Experimental Status and Differences in Knowledge (DK), Attitude (DA), and Practice (DP) on Difference in Poor Perceived Health (DPPH)

\begin{tabular}{|l|l|l|l|l|}
\hline Indicator/Item & $\begin{array}{l}\text { Standardized } \\
\text { Parameter or } \\
\text { Factor Loading }\end{array}$ & $\begin{array}{l}\text { Unstandardized } \\
\text { Factor Loading }\end{array}$ & $\begin{array}{l}\text { Standard } \\
\text { Error(S.E) }\end{array}$ & $\begin{array}{l}\text { P Value/ } \\
\text { Significance }\end{array}$ \\
\hline DK <--- Exp_Status & .129 & 1.031 & .671 & .124 \\
\hline DA <--- Exp_Status & .057 & .433 & .637 & .497 \\
\hline DP <--- Exp_Status & .090 & 2.580 & 2.424 & .287 \\
\hline DP <--- DK & .001 & .004 & .305 & .991 \\
\hline DP <--- DA & .121 & .459 & .318 & .149 \\
\hline DPPH <--- DP & -.146 & -.226 & .130 & .082 \\
\hline
\end{tabular}

NS = Not statistically significant at 0.05 or lower level.

*Statistically significant at 0.05 or lower level. 


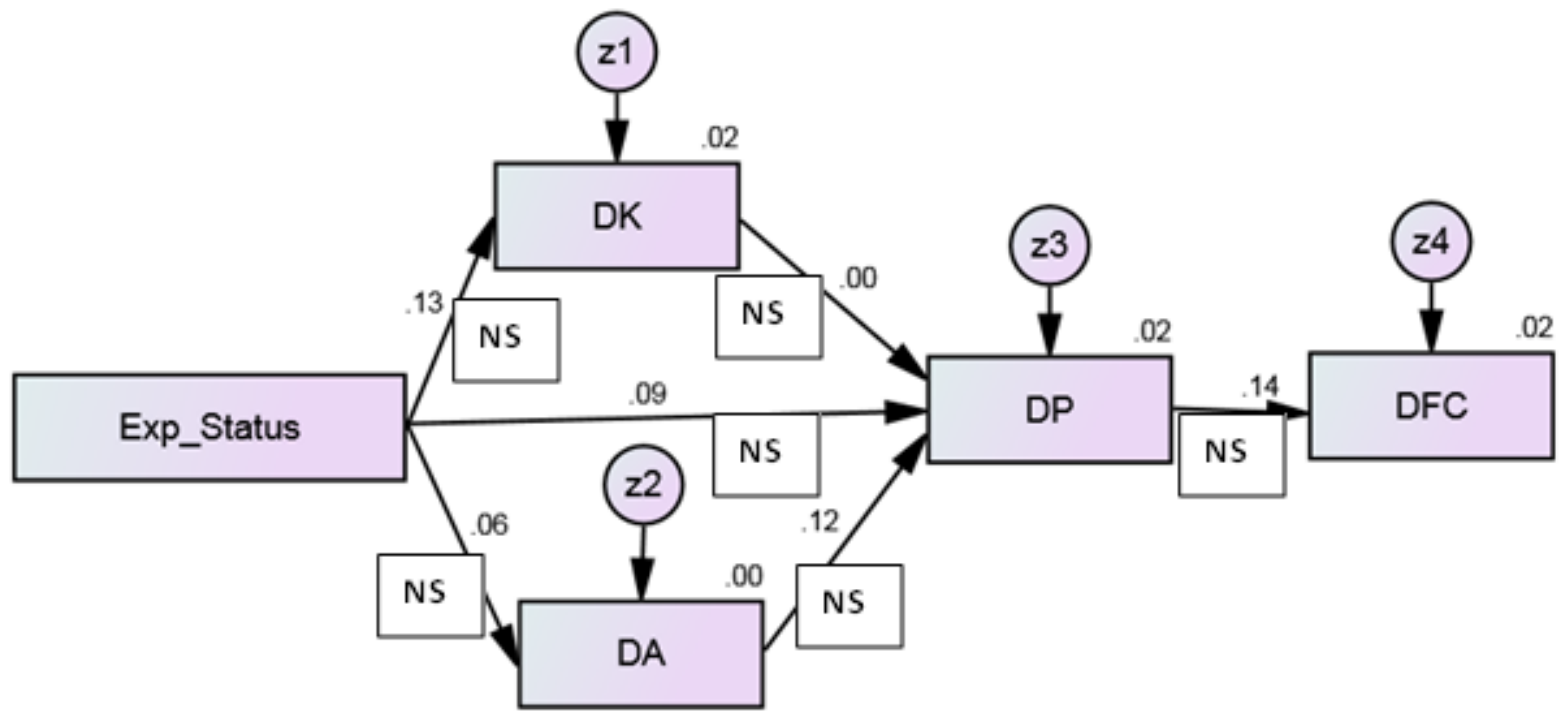

NS $=$ Not statistically significant at 0.05 or lower level

*Statistically significant at 0.05 or lower level

Goodness of Fit Statistics: Chi Square $=4.128$ with $\mathrm{DF}=4, \mathrm{P}=0.389, \mathrm{TLI}=1.281, \mathrm{RMSEA}=0.015, \mathrm{R}^{2}=0.02$.

Comments on Model Fit: Non significant Chi square value and Chi Square/DF=1.032, $\mathrm{p}=0.389$, suggests that the model fit reasonably well; RMSEA less than 0.05 indicates an excellent fit.

Figure 10. The Net Effect of Experimental Status and Differences in Knowledge (DK), Attitude (DA), and Practice (DP) on Difference in Functional Capacity (DFC)

Table 15. The Net Effect of Experimental Status and Differences in Knowledge (DK), Attitude (DA), and Practice (DP) on Difference in Functional Capacity (DFC)

\begin{tabular}{|l|l|l|l|l|}
\hline Indicator/Item & $\begin{array}{l}\text { Standardized } \\
\text { Parameter or } \\
\text { Factor Loading }\end{array}$ & $\begin{array}{l}\text { Unstandardized } \\
\text { Factor Loading }\end{array}$ & $\begin{array}{l}\text { Standard } \\
\text { Error(S.E) }\end{array}$ & $\begin{array}{l}\text { P Value/ } \\
\text { Significance }\end{array}$ \\
\hline DK <--- Exp_Status & .131 & 1.045 & .674 & .121 \\
\hline DA <--- Exp_Status & .058 & .435 & .641 & .497 \\
\hline DP <--- DK & .001 & .004 & .306 & .990 \\
\hline DP <--- DA & .121 & .459 & .319 & .151 \\
\hline DP <--- Exp_Status & .089 & 2.568 & 2.439 & .292 \\
\hline DFC <--- DP & .145 & .048 & .028 & .086 \\
\hline
\end{tabular}

*Statistically significant at 0.05 or lower level. 
In summary, the difference-in-differences analyses of experimental effect and differences in knowledge (DK), attitude (DA) and practice (DP) on differences in outcomes shows that difference in practice affects only the difference in glycated hemoglobin (DA1C), but not differences in any of the other outcomes: low-density lipoprotein cholesterol, functional capacity, or poor perceived health. Self-care or lack thereof affects A1C, which is the most important indicator of the control of diabetes. The data from this experiment do not support a causal path of experimental status, knowledge, attitude, practice and outcomes. 


\section{CHAPTER FIVE: SUMMARY, IMPLICATIONS AND CONCLUSIONS}

\section{Introduction}

Although a majority of diabetes self-management programs have been shown to improve knowledge, attitude, practice, and health care outcomes, the underlying causal mechanisms for improvement attributable to health education have not been systematically explored. The literature has not adequately addressed how diabetes educational intervention may affect diabetes care outcomes. The purpose of the present study was to identify the causal mechanisms responsible for improved knowledge, attitude, practice and outcomes so that educational interventions can be tailored efficiently and effectively to the groups of patients who are most likely to benefit from self-care management. The study used the knowledge, attitude, practice and outcome (KAP-O) framework. More specifically, the purpose of the study was to examine the causes of variation in the outcomes of glycated hemoglobin (A1C), low-density lipoprotein cholesterol (LDLC), functional capacity (FC), and poor perceived health (PPH).

An experimental study with a randomized control trial design involving 141 participants was conducted. The experimental group $(\mathrm{N}=87)$ and control group $(\mathrm{N}=52)$ were comparable in terms of demographics and major diagnoses. The health educational intervention was a predictor variable of the endogenous variables knowledge, attitude, practice and outcomes. The study variables were measured pre-and post- intervention, using reliable and valid instruments. The study employed a newly developed instrument to assess the three components of attitude: cognition, affect, and behavioral tendency. Multiple analytic strategies were applied to the analysis of the experimental data.

The study sought answers to the following research questions: 1) Does health education directly affect knowledge, attitude, practice of self-care, and health care outcomes? 2) Based on 
the KAP model, what is the effect of health education on knowledge, attitude, and practice? 3 ) Based on the theoretical specification of the KAP-O model, does health education affect health care outcomes indirectly through improved changes in knowledge, attitude and self-care practice?

\section{Statistical Procedures}

\section{The Intention-to-Treat Analysis: Independent Sample T-Tests}

First, the experimental effect of health educational intervention was analyzed using independent sample t-tests for each of the seven variables: knowledge $(\mathrm{K})$, attitude (A), practice (P), and four outcome variables \{ glycated hemoglobin (A1C), low-density lipoprotein cholesterol (LDLC), functional capacity (FC), and poor perceived health (PPH) $\}$. The analysis was performed separately for Time-1 (T1) and Time-2 (T2) without controlling for the effects of other predictors.

\section{The Intention-to-Treat Analysis with Statistical Control of the Prior Score}

Second, the intention-to-treat analysis was performed by regression analysis to determine the net experimental effect at $\mathrm{T} 2$ of health educational intervention on each of the seven study variables knowledge $(\mathrm{K})$, attitude $(\mathrm{A})$, practice $(\mathrm{P})$, and the four outcomes, holding the respective prior measures of the variables constant.

\section{Causal Modeling of KAP Relationships in \{(Exp_Status)-(K-T2)-(A-T2)-(P-T2)\} Model}

This model of $\{($ Exp_Status)-(K-T2)-(A-T2)-(P-T2) $\}$ was analyzed in SEM to determine the KAP relationships of experimental status, knowledge, attitude, and practice and the relationship of knowledge and attitude to preventive practice. 


\section{Difference-in-Differences Analysis}

The difference in differences analysis of the model $\{$ (Exp_Status)-(DK)-(DA)-(DP) $\}$ with each difference in the outcome variables: glycated hemoglobin (DA1C), low-density lipoprotein cholesterol (DLDLC), functional capacity (DFC), and poor perceived health (DPPH) was analyzed in SEM. This model enables examination of the direct or indirect effects of health educational intervention on the change in each outcome variable which were analyzed separately since the four outcomes did not constitute a single latent construct.

\section{Summary of Major Findings}

\section{Finding Related to Justification for Treating Outcome Variables as Separate Constructs}

Pearson correlation analysis of four outcome variables: glycated hemoglobin (A1C), lowdensity lipoprotein cholesterol (LDLC), poor perceived health (PPH), and functional capacity at T1 was performed. The inter-correlations among the outcome variables are relatively weak, with the exception of the following pairs of variables: (LDLC-T1 and A1C-T1) and (FC-T1 and PPH-T1), which have moderate correlations. Thus, these four outcome variables do not constitute a common factor or construct that enables the development of a single common factor measurement model for the outcome evaluation. Therefore, independent analysis of the experimental effect on each outcome variable was performed in SEM.

There have been no comprehensive instruments to measure the three components of patients' attitudes: cognition, affect, and behavioral tendency. Therefore, this study created an instrument that could be used to assess a patient's attitude and provide appropriate counseling to improve each of the three components of attitude. 


\section{Findings of the Intention-to-Treat Analysis: Independent Sample T-Tests}

Findings of the analysis through T-tests of the experimental effect of health educational intervention on knowledge, attitude, practice (KAP), and outcome variables \{ glycated hemoglobin (A1C), low-density 1ipoprotein cholesterol (LDLC), functional capacity(FC), and poor perceived health (PPH) \} without controlling for the effect of other predictors are as follows.

At T2, the mean knowledge score of the experimental group improved; there was a statistically significant difference between the mean knowledge scores for the experimental group $(M=31.44, S D=5.30)$ and those for the control group $(M=29.56, S D=5.18) ;(p<$ $0.05)$.

Hypothesis H1: Health educational intervention directly improves knowledge about diabetes is supported.

Health education had no statistically significant direct effect on attitude, preventive practice, and the outcome variables.

\section{Findings of the Intention-to-Treat Analysis on KAP Components and Outcome Variables with Statistical Control of the Prior Score}

Experimental status did not have statistically significant effect on knowledge, attitude, or practice at T2 with their prior levels controlled. The analysis showed that the experimental variable did not contribute much to the variation at T2 in knowledge, attitude, or practice scores; i.e. health educational intervention had little direct causal influence on any of the variables: knowledge $(\mathrm{K})$, attitude $(\mathrm{A})$, and practice $(\mathrm{P})$.

The results of the analyses examining the net effect of experimental status on each of the four outcome variables are as follows: The effect of experimental status on A1C at T2 (A1C-T2) 
was statistically significant. There was a direct causal effect of experimental status on glycated hemoglobin (A1C).

$\mathrm{H} 4_{1}$ : Health educational intervention directly lowers glycated hemoglobin (A1C) is supported.

The net effect of experimental status on each of the outcomes: low-density lipoprotein cholesterol, functional capacity, and poor perceived health at T2, holding their respective prior levels constant, was not statistically significant and is illustrated in figures 13,14 and 15 in appendix K. This analysis examining the net effect of the experimental variable on each of the four outcome variables when holding the prior levels constant demonstrated that there was no direct effect of experimental status on outcome variables, with the sole exception of the direct effect on glycated hemoglobin (A1C). Thus an indirect causal effect of health education mediated via the change variables of DK, DA, and DP on outcome variables was assumed in the difference-in-differences analysis.

The prior levels of all outcome variables at T1 are strongly associated with their respective levels at $\mathrm{T} 2$, with $\beta$ coefficients of 0.752 for $\mathrm{A} 1 \mathrm{C}, 0.815$ for $\mathrm{FC}, 0.558$ for $\mathrm{LDL}$, and 0.557 for poor perceived health.

\section{Findings of the Causal Modeling of KAP Relationships in \{(Exp_Status)-(K-T2)-(A-T2)-(P- T2)\} Model}

This was not a full examination of the causal model, since the prior levels were not statistically controlled. The finding showed a concomitant effect of experimental status, knowledge and attitude on practice. Experimental status had no direct effect on the practice of preventive self-care, controlling for knowledge and attitude, at T2. However, the experimental status had an indirect effect on practice through knowledge. Knowledge at T2 had a statistically 
significant effect on practice of self-care, with $\beta=-0.204$. The effect of experimental status on attitude at T2 was not statistically significant. The effect of attitude at T2 (A-T2) on practice at T2 (P-T2) was statistically significant, with $\beta=0.449$. The effect of attitude (A-T2) was greater than the effect of knowledge on preventive practice of self-care.

\section{Findings of the Difference-in-Differences Analysis}

The causal model of experimental status, differences in knowledge (DK), attitude (DA), and practice (DP) and differences in outcomes over time (T2-T1) has a reasonable fit to the data as illustrated by GOF statistics. This model enabled examination of the direct or indirect effects of health educational intervention on the change in each outcome variable-analyzed separately since the four outcomes in this study did not constitute a single latent construct. The effects of experimental status on the scores for differences in knowledge (DK), attitude (DA), and practice (DP) and scores for differences in each outcome (DA1C), (DLDLC), (DFC) and (DPPH) were analyzed separately between the two time points, T1 and T2. The difference in practice scores (DP) directly affected only the difference in glycated hemoglobin (DA1C); the difference in practice scores (DP) did not affect any of the differences in scores for the other outcomes: (DLDLC), (DFC) and (DPPH). The data from this experiment do not support a strong causal path of experimental effects on outcomes via knowledge, attitude, and practice of self-care. The lack of variability in the patients in the practice with a single provider may have prevented an adequate demonstration of the viability of the proposed causal model.

\section{Literature Supporting Finding One}

Finding 1: Several studies support the concept that health education improves knowledge (Adepu et al., 2007; Baradaran et al., 2006; Garrett et al., 2005; Hogue et al., 2003; Holmes et 
al., 2012; Malathy et al., 2011; Norris et al., 2001; Vimalavathini et al., 2008). These studies are described below.

Norris et al. (2001) reviewed 72 studies focusing on effectiveness of self-management education for a period of six months or less. The findings of the studies were that selfmanagement education improves knowledge.

A study of a community pharmacy-based program of diabetes education based on the American Diabetes Association Standards with 381 participants by Hogue et al. (2003) found improvement in diabetes knowledge scores.

Evaluation of an educational program on the knowledge, attitude and practices (KAP) of a single-group, prospective pre- and post- intervention in 67 Type 1 diabetic patients who were receiving free monthly supplies of human insulin at an outpatient clinic of a tertiary care hospital was undertaken by Vimalavathini et al. (2008). This was a prospective interventional study using a convenience sample. Diabetes knowledge improved after the intervention.

Holmes et al. (2012) conducted a single-group prospective pre- and post- intervention study using a postal questionnaire with ninety-seven diabetic women, aged 18-40 years (Type 1, $\mathrm{n}=89 ;$ Type $2, \mathrm{n}=8$ ), in Ireland. At post-intervention, knowledge about pregnancy planning increased significantly, as did knowledge of pregnancy-related risks after viewing the DVD.

Malathy et al. (2011) evaluated a custom-designed counseling program for the effect of counseling on knowledge in the counseled group $(n=137)$ vs. a control group $(n=70)$, in a randomized sample of Type 2 diabetes patients in South India. While the knowledge scores of the test group patients improved significantly $(P<0.0001)$, there was no statistically significant change in the knowledge scores of the control group. 
A multi-site, prospective study of South Asians in Scotland randomly selected by Baradaran et al. (2006) evaluated a custom-tailored educational intervention by doing a group comparison of change in diabetes knowledge between the test, and the ethnic control and white control groups. Only 101 patients completed the study. The test group had low KAP at baseline. There was a significant improvement in scores for knowledge in the intervention group at postintervention.

Evaluation of the effectiveness of a small-group diabetes educational intervention was undertaken by Garrett et al. (2005) using random assignment of volunteers into an intervention group $(\mathrm{n}=382)$ that participated in the small-group learning activity and a control group $(\mathrm{n}=$ 382) that received a diabetes self-care book. There was a significant change in knowledge in the intervention group as compared to the control group after adjusting for demographic differences between the groups.

Adepu et al. (2007) evaluated the effect of pharmacist-provided patient counseling on patients' perception about diabetes management and quality of life in Type 2 diabetes patients from two community pharmacies. This was a randomized, prospective controlled study of Type 2 diabetes patients in Calicut, Kerala, India. A total of 60 Type 2 diabetes patients were randomized into test $(n=32)$ and control $(n=28)$ groups. Knowledge score in the test group markedly improved.

\section{Literature Not Supporting Finding Two}

Finding 2: Health educational intervention had little causal influence on any of the KAP components: knowledge $(\mathrm{K})$ attitude $(\mathrm{A})$ and practice $(\mathrm{P})$. No studies have examined the causal influence of health education on knowledge, attitude, and practice. However, a few studies using 
a test-control, random assignment, pre-post design have noted increases in knowledge, attitude and practice scores. Such studies used relatively short instruments to assess knowledge, attitude and practice. The questionnaires had few items testing attitude.

Malathy et al. (2011) evaluated a custom-designed counseling program and assessed effects of counseling on knowledge and practice in a randomized sample of 207 Type 2 diabetes patients in South India with an intervention group $(n=137)$ and a control group $(n=70)$. The knowledge scores and attitude scores in the post-intervention assessment of the test-group patients improved significantly $(\mathrm{p}<0.0001)$. The practice scores showed no improvement $(\mathrm{p}<0.06)$, since the baseline practice scores were relatively high. No significant changes in the control group's KAP scores were observed.

A multi-site prospective study of randomly selected Asians in Scotland by Baradaran et al. (2006) evaluated a custom-tailored educational intervention for South Asians by comparing the changes in knowledge between the test group, and the ethnic control and white control groups. Only 101 patients completed the study. The test group had low KAP scores at baseline. There were significant improvements in scores for knowledge $(+12.5 \%)$, serious attitudes toward diabetes $(+13.5 \%)$, and practice $(+20.0 \%)$ in the intervention group. Differences in KAP improvements between the members of the two control groups (white \& ethnic) were not significant.

Evaluation of the effectiveness of a small-group diabetes educational intervention was undertaken by Garrett et al. (2005). Random assignment of volunteers into an intervention group $(n=382)$ and a control group $(n=382)$ was made to investigate the effect of a learning activity with a diabetes self-care book. Adjusting for demographic differences between the groups, there were significant changes in knowledge, feeling of control and behavior related to self- 
management of diabetes in the intervention group as compared to the control group. Although the study was based on a randomly selected sample, the volunteers had higher motivation than would general population members, which may introduce a selection bias. Hence the study findings were limited in their generalizability.

Adepu et al. (2007) evaluated the effect of pharmacist-provided patient counseling on patients' perception about disease management and quality of life in Type 2 diabetes patients from two community pharmacies, in a randomized, prospective controlled study of Type 2 diabetes patients in India. A total of 60 Type 2 diabetes patients were randomized into the test group $(n=32)$ and the control group $(n=28)$. Knowledge, attitude and practices scores markedly improved $(\mathrm{P}<0.05)$ in the test group patients.

\section{Studies Reporting Improvement in A1C Post-Self-Management Education}

Finding 3: There is a direct causal effect of experimental status on glycated hemoglobin (A1C), an indicator of the control of diabetes. No studies have studied the causal influence of health education on outcomes such as glycated hemoglobin (A1C).

\section{Studies Supporting the Indirect Effect of Experimental Status on Preventive Practice via Knowledge and Attitude}

Finding 4: Experimental status had an indirect effect on preventive practice via knowledge (K-T2). The effect of attitude at T2 (A-T2) on practice at T2 (P-T2) was statistically significant, with $\beta=0.449$.The effect of attitude (A-T2) was greater than the effect of knowledge. No studies reviewed here have studied the indirect causal effect of experimental status on preventive practice via attitude and knowledge. 


\section{Studies Supporting the Causal Effect of Preventive Practice on Glycated Hemoglobin (A1C)}

Finding 5: Change in practice statistically significantly affects change in the outcome of glycated hemoglobin (A1C). The greater the preventive practice, the more lowering of glycated hemoglobin (A1C), indicating better control of diabetes. No studies reviewed here have studied the causal influence of preventive practice on the outcome of glycated hemoglobin (A1C).

\section{Other Findings}

Finding 6: The effect of attitude is twice as influential as the effect of knowledge on preventive practice. Patients with better attitude engage in more preventive behavior, so the focus of health education should be to increase positive attitude. No previous studies have focused on whether knowledge or attitude is a more dominant factor influencing preventive care.

\section{Literature Related to Finding 7}

Finding 7: Experimental status improves knowledge, and knowledge has a negative effect on preventive practice. This finding suggests that more knowledge about diabetes may not improve preventive practice. It is possible that patients rely more on medications than on preventive practice to control diabetes.

Several of the KAP studies summarized earlier showed that high knowledge and attitude scores are not necessarily associated with preventive practice. Such studies are described below.

A cross-sectional descriptive community study by Nafissi et al. (2012) in Iran of 650 females aged more than 18 years with no breast complaints found that $30.8 \%$ of respondents knew the importance of breast self-exam (BSE). Although 59.9\% of these participants were able to do BSE, only $12.9 \%$ of them practiced BSE regularly. 
Kharkar and Bowalekar (2012), studying a random sample of 870 medical practitioners from north, south-east and west regions of India, reported that a total of 59.2\% recognized the importance of reporting adverse drug reactions (ADR) to government centers. They were familiar with the procedure of reporting ADR. However, only $18.5 \%$ of physicians reported the observed ADR to government ADR centers.

Van Geertruyden et al. (2005), in a cross-sectional malaria survey of 1432 pregnant women attending six health centers in Rwanda, found that most knew that malaria might have serious consequences for their pregnancy and that insecticide-treated bed nets are useful for malaria prevention. However, only $8.3 \%$ slept under such a net because the vast majority could not afford the price.

Romanian patients with smear-positive TB are treated in hospital for 2 months until they are smear negative and then released. These patients must continue with medication for another four months to avoid the spread of TB. Berger and Bratu (2006) surveyed 151 Romanian TB patients. Although a high number acknowledged that it was necessary to continue treatment after discharge from the hospital, adherence to the medication regimen was not high, because the doctors' fees and medications were unaffordable.

Lin et al. (2011), in a telephone survey of 5,300 Chinese citizens, found that although $50 \%$ knew prevention and control strategies for pandemic influenza, and $72 \%$ knew that A/H1N1 vaccination was available free of charge, nevertheless the immunization rate for the flu was only $7.5 \%$.

Maina et al. (2011) conducted a cross-sectional study of 1982 general population respondents randomly selected from provinces in Kenya with high prevalence of diabetes and 
found that only $27 \%$ of the respondents had good knowledge of diabetes. However, practices to manage diabetes in $49 \%$ of these respondents were poor.

Abubakari et al. (2011), in a cross-sectional study of 359 diabetes patients in London, found that perceiving diabetes to have severe consequences was associated with poor selfmanagement in both African-origin (black-African and black-Caribbean) and European-origin (white-British) patients with Type 2 diabetes.

\section{The Contribution of the Study}

\section{Theoretical Implications}

The study makes a novel use of the KAP (Knowledge, Attitude, and Practice) and adds another construct outcome to form the KAP-O framework. This framework has been noted in a paper by Wan (2014) in the International Journal of Public Policy. The data of this study did not support a strong causal path of experimental effects on outcomes via knowledge, attitude, and practice of self-care. However, other evaluation studies of diabetes education using test- control ,random assignment and pre-post education showed improvement in knowledge, attitude, and practice scores (Baradaran et al., 2006; Garrett et al., 2005; and Adepu at et., 2007). The study by Adepu et al.in addition showed improvement in healthcare outcomes of quality of life scores and capillary blood glucose level. A study using test-control random assignment and pre- postdesign by Malathy et al. (2011) showed improvement in knowledge, attitude, and post prandial

glucose level. A prospective pre-post evaluation study of an educational program for a single group of 67 Type 1 diabetes patients by Vimalavathini et al. (2008) resulted in improved knowledge, improved attitude, and improvement in some aspects of practice. 
These studies did not investigate causal relationships among the components of knowledge, attitude, practice, and healthcare outcomes and the sample sizes ranged from 60 to 764 patients.

Lack of support for the KAP-O model in this study could be attributed to lack of variability in the sample due to relatively homogenous patient population selected from a single medical practice with a single provider. The participants in both the control and the experimental groups had relatively high knowledge scores at baseline with duration of diabetes of 8-10 years and had picked up knowledge from interaction with healthcare providers.

The viability of the KAP-O framework needs to be determined using a larger representative national sample of 100,000 from multiple centers with multiple providers and a diverse population of Type 2 patients. Also the trajectory of change in each outcome variable could more easily be delineated by extending the length of the experimental study to 1-2 years with four or more outcome assessments. Also, knowledge, attitude, and preventive practice need to be assessed at pre-intervention. The knowledge gaps thus identified need to be addressed continuously and simultaneously with enhancement of attitude rather than a one shot deal administration of education right after pre-assessment of knowledge, attitude, and practice.

This study evaluates the outcomes measurement model and causal relationships among the components of KAP-O (knowledge, attitude, practice, and outcome) in a behavioral system model. 


\section{Methodological Implications}

Multiple analytical strategies were employed in the analysis of data generated from a randomized clinical trial to yield solid evidence regarding the assumed relationships among the KAP-O components under the influence of the educational intervention.

The study confirms the utility of structural equation modeling (SEM) as a valuable statistical technique to study such complex relationships as those between changes in knowledge, attitude and practice, and health care outcomes. Most previous studies evaluate educational programs and measure changes in outcomes. No previous studies sought to determine the causal mechanism of how health education results in improved outcomes.

\section{Practical Implications}

Non-availability of technical staff to help patients with limited technical literacy access the tutorials may have discouraged patients from using the web-based program and led them to read the printed text instead (The print content was identical to the web-based context). In this study, technology was not fully utilized.

However in a tech-savvy population, the study findings can change the service delivery modality of diabetes education, in that Diabetes Tutor is noted as a web-based, self-management and educational tool that can broaden access to education.

This study is unique as the first study evaluating the innovative Diabetes Tutor in clinical practice and as a tool to influence patient health outcomes. There is a need to expand the study in multiple practices with a diverse population. The dose-response relationship between health education and outcomes is still unknown. 


\section{Policy and Practical Implications}

From a policy-relevant perspective, the study findings can have a useful influence on the funding allocation for diabetes education. Identifying the interventions that are more effective can help allocate resources wisely. Thus far, causal analysis of the effects of diabetes education has been limited. This study advances the causal analysis of one type of diabetes education, pointing out where education is most effective and where it is not.

Most diabetes education focuses on improving knowledge, whereas this study showed that attitude is a more dominant factor than knowledge in influencing preventive practice. Therefore, it would be necessary to assess the three components of the attitude of a patient with the purpose of encouraging development of positive attitude; or suggesting behavior changes to patients that may compensate for poor attitude. Health education for diabetes control should also include at regular intervals interaction between diabetes educator and patient to yield strategies for attitudinal change. This implication can inform policy.

The gaps in diabetes patients' knowledge about their disease should be assessed and addressed through booster doses of education, since the effects of education at a single point decrease with time. The effects of education can be reinforced by booster sessions to sustain knowledge. Since Healthy Tutor can be accessed on desktop, tablet, and mobile computer

interfaces, its tutorials can easily be repeated. Further, Healthy Tutor can inform the provider of knowledge deficits that persist after completion of each tutorial. This function which enables focused counseling was not activated for the study.

Providing information about diabetes to a patient at initial diagnosis is not as efficacious as actively engaging the patient in self-care through continuous interaction with a diabetes educator, or a very interactive diabetes informational website that also records and tracks patient 
outcomes. Norris et al. (2002) found that every additional 23.6 hours of education by a patient's interaction with a diabetes educator resulted in a $1 \%$ decrease in glycated hemoglobin (A1C), which is a marker of diabetes control.

\section{Patient Comments about Healthy Tutor}

Most of the patients had long-standing diabetes, so they were not uninformed. A majority of the patients liked Healthy Tutor, as it refreshed their knowledge. They thought it would be a great tool to enhance knowledge of diabetes self-care management in newly diagnosed diabetic patients. Many patients said they picked up new knowledge. Some patients said they had started exercising and eating healthy as a result of watching the tutorials but had to take a break due to either personal health issues or other family obligations. A few of the patients said that the tutorials could be shorter.

\section{Limitations of the Study}

This study was conducted in a single medical practice with a single provider and using a sample drawn from a homogeneous population, so it is not widely generalizable. There was some drop-out due to patients switching to a different practice.

Another limitation of the study was that the instructional materials were tailored for a sixth grade level reader. One type of educational intervention may not suit all groups. When appropriate, the content of health education should be tailored to people of limited education by doing a KAP assessment to identify the deficits in knowledge. Information to remedy particular deficits should be presented, and also reinforced by repetition. Illiterate patients need to view videos and require hands on demonstration. 
In addition, the subjects did not receive face-to-face counseling focusing on the individual subject's knowledge deficits. Future studies are needed to test Healthy Tutor's individualized knowledge deficit assessments and reports. These components are designed for patient-centered primary care practices.

An important finding in the KAP-O model was that the education intervention did not influence knowledge much. The participants of the study were not newly diagnosed diabetics; their onset had generally occurred 8 to 10 years prior to the study. Hence, the subjects may have already learned about diabetes through group classes, pamphlets, pharmacy encounters, and conversations with their providers. Both experimental and control groups began with high knowledge scores. There was no bias, since the subjects were randomly assigned to their respective groups.

The length of the experimental study could be extended beyond one year with multiple education sessions and multiple outcome assessments to elicit the trajectory of change of each outcome variable.

\section{Lessons Learned - Implications for Future Research}

The data from this experiment do not support a causal model of experimental status and predictor change variables DK, DA, DP causing changes in outcome variables DA1C, DLDLC, DPPH, DFC (KAP-O).

The study was conducted in a single practice with a single provider in a single region. The provider consistently applied the same treatment protocol for all the diabetic patients. Participants in both test and control groups were homogeneous exhibiting the same attributes. The subjects, whether in the experimental or the control group, were compliant using the 
medication prescribed by the same physician. Consequently, there was not much variation in outcomes in spite of the intervention.

In that context the functionality of the model remains undetermined. The KAP-O model could work in other, diverse patient populations. Future studies should use the KAP-O model in research based on multi-centers with multiple providers treating a diverse population of Type 2 diabetes patients.

The duration of such studies should be of one to two years with four or more outcome assessments during the course of the study, in order to elicit the trajectory of changes, since the effects cannot be detected in a study of six months duration.

Most health education providers assume that diabetes education should work once given, just as medication does, which is a mistake. The results of education should be monitored and education should be improved to prevent wastage of resources.

Maez et al. (2014) did a review of fifteen articles concerning patient diabetic education in rural areas and concluded that consistency and follow-up after education is essential for improved diabetic patient outcomes. Illiterate patients need to view videos and require hands on demonstration. They also suggested that education should be culturally sensitive. A KAP assessment in ethnic populations will inform practitioners about patients' diets, some of which may have adverse effects on health. For example, ethnic groups who are used to a diet consisting predominately of high-fat food cooked with butter or lard would find it hard to reduce consumption of high-fat food; it may be possible to compensate for such eating habits by increasing physical activity.

A good feature of Healthy Tutor used in the study was that each module started with a pre-test, followed by education and then post-test. The use of the pre-test may have prompted a 
more focused learning experience. The post-test may have reinforced the knowledge covered in the tutorial. The Healthy Tutor tutorials could be more useful if reports of post-tutorial knowledge gaps were downloaded into the patient's electronic medical records. This function of Healthy Tutor which was intentionally deactivated in the study would help the provider followup and counsel patients regarding specific deficits in knowledge.

A booster educational session at regular intervals after face-to-face interaction with a diabetes educator to address knowledge gaps would help patients' retain the knowledge. An important step would be to monitor patients' preventive practices. Improvement in attitude could also be fostered by focused interactions with an educator who could suggest a change in practice that a patient could incorporate to compensate for poor attitude. For example, a patient may find walking as an exercise, boring. The educator could suggest that the patient watch his favorite television show while walking on the treadmill. In summary, money could be allocated toward promoting attitudinal change, self-care, and on increasing knowledge. 


\section{APPENDIX A: PERMISSION FROM SITE}




\section{MedicAl SPECIALISTS}

Date:

\section{UCF IRB}

RE: Support of research for Karen Rav-Marathe

To Whom It May Concern:

This letter will serve to support the research which will take place in my St Augustine and Palm coast office. I am strongly interested in this research and keen to learn the determinants of optimal health status of my patients with diabetes. I would like my patients to have a good quality of life and delay complications such as heart attack, stroke, kidney disease, eye and nerve disease. I wholeheartedly support Mrs. Karen Rav-Marathe's research proposal and will serve as the host for this study.

Sincerely,

Shriram Marathe MD, PhD 


\section{APPENDIX B: UCF IRB APPROVAL OF HUMAN RESEARCH}


University of Central Florida Institutional Review Board

Centrivity of

Office of Research \& Commercialization

12201 Research Parkway, Suite 501

Orlando, Florida 32826-3246

Telephone: 407-823-2901 or 407-882-2276

www.research.ucf.edu/compliance/irb.htm]

\section{Approval of Human Research}

\section{From: $\quad$ UCF Institutional Review Board \#1 \\ FWA00000351, IRB00001138}

To:

Karen Rav-Marathe

Date:

May 29, 2013

Dear Researcher:

On 5/29/2013, the IRB approved the following human participant research until 5/28/2014 inclusive:

Type of Review: IRB Continuing Review Application Form

Project Title: The Effect of Web-Based Education Sessions on Clinical

Outcomes of Patients with Type II Diabetes in a Medical Practice

Group

Investigator: Karen Rav-Marathe

IRB Number: SBE-11-07722

Funding Agency:

Grant Title:

Research ID: NiA

The scientific merit of the research was considered during the IRB review. The Continuing Review Application must be submitted 30 days prior to the expiration date for studies that were previously expedited, and 60 days prior to the expiration date for research that was previously reviewed at a convened meeting. Do not make changes to the study (i.e., protocol, methodology, consent form, personnel, site. ete.) before obtaining IRB approval. A Modification Form eannot be used to extend the approval period of a study. All forms may be completed and submitted online at bittps:iris, research.ucfechu .

If continuing review approval is not granted before the expiration date of 5/28/2014, approval of this research expires on that date. When you have completed your research, please submit a Study Closure request in iRIS so that IRB records will be accurate.

In the conduct of this research, you are responsible to follow the requirements of the Investigator Manual.

On behalf of Sophia Dziegielewski, Ph.D., L.C.S.W., UCF IRB Chair, this letter is signed by:

Signature applied by Joenne Muratori on 05/29/2013 11:19:33 AM EDT

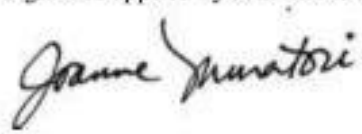

IRB Coordinator

Page 1 of 1 


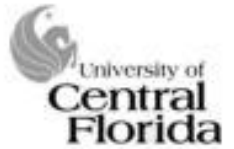

University of Central Florida Institutional Review Board
Office of Research \& Commercialization
12201 Research Parkway, Suite 501
Orlando, Florida $32826-3246$
Telephone: $407-823-2901$ or $407-882-2276$
www.research.ucf.edu/compliance/irb.htm]

\title{
Approval of Human Research
}

\author{
From: \\ To: Karen Rav-Marathe \\ Date; $\quad$ August 04, 2011 \\ Dear Researcher:
}

UCF Institutional Review Board \#1

FWA00000351, IRB00001138

On 8/4/2011, the IRB approved the following human participant research until 8/3/2012 inclusive:

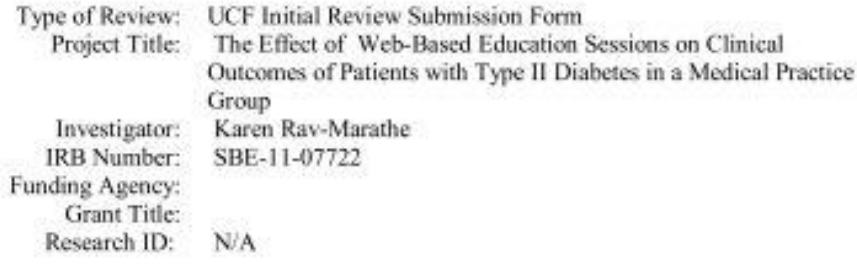

The Continuing Review Application must be submitted 30days prior to the expiration date for studies that were previously expedited, and 60 days prior to the expiration date for research that was previously reviewed at a convened meeting. Do not make changes to the study (i.c., protocol, methodology, consent form, personnel, site, etc.) before obtaining IRB approval. A Modification Form cannot be used to extend the approval period of a study. All forms may be completed and submitted online at hitps:/iris research ucfedu.

If continuing review approval is not granted before the expiration date of $8 / 3 / 2012$, approval of this research expires on that date. When you have completed your research, please submit a Study Closure request in iRIS so that IRB reoords will be accurate.

Use of the approved, stamped consent document(s) is required. The new form supersedes all previous versions, which are now invalid for further use. Only approved investigators (or other approved key study personnel) may solicit consent for research participation. Participants or their representatives must receive a copy of the consent form(s).

In the conduct of this research, you are responsible to follow the requirements of the Investigator Manual.

On behalf of Kendra Dimond Campbell, MA, JD, UCF IRB Interim Chair, this letter is signed by:

Signature applied by Joanne Muratori on 08/04/2011 11:48:25 AM EDT

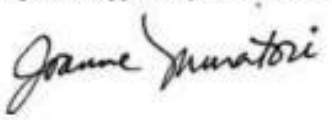

IRB Coordinator

Page 1 of 1 


\section{APPENDIX C: LETTER TO PARTICIPANTS}


MEDICAL SPECIALISTS

Date:

Dear Patient,

I wish to invite you to participate in a research study conducted by Mrs. Karen Rav-Marathe from University of Central Florida comparing two ways to educate patients about diabetes. This study may help you better understand diabetes, care for yourself, and prevent complications such as stroke, heart attack, kidney disease, and nerve damage.

If you voluntarily choose to participate in the study, you will be invited to complete several questionnaires at the beginning of the study, after 3 months, and at the end of the study 6 months later. Each set of questionnaires will require about 40 minutes of your time. The study will be conducted at your Medical Specialists doctor's office. Whether you choose to participate or not, you will continue to receive routine medical care throughout the study and thereafter. You will also be free to withdraw from the study at any time.

The information collected during the study will help your doctor understand how to best guide you in the management of your diabetes. Your answers on the questionnaires and your related clinical data will remain confidential. No information that can be linked to you will be releasod.

If you wish to participate in the study, please come by the Medical Specialists office, sign the informed consent form, and arrange to begin the study. Feel free to ask questions at any time. I welcome your participation because it is you who will benefit from this study. If you have questions, please direct them to me or Mrs. Karen Rav-Marathe at karenravmarathe@gmail.com or $904-347-5536$.

Sincerely yours,

Shrirarnofathe, MD, PhD 
APPENDIX D: INFORMED CONSENT 


\section{University of \\ Central Florida}

The Effect of Web-Based Education Sessions on Clinical Outcomes of Patients with Type 2 Diabetes in a Medical Practice Group.

\section{Informed Consent}

Principal Investigator(s): $\quad$ Karen Rav-Marathe, Ph.D. Candidate

Faculty Supervisor: $\quad$ Dr. Thomas T. H. Wan, Department of Public Affairs, University of Central Florida twan@mail.ucf.edu

Investigational Site(s): $\quad 665$ State Road 207, Suite 102, St Augustine, FL 32084 4869 Palm Coast Parkway NW, Suite 2, Palm Coast, Fl32137

Introduction: You are being invited to participate in a research study that will include about 200300 people who are patients of Medical Specialists. You are being asked to take part in this research study because your health status satisfies some of the inclusion criteria which are noted in the paragraph below entitled inclusion criteria.

\section{Inclusion criteria}

Patients with diagnosis of diabetes mellitus Type 2 as indicated by some of the, ICD9 codes 249.00-250.99. or who have been told by health practitioners that they have high blood sugar and are controlled by Metformin and lifestyle interventions or patient who present to clinic with classic symptoms of hyperglycemia or hyperglycemic crisis and random plasma glucose of $>200$ $\mathrm{mg} / \mathrm{dl}$. All participants will be at least 18 years of age. The surveys utilized in this research project are only available in English and those who do not speak or write English will not be able to participate in the study. Patients must take a reading/literacy test "LAD" that will determine whether they will be able to take part in the study.

Some patients of Medical Specialists are not included in the study because their health status satisfies some of the exclusion criteria as noted below in paragraph entitled exclusion criteria. 


\section{Exclusion criteria:}

Exclusion criteria will be patients with type I diabetes, patients who have completed more than 2 hours of diabetes education within the past 6 months, patients reading below the sixth grade level as determined by health literacy survey instrument and individuals less than eighteen years of age.

Also diabetic patients with complications such as Kidney failure stage IV (i.e. glomerular filtration rate of $30 \%$ or less), $\mathrm{CHF}$, ischemic ulcer, amputations for vascular insufficiency, irreversible comorbid conditions and legal blindness from diabetic retinopathy." will be excluded as the disease process has progressed too far and adherence to self-management behavior will not reverse the disease.

The person doing this research is Mrs. Karen Rav-Marathe of the University of Central Florida, Department of Public Affairs. She is guided by Dr. Thomas T. H. Wan, a UCF faculty supervisor in Public Affairs.

Voluntary Participation: Your decision to participate in this research is voluntary. You can choose to withdraw from the research at any time. If you choose not to participate or choose to withdraw, you will not be penalized or lose any benefits.

Purpose of the research study: The purpose of this study is to find out if Web-based diabetes education sessions help patients gain knowledge of their disease, improve their attitude about diabetes, increase their self-care, and achieve better health.

Several randomized, controlled research trials have demonstrated that patients who complete diabetes education programs have better clinical outcomes than patients receiving no diabetes education. Unlike previous studies, this research study uses Web -based, interactive diabetes education sessions that are convenient, accessible at any time, and capable of being repeated.

What you will be asked to do in the study: Under the guidance of Mrs. Karen Rav-Marathe, you will first be asked to complete a health literacy survey in the office conference room. Based on the results of this test you may or may not be eligible to participate in the study. Next you will be asked to complete a test on diabetes knowledge, an attitude survey, and a self-care survey. You will again complete the surveys after about 3 months. Your lab test results at 0,3 , and 6 months will also be documented. Some of you will be selected to complete a series of Web-based diabetes education sessions on a computer terminal for 5-6 weeks. Patients completing the education sessions will also answer a 10 -question pretest and posttest with each education session.

Location: The research will be carried out at Medical Specialists two office locations in St Augustine and Palm Coast.

Time and effort required: You will be in this research study for about six months. You will require about $30-40$ minutes to complete the surveys. You will be asked to complete the surveys three times in a period of approximately six months. 
If you are selected to complete diabetes education sessions on a computer terminal and do not have access to the Internet in your home, you may have to return to one of the two office locations once a week to complete the sessions. Each session is 20 to 40 minutes long and contains colorful pictures and large, easy to read writing.

Benefits and Risks: The study may increase your awareness of how much you know about diabetes, your attitude about diabetes, and your self-care habits. If you are selected to complete the health education sessions, you may increase your knowledge of diabetes, change your attitude about diabetes, change your self-care habits, and improve your health. This study may benefit society by enhancing the availability of Web-based diabetes education sessions. As a result of participating in this study, you may develop unanswered questions about diabetes. You may need to find answers to such questions from your physician, nurse, diabetes educator, or other trusted source of medical information.

Compensation or payment: There is no payment or reward to you for taking part in this study.

Confidentiality: Your participation in this research is confidential. Your data will be stored at the Medical Specialists offices in locked cabinets or password protected computer files. The University of Central Florida Institutional Review Board and other representatives of UCF may review records related to this research study. If this study results in a publication or presentation, your personally identifiable information will not be shared. Code numbers will be assigned to your completed surveys and laboratory data. Only researchers will have access to your identity.

Questions about the study or to report a problem: If you have questions, concerns, or complaints, talk to Mrs. Karen Rav-Marathe, Graduate Student, College of Health and Public Affairs, at karenravmarathe@gmail.com or Dr.Thomas T.H. Wan, Faculty Supervisor, Department of Public Affairs at twan@mail.ucf.edu.

IRB contact about your rights or to report a complaint: Please contact Privacy Officer Mrs. Sharon Koufas, 665 State Road 207, Suite 102, 9048248158 first to resolve any issues you may have. If you are not completely satisfied, you may contact Institutional Review Board, University of Central Florida, Office of Research \& Commercialization, 12201 Research Parkway, Suite 501, Orlando, FL 32826-3246 or by telephone at (407) 823-2901.

Dismissal from the study: The Principal Investigator may remove you from the research study without your approval. Possible reasons for removal include failure to follow instructions and failure to complete necessary tasks for the study. You will not be penalized or lose any medical benefits if you are dismissed from the study.

Medical Specialists federally compliant HIPPA privacy statement item 3 refers to use of patient health information to evaluate the quality of care received by patients from this practice. The proposed research study will test the efficacy of a lower cost alternative form of patient education which necessitates access to your personal health information therefore we request your consent for release of records for research in addition to your consent to take part in the study. 
You may sign below to indicate that you wish to participate in this research study of your own free will and that you wish to disclose any protected health information related to this study to the investigators for the purpose of completing the study and nothing more.

Name of participant

Signature of participant Date

Signature of person obtaining consent

Date 


\section{APPENDIX E: LITERACY ASSESSMENT OF DIABETES INSTRUMENT}




\begin{tabular}{lll} 
eat & thirst & artery \\
pill & exercise & biosynthetic \\
eye & exchange & abnormal \\
fat & direction & cholesterol \\
milk & hospital & glycogen \\
sugar & calorie & nephropathy \\
lunch & colon & prescription \\
meal & urination & pregnancy \\
kidney & vision & ketones \\
drink & protein & ketoacidosis \\
nurse & vegetable & pancreas \\
fiber & snack & hypoglycemia \\
fruit & cereal & atherosclerosis \\
supper & injection & occupation \\
bread & glucose & triglycerides \\
heart & breakfast & emergency \\
blood & insulin & communication \\
stress & alcohol & hemoglobin \\
meat & medication & endocrinologist \\
doctor & symptom & retinopathy \\
Word List & & \\
\hline & &
\end{tabular}


APPENDIX F: TEST OF FUNCTIONAL CAPACITY (EQ-5D-5L) WITH 5 ADDITIONAL DIMENSIONS PROPOSED BY PERNEGER AND COURVOISIER (2011) 
(English version for the USA)Under each heading, please check the ONE box that best describes your health TODAY

\section{MOBILITY}

I have no problems walking

I have slight problems walking

I have moderate problems walking

I have severe problems walking

I am unable to walk

\section{SELF-CARE}

I have no problems washing or dressing myself

I have slight problems washing or dressing myself

I have moderate problems washing or dressing myself

I have severe problems washing or dressing myself

I am unable to wash or dress myself

USUAL ACTIVITIES (e.g. work, study, housework, family or leisure activities)

I have no problems doing my usual activities

I have slight problems doing my usual activities

I have moderate problems doing my usual activities

I have severe problems doing my usual activities

I am unable to do my usual activities

\section{PAIN / DISCOMFORT}

I have no pain or discomfort

I have slight pain or discomfort

I have moderate pain or discomfort

I have severe pain or discomfort

I have extreme pain or discomfort

\section{ANXIETY / DEPRESSION}

I am not anxious or depressed

I am slightly anxious or depressed

I am moderately anxious or depressed

I am severely anxious or depressed

I am extremely anxious or depressed 
Additional items as used by Perneger and Courvoisier 2011

Under each heading, please check the ONE box that best describes your health TODAY

\section{SLEEP}

I have no problems with sleep

I have moderate difficulties with sleep

I have extreme difficulties with sleep

\section{MEMORY / CONCENTRATION}

I have no problems with memory or concentration

I have moderate difficulties with memory or concentration

I have extreme difficulties with memory or concentration

\section{FATIGUE / ENERGY}

I am full of energy

I am moderately tired or lacking in energy

I am extremely tired or lacking in energy

SEEING AND HEARING (with glasses, contact lenses or hearing aid if you have them)

I see and hear without difficulty

I have moderate seeing and hearing

I have extreme difficulties seeing or hearing

\section{CONTACT WITH OTHERS}

I have very good contacts with my family and friends

I lack contact with my family and friends

I am completely isolated from my family and friends 
APPENDIX G: TEST OF PERCEIVED POOR HEALTH EUROPEAN QUALITY VISUAL ANALOGUE SCALE (EQ-VAS) 
The best health you can imagine

- We would like to know how good or bad your health is TODAY.

- $\quad$ This scale is numbered from 0 to 100 .

- 100 means the best health you can imagine.

0 means the worst health you can imagine.

- Mark an X on the scale to indicate how your health is TODAY.

- Now, please write the number you marked on the scale in the box below.

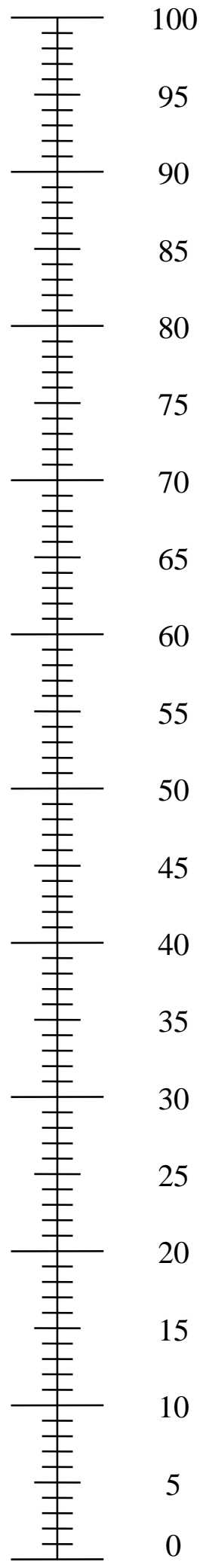

The worst health you can imagine 
APPENDIX H: SUMMARY OF DIABETES SELF-CARE ACTIVITIES INSTRUMENT 
The Summary of Diabetes Self-Care Activities

Instructions: The questions below ask you about your diabetes self-care activities during the past 7 days. If you were sick during the past 7 days, please think back to the last 7 days that you were not sick. Please circle one answer for each statement below.

\section{START HERE}

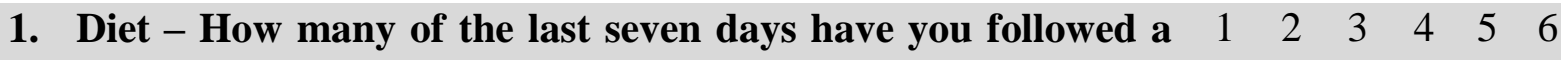
healthful eating plan?

2. Diet - On average, over the past month, how $\begin{array}{llllll}1 & 2 & 3 & 4 & 5 & 67\end{array}$ many DAYS PER WEEK have you followed your eating plan?

3. Diet - On how many of the last SEVEN DAYS did you eat $\quad$\begin{tabular}{lll|l|l|l|}
1 & 2 & 3 & 4 & 5 & 67
\end{tabular} five or more servings of fruits and vegetables?

4. Diet - On how many of the last SEVEN DAYS did you eat high fat foods such as red meat or full-fat dairy products?

5. Exercise - On how many of the last SEVEN DAYS did you participate in at least 30 minutes of physical activity?(Total minutes of continuous activity, including walking).

6. Exercise - On how many of the last SEVEN DAYS did you $\begin{array}{llllll}1 & 2 & 3 & 4 & 5 & 67\end{array}$ participate in a specific exercise session (such as swimming, walking, biking) other than what you do around the house or as part of your work?

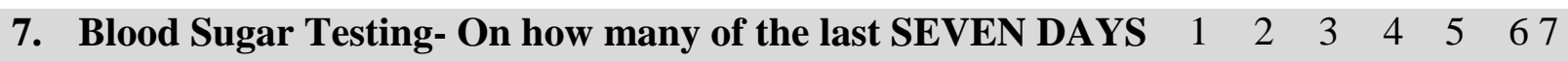
did you test your blood sugar?

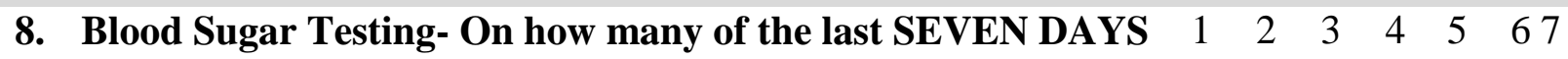
did you test your blood sugar the number of times recommended by your health care 
Instructions: Please circle one answer for each statement below.

\section{CONTINUE HERE}

9. Blood Pressure Checking- On how many of the last SEVEN DAYS did you check your blood pressure?

10. Blood Pressure Checking- On how many of the last SEVEN $\quad \begin{array}{llllll}1 & 2 & 3 & 4 & 5 & 6\end{array}$ DAYS did you check your blood pressure the number of times recommended by your health care provider?

11. Foot Care- On how many of the last SEVEN DAYS did you check your feet?

12. Foot Care- On how many of the last SEVEN DAYS did you $\begin{array}{llllll}1 & 2 & 3 & 4 & 5 & 6\end{array}$ inspect the inside of your shoes?

13. Smoking- Have you smoked a cigarette -even one puff No Yes during the past SEVEN DAYS? If yes, how many cigarettes did you smoke on an average day?

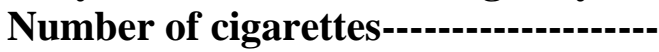

** Thank you for your time in completing this questionnaire. ** 
APPENDIX I: HEALTHY TUTOR DIABETES KNOWLEDGE TEST 
1) What is the body's main fuel?
A) Glucose
B) Fructose
C) Lactose
D) Galactose

2) Insulin is a hormone produced naturally by the body and needed to:
A) Break down sugars in the body to make energy
B) Break down fats in the body to make energy
C) All of the above
D) None of the above

3) In order for the body to use the sugar from food for energy:
A) The body must make enough insulin.
B) Insulin must be able to get into the cells to let sugars be used for energy
C) Sugar must be able to get into the cells
D) All of the above

\section{4) If you are told you have Diabetes, this means}
A) Your body has problems getting the sugar it needs to make energy.
B) You have an illness with no good treatments that always causes death
C) You have an illness you can only get from your mother or father
D) You have an illness caused by eating too much sugar

\section{5) People with diabetes may have:}
A) Problems with sex
B) Increased heart problems
C) All of the above
D) None of the above

6) A person can help to manage their Diabetes by:
A) Eating healthy foods
B) Exercising and staying active
C) All of the above
D) None of the above 
7) What is the normal range for blood sugar?
A) $50-150 \mathrm{mg} / \mathrm{dl}$
B) $200-300 \mathrm{mg} / \mathrm{dl}$
C) $60-120 \mathrm{mg} / \mathrm{dl}$
D) $100-200 \mathrm{mg} / \mathrm{dl}$

8) Sometimes people with Diabetes get too much medicine or don't eat enough and their sugar levels get too low. Which is a sign of low blood sugar?
A) Feeling weak, dizzy, drowsy, or confused
B) Having a cold clammy feeling
C) All of the above
D) None of the above

9) If your blood sugar drops too low, you should:
A) Drink lots of water
B) Eat or drink something with sugar in it0
C) Take more insulin
D) Call an ambulance right away

10) The body gets most of its glucose from carbohydrates. What are some foods that contain carbohydrates?
A) Bread
B) Potatoes
C) All of the above
D) None of the above

11) There are 2 types of carbohydrates (carbs). Which of these is a simple carbohydrate?
A) Soda
B) Apples
C) Broccoli
D) Oatmeal

12) Foods with protein are:
A) Fish
B) Peas
C) All of the above
D) None of the above 
13) People with diabetes should:
A) Eat different kinds of vegetables
B) Have fresh fruits instead of fruit juice
C) All the above
D) None the above

14) The foods that you eat have impact on your diabetes. $\square$ To help control your diabetes you should:
A) Eat regularly
B) Eat a meal or snack every 4-5 hours during the day
C) All of the above
D) None of the above

15) Carbohydrates are found in many different foods. It is important to choose healthy carbohydrates as part of your diet plan. Some examples of healthy carbohydrates include:
A) Peas, lentils, and beans (examples: pinto, kidney and black beans)
B) Whole grains that include: whole grain breads, cereals, pastas, crackers, brown rice, Oatmeal, bulgur, barley, whole cornmeal
C) All of the above
D) None of the above

16) Eating carbohydrates affects your blood sugar. $\square$ How high your blood sugar rises after eating carbohydrates depends on:
A) How much insulin you have in your body and how well this insulin works
B) What and how much you ate
C) Both $a$ and $b$
D) What time you ate

17) Learning to read food labels is important to help you count your carbohydrates and convert the grams into servings. $\square$ Which of the following is true?
A) 1 ounce $=1$ serving
B) 15 grams $=1$ serving
C) 45 grams $=3$ servings
D) Both b and c

18) The energy we get from food is measured in calories.
A) True
B) False 
19) What are some ways that fiber is important in our diets?

A) It plays an important role in the digestive process, adding bulk to the intestinal contents

B) Helps lower your blood cholesterol

C) All of the above

D) None of the above

20) Your doctor and dietitian will help you with how many calories and carbohydrates you need each day. If you are placed on an 1800 calorie ADA diet how could you plan your carbohydrates for the day?
A) 15 carbohydrate servings for the day
B) 4 servings of carbohydrates for lunch and dinner
C) All of the above
D) None of the above

21) Things that a diabetic person might do to care for their feet are:
A) Using a mirror to look for problems on the bottom of the feet
B) Cutting the skin on the end of the toes
C) Putting lotion between the toes
D) Washing the feet every week

22) Other things people with diabetes can do to prevent foot problems are:
A) Exercise
B) Stop smoking
C) All of the above
D) None of the above

23) Your doctor can find your Healthy Weight by using what measurement?
A) Age
B) Gender
C) Body Mass Index
D) Both a. and c.

24) The best way to begin losing weight is to do what?
A) Explore diet programs
B) Lose weight as fast as you can
C) Try to be active
D) Both a. and c. 
25) Exercise helps to decrease risks for:
A) diabetes
B) high cholesterol
C) all of the above
D) None of the above

26) Which are types of aerobic exercise?
A) bowling
B) weight lifting
C) walking
D) gardening

27) You should exercise about how many minutes each day?
A) 15
B) 20
C) 30
D) 45

28) When you begin to do regular exercise, it is best to exercise very hard and for long amounts of time.
A) true
B) false

29) There is no need to ever check with your doctor before starting exercise.
A) true
B) false

30) If you get bored with your exercise, you should:
A) stop exercising all together
B) change to a different type of exercise
C) keep on doing that exercise until you are no longer bored
D) call your doctor

31) If you have chest pain when you are exercising, you should:
A) stop exercising and call your doctor
B) keep exercising and hope the pain goes away
C) take an aspirin and keep exercising
D) exercise harder until the pain stops 
32) A normal, healthy blood pressure is:
A) $140 / 90$
B) $120 / 80$
C) $130 / 96$
D) $160 / 100$

33) Which parts of the body can be harmed when high blood pressure is not treated? :
A) eyes
B) Kidneys
C) All of the above
D) None of the above

34) What can a person with high blood pressure do to make their health better?
A) Exercise
B) Take their blood pressure medicines
C) All of the above
D) None of the above

35) Which of the following foods are NOT high in salt (sodium)?
A) apples
B) pickles
C) canned green beans
D) soda

36) You should just stop your high blood pressure medicine if it makes you feel bad.
A) True
B) False

37) The Heart
A) Is the most important muscle in the body
B) Pumps blood with oxygen and nutrients
C) All of the above
D) None of the above 
38) Things that can increase your risk for heart disease are:
A) Surgery
B) Being overweight
C) High blood pressure
D) Both B and C

39) Which lowers your risk of heart disease?
A) Eating hamburgers
B) Stopping smoking
C) Working long hours
D) Not exercising

40) Cholesterol can cause blood vessels to narrow.
A) True
B) False

41) Foods high in cholesterol and bad fats are:
A) Red meat
B) Egg whites
C) Fish
D) Wheat Bread

42) Your total cholesterol should be at what level?
A) Below 100
B) Below 200
C) Below 300
D) Below 50

43) What are some things you can do to keep your cholesterol levels down?
A) Losing weight
B) Correcting thyroid problems
C) All of the above
D) None of the above 
44) What are some dietary guidelines that need to be followed to help control cholesterol levels?
A) No more than $30 \%$ of total daily calories should be from fat, and no more than $8-10 \%$ of total daily calories should be from saturated fat
B) No more $300 \mathrm{mg}$ of cholesterol should be eaten in a day
C) All of the above
D) None of the above 
APPENDIX J: ATTITUDE INSTRUMENT 


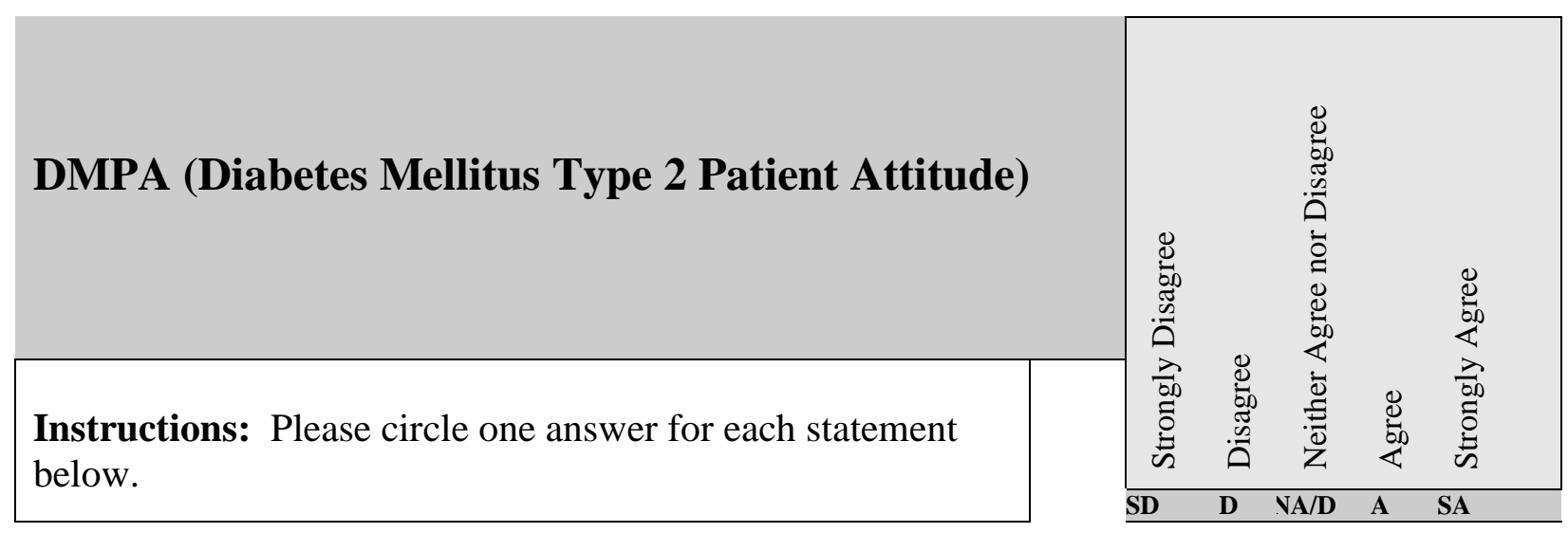

\section{START HERE}

1. I think Type 2 Diabetes is a serious health condition. $\quad \begin{array}{lllll}2 & 2 & 3 & 4 & 5\end{array}$

2. I worry that I will get serious complications if I do have $\quad \begin{array}{lllll}2 & 3 & 4 & 5\end{array}$ diabetes under control.

3. I can be healthy if I follow my doctor's advice. $\quad \begin{array}{lllll}2 & 3 & 4 & 5\end{array}$

4. I have to spend money and put in a lot of effort to take care $\quad \begin{array}{lllll}2 & 2 & 3 & 4 & 5\end{array}$ of my diabetes.

5. I can count on my significant other, relatives, friends and $\quad \begin{array}{lllll}1 & 2 & 3 & 4 & 5\end{array}$ coworkers for emotional and practical help in taking care of my diabetes.

6. I realize that I cannot afford my medicines.

$\begin{array}{lllll}1 & 2 & 3 & 4 & 5\end{array}$

7. The medical advice I receive regarding diabetes and its $\quad \begin{array}{llllll}1 & 2 & 3 & 4 & 5\end{array}$ care is different from my cultural beliefs.

8. I feel deprived regarding my favorite foods.

$\begin{array}{lllll}1 & 2 & 3 & 4 & 5\end{array}$

\section{Please Continue on the Back}


Instructions: Please circle one answer for each statement below.

\section{CONTINUE HERE}

9. I dislike feeling constantly concerned about quantity and type $\begin{array}{lllll}1 & 2 & 3 & 4 & 5\end{array}$ of food I eat.

10. I like to exercise because I feel better, sleep better, have more $\begin{array}{llllll}1 & 2 & 3 & 4 & 5\end{array}$ energy and rest more.

11. I dislike exercise because it is boring. $\quad \begin{array}{lllll}1 & 2 & 3 & 4 & 5\end{array}$

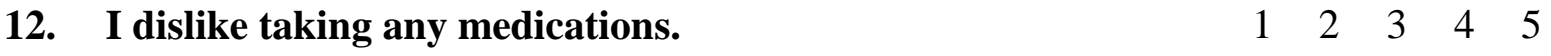

13. I like taking my diabetes medicines as they help me stay well. $\begin{array}{lllll}1 & 2 & 3 & 4 & 5\end{array}$

14. I do not like pricking myself to test for blood sugar. $\quad \begin{array}{lllll}1 & 2 & 3 & 4 & 5\end{array}$

15. I like to test my blood glucose. $\quad \begin{array}{lllll}1 & 2 & 3 & 4 & 5\end{array}$

16. I like to check my blood pressure. $\quad \begin{array}{lllll}1 & 2 & 3 & 4 & 5\end{array}$

\section{Please Continue on the Back}


Instructions: Please circle one answer for each statement below.

\section{CONTINUE HERE}

17. I like to check my feet.

18. I like to smoke.

19. I like regular quarterly visits to my primary care doctor since $1 \begin{array}{lllll}1 & 2 & 3 & 4 & 5\end{array}$ my doctor addresses my concerns, discusses my lab results and lets me know how I am doing and makes changes in my medicines if necessary.

20. I dislike seeing any doctor. $\begin{array}{lllll}1 & 2 & 3 & 4 & 5\end{array}$

21. My diabetes makes me angry, scared, anxious, upset or depressed.

22. I would have to change too many habits to follow my diet. $\begin{array}{lllll}1 & 2 & 3 & 4 & 5\end{array}$

23. It is easier for me to find excuses not to exercise than to go out $1 \begin{array}{lllll}2 & 2 & 4 & 5\end{array}$ to do something.

24. Putting out my tablets in a pill box would make it easier for $\begin{array}{llllll}1 & 2 & 3 & 4 & 5\end{array}$ me to take my medicine.

\section{Please Continue on the Back}


Instructions: Please circle one answer for each statement below.

CONTINUE HERE

25. It is difficult for me to take my diabetes medicines consistently.

SD D NA/D A A SA

$\begin{array}{lllll}1 & 2 & 3 & 4 & 5\end{array}$

26. I tend not to test my blood sugar regularly since I can tell my $\quad \begin{array}{lllll}1 & 2 & 3 & 4 & 5\end{array}$ blood sugar is abnormal without testing it.

27. I tend to avoid checking my blood pressure regularly. $\quad \begin{array}{lllll}1 & 2 & 3 & 4 & 5\end{array}$

28. I tend not to check my feet regularly. $\begin{array}{lllll}1 & 2 & 3 & 4 & 5\end{array}$

29. It is very difficult for me to cut back or give up smoking. $\begin{array}{lllll}1 & 2 & 3 & 4 & 5\end{array}$

30. I see my doctor for the slightest discomfort. $\begin{array}{lllll}1 & 2 & 3 & 4 & 5\end{array}$

** Thank you for your time in completing this questionnaire. **

Please share any additional comments you have in the box provided below. 
APPENDIX K: FINDINGS OF ANALYSES NOT INCLUDED IN THE TEXT 
The net effect of experimental status on attitude at T2, holding attitude at T1 constant, is shown in figure 11.

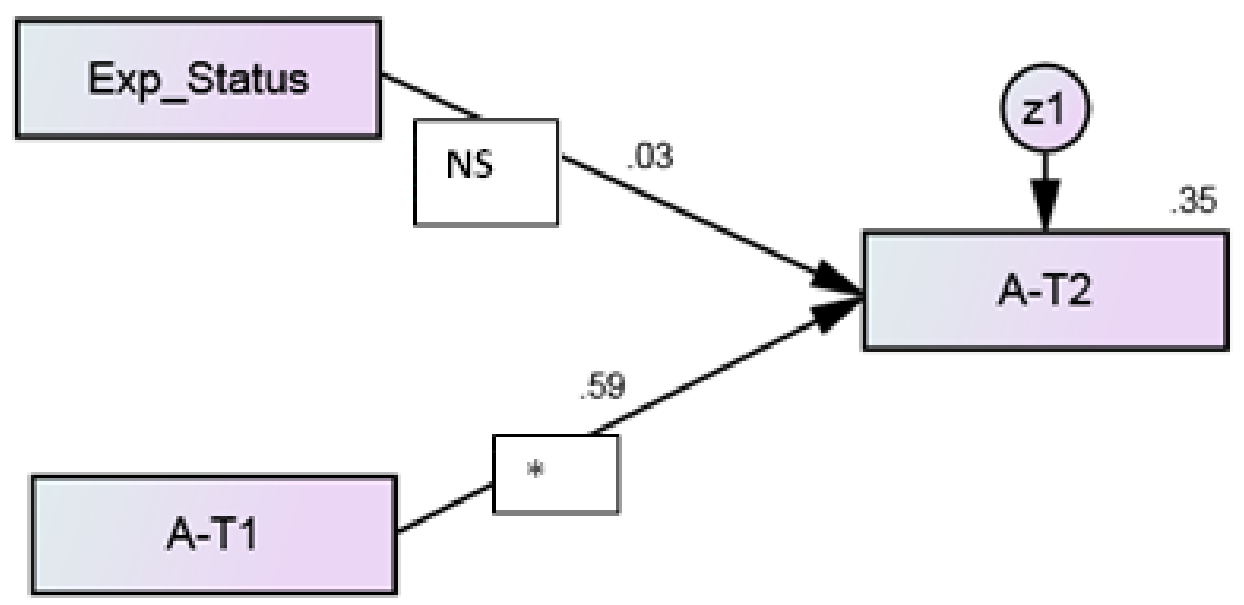

$\mathrm{NS}=$ Not statistically significant at 0.05 or lower level.

*Statistically significant at 0.05 or lower level

Goodness-of-fit Statistics: Chi Square $=0.281$ with $\mathrm{DF}=1, \mathrm{P}=0.596, \mathrm{CFI}=1, \mathrm{TLI}=1.038, \mathrm{RMSEA}=0.00, \mathrm{R}^{2}=$ 0.35

Comments on Model Fit: Non significant Chi square value and Chi Square/DF=0.281, $\mathrm{p}=0.596$, suggests that the model fit reasonably well; RMSEA less than 0.05 indicates an excellent fit.

Figure 11. The Net Effect of Experimental Status on Attitude at T2 (A-T2)

Experimental status does not affect attitude at T2 (A-T2) with statistical significance while holding the prior attitude constant. The influence of attitude at $\mathrm{T} 1$ on attitude at $\mathrm{T} 2 \mathrm{is}$ statistically significant, with $\beta=0.59$. This is a partial examination of the model. There is a very small change in attitude over time; experimental status does not have much influence on attitude.

The net effect of experimental status on practice at $\mathrm{T} 2$, holding practice at $\mathrm{T} 1$ constant, is shown in figure 12. 


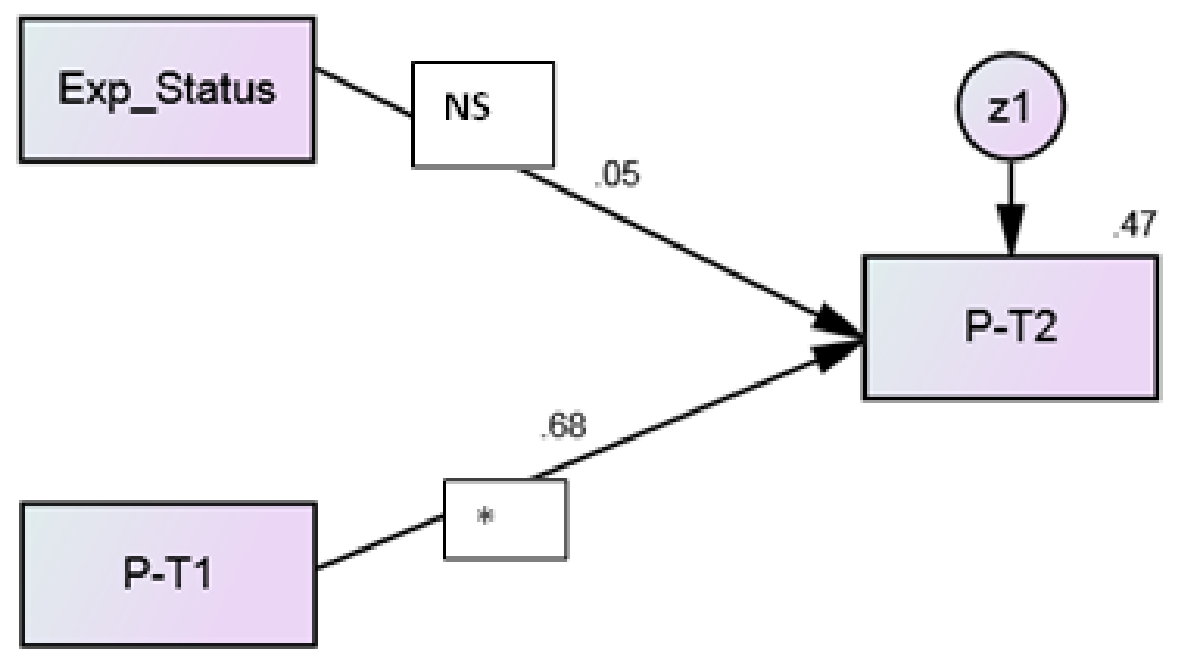

$\mathrm{NS}=$ Not statistically significant at 0.05 or lower level.

*Statistically significant at 0.05 or lower level

Goodness-of-fit Statistics: Chi Square $=0.677$ with $\mathrm{DF}=1, \mathrm{P}=0.411, \mathrm{CFI}=1, \mathrm{TLI}=1.024, \mathrm{RMSEA}=0.00, \mathrm{R}^{2}=$ 0.47 .

Comments on Model Fit: Non significant Chi square value and Chi Square/DF=0.677, $\mathrm{p}=0.411$, suggests that the model fit reasonably well; RMSEA less than 0.05 indicates an excellent fit.

Figure 12. The Net Effect of Experimental Status on Practice at T2

The effect of experimental status on practice at T2 (P-T2) is not statistically significant. The effect of practice at $\mathrm{T} 1$ on practice at $\mathrm{T} 2$ is statistically significant, with $\beta=0.68$.

Experimental status accounts for very little change in P-T2.

The net effect of experimental status on LDLC at T2, holding LDLC at T1 constant, is shown in figure 13. 


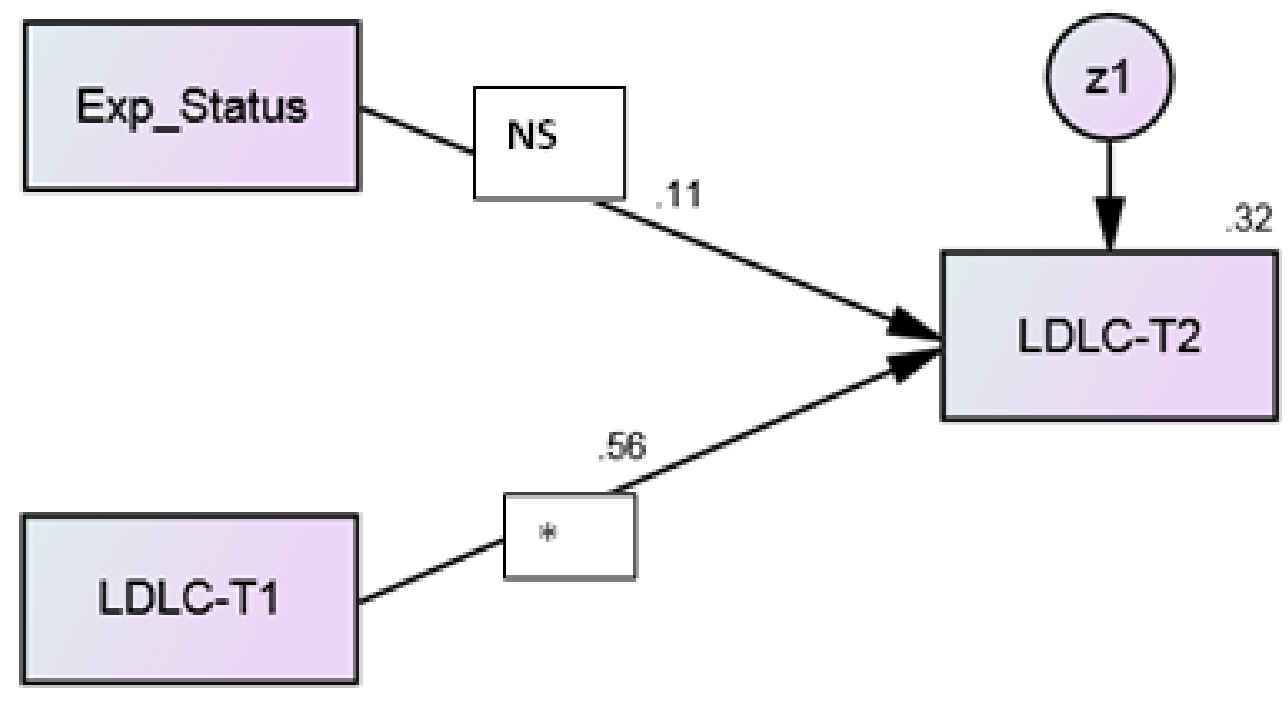

$\mathrm{NS}=$ not statistically significant at 0.05 or lower level.

*Statistically significant at 0.05 or lower level

Goodness-of-fit Statistics: Chi Square $=0.330$, with DF $=1, \mathrm{P}=0.566, \mathrm{CFI}=1, \mathrm{TLI}=1.097, \mathrm{RMSEA}=0.00, \mathrm{R}^{2}=$ 0.32 .

Comments on Model Fit: Non significant Chi square value and Chi Square/DF=0.330, $\mathrm{p}=0.566$, suggests that the model fit reasonably well; RMSEA less than 0.05 indicates an excellent fit.

Figure 13. The Net Effect of Experimental Status on Low-Density Lipoprotein Cholesterol (LDLC) at T2

The effect of experimental status on LDLC at T2 (LDLC-T2), holding prior level of LDLC-T1 constant, is not statistically significant. The effect of LDLC at T1 on LDLC at T2 is statistically significant, with $\beta=0.56$.

The net effect of experimental status on functional capacity $(\mathrm{FC})$ at $\mathrm{T} 2$ is illustrated in figure 14. 


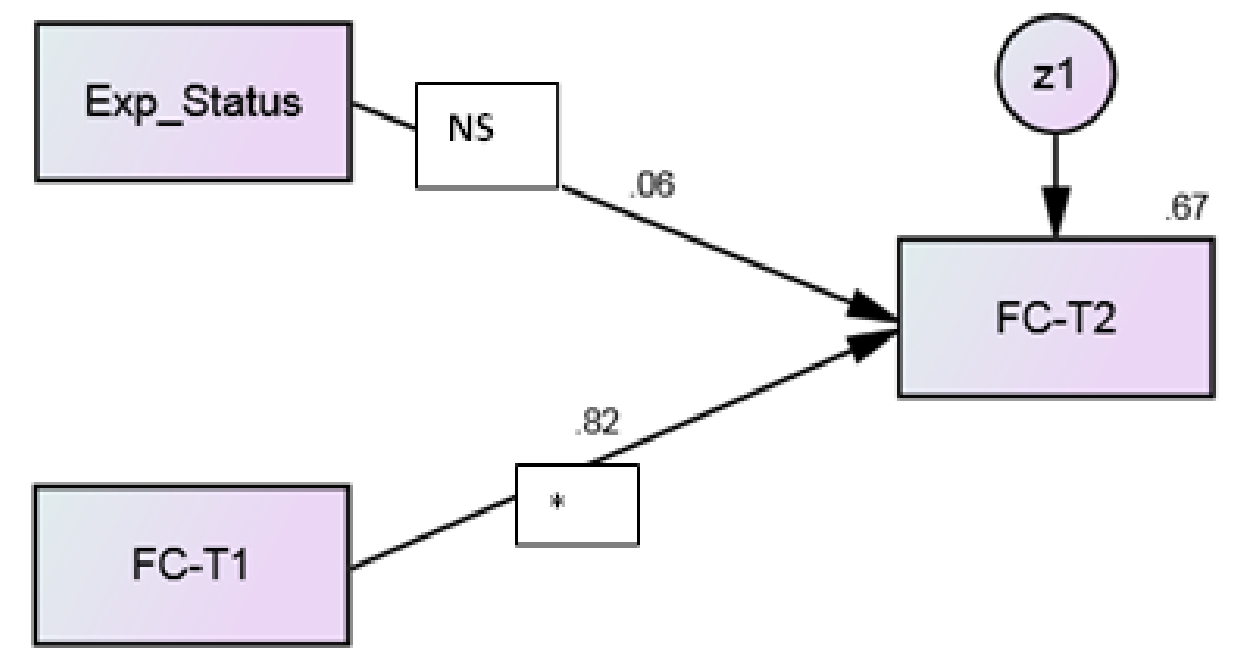

$\mathrm{NS}=$ not statistically significant at 0.05 or lower level

*Statistically significant at 0.05 or lower level

Goodness-of-fit Statistics: Chi Square $=1.391$, with DF $=1, \mathrm{P}=0.238, \mathrm{CFI}=0.997, \mathrm{TLI}=0.992, \mathrm{RMSEA}=0.053$, $\mathrm{R}^{2}=0.67$.

Comments on Model Fit: Non significant Chi square value and Chi Square/DF=1.391, p $=0.238$, suggests that the model fit reasonably well; RMSEA less than 0.08 indicates a good fit.

Figure 14. The Net Effect of Experimental Status on Functional Capacity (FC) at T2

The effect of experimental status on functional capacity at T2 (FC-T2) is not statistically significant. The effect of functional capacity FC at $\mathrm{T} 1$ on functional capacity at $\mathrm{T} 2$ is statistically significant, with $\beta=0.82$.

The net effect of experimental status on poor perceived health (PPH) at $\mathrm{T} 2$, holding $\mathrm{PPH}$ at $\mathrm{T} 1$ constant, is illustrated in figure 15. 


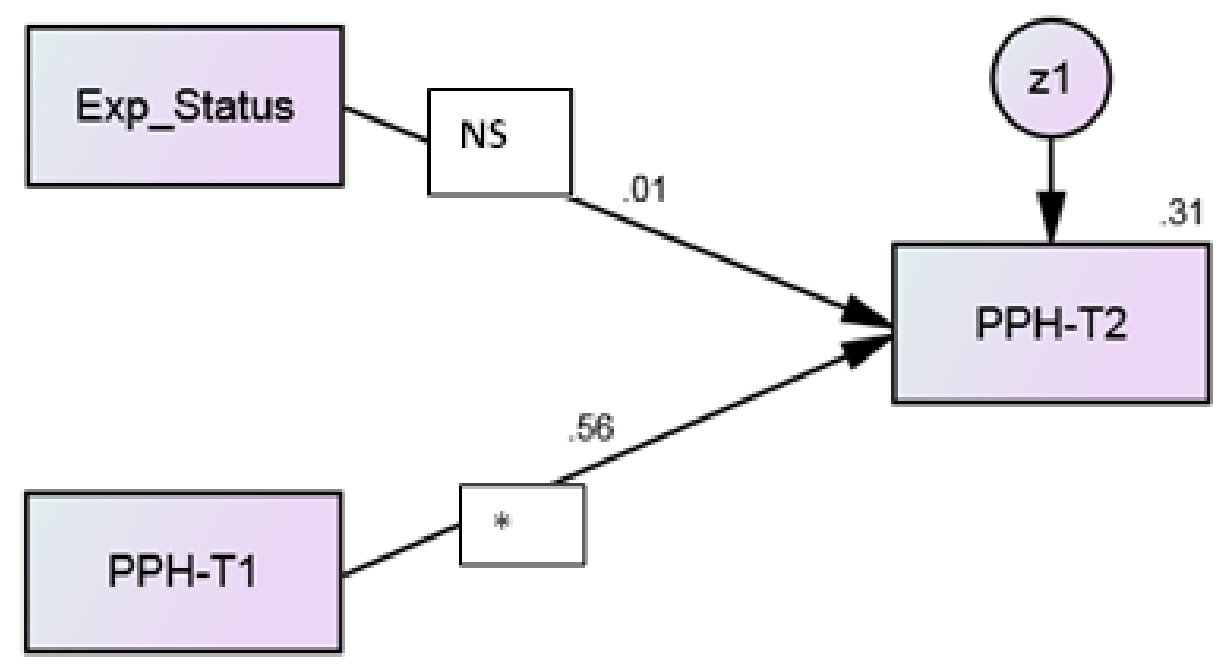

$\mathrm{NS}=$ not statistically significant at 0.05 or lower level

*Statistically significant at 0.05 or lower level

Goodness-of-fit Statistics: Chi Square $=0.722$, with DF $=1, \mathrm{P}=0.396, \mathrm{CFI}=1, \mathrm{TLI}=1.017, \mathrm{RMSEA}=0.00, \mathrm{R}^{2}$ $=0.31$.

Comments on Model Fit: Non significant Chi square value and Chi Square/DF=0.722, $\mathrm{p}=0.396$, suggests that the model fit reasonably well, RMSEA less than 0.05 indicates an excellent fit.

Figure 15. The Net Effect of Experimental Status on Poor Perceived Health (PPH) at T2

The effect of experimental status on poor perceived health at T2 (PPH-T2), holding the prior level PPH-T1 constant, is not statistically significant. The effect of poor perceived health at $\mathrm{T} 1$ on poor perceived health at $\mathrm{T} 2$ is statistically significant, with $\beta=0.557$. 


\section{APPENDIX L: SUMMARY OF THE FINDINGS}




\section{Summary of the Findings}

There was no statistically significant difference between the experimental and the control group in terms of demographic characteristics and major diagnoses.

The correlations among the four outcome variables were relatively weak. Thus, the four outcome variables did not constitute one common factor measurement model for outcome evaluation.

\section{The Intention-to-Treat Analysis: Independent Sample T-Tests}

First, the experimental effect of a health educational intervention was analyzed using independent sample $t$-tests for each of the seven variables: knowledge $(K)$, attitude (A), practice $(\mathrm{P})$, and four outcome variables \{ glycated hemoglobin (A1C), low-density lipoprotein cholesterol, functional capacity, and poor perceived health\}. The analysis was performed for Time-1 (T1) and Time-2 (T2) separately without controlling for the effects of other predictors. Findings of the analysis of the experimental effect of health educational intervention on knowledge, attitude, practice (KAP), and outcome variables \{ glycated hemoglobin (A1C), lowdensity lipoprotein cholesterol, functional capacity, and poor perceived health $\}$ without controlling for the effect of other predictors at $\mathrm{T} 2$ through t-tests are as follows.

At T2, the mean knowledge score of the experimental group improved; there was a statistically significant difference between the mean knowledge scores for the experimental group $(M=31.44, S D=5.30)$ and those for the control group $(M=29.56, S D=5.18) ;(p<0.05)$.

Hypothesis H1: Health educational intervention directly improves knowledge about diabetes is supported.

Health education had no statistically significant direct effect on attitude, preventive practice, and the outcome variables.

\section{The Intention-to-Treat Analysis with Statistical Control of the Prior Score (Regression}

\section{Analysis)}

Second, the intention-to-treat analysis was performed by regression analysis to determine the net experimental effect of health educational intervention on each of the seven study variables ( $\mathrm{K}, \mathrm{A}, \mathrm{P}$, and four outcomes) at $\mathrm{T} 2$, holding the respective prior measure of the variable constant. This was a partial examination of the causal model. The experimental status did not 
statistically affect any of knowledge, attitude, and practice at T2 with their prior levels controlled. The analysis showed that the experimental variable did not contribute much to the variation at $\mathrm{T} 2$ in knowledge, attitude, or practice scores. Health educational intervention had little direct causal influence on any of the variables: knowledge (K), attitude (A), and practice $(\mathrm{P})$.

The results of the analysis examining the net effect of experimental status on each of the four outcome variables are as follows. The effect of experimental status on A1C at T2 (A1C-T2) was statistically significant $(\mathrm{p}<0.05)$. There was a direct causal effect of experimental status on glycated hemoglobin (A1C).

$\mathrm{H} 4_{1}$ : Health educational intervention directly lowers glycated hemoglobin (A1C) is supported.

The net effect of experimental status on each of the outcomes: low-density lipoprotein cholesterol, functional capacity, and poor perceived health at T2, holding their respective prior levels constant, was not statistically significant and is illustrated in figures 13, 14, 15 in appendix K. This analysis examining the net effect of experimental variable on each of the four outcome variables when holding the prior levels constant demonstrates that there was no direct effect of experimental status on outcome variables, with the sole exception of the direct effect on glycated hemoglobin (A1C). Thus an indirect causal effect of health education mediated via the change variables of DK, DA, and DP on outcome variables is assumed in the difference-in-differences analysis.

The prior levels of all outcome variables at T1 are strongly associated with their respective levels at T2, with $\beta$ coefficients of 0.752 for A1C, 0.815 for FC, 0.558 for LDL, and 0.557 for poor perceived health.

\section{Causal Modeling of KAP Relationships in \{(Exp_Status)-(K-T2)-(A-T2)-(P-T2)\} Model}

Next, the model of $\{($ Exp_Status)-(K-T2)-(A-T2)-(P-T2) $\}$ was analyzed in SEM. Findings of the causal modeling of KAP relationships in the $\{($ Exp_Status)-(K-T2)-(A-T2)-(P-T2) $\}$ model are as follows. This was not a full examination of the causal model, since the prior levels were not statistically controlled. The finding showed a concomitant effect of experimental status, knowledge and attitude on practice. The experimental status had no direct effect on the practice of preventive self-care, controlling for knowledge and attitude, at T2. However, the experimental status had an indirect effect on practice through knowledge. Knowledge at T2 had a statistically 
significant effect on practice of self-care, with $\beta=-0.204$. The effect of experimental status on attitude at T2 was not statistically significant. The effect of attitude at T2, (A-T2) on practice at T2 (P-T2) was positive and statistically significant, with $\beta=0.449$. The effect of attitude (A-T2) was greater than the effect of knowledge.

\section{Difference-in-Differences Analysis}

Findings of the difference-in-differences analysis are as follows. The causal model of experimental status, differences in knowledge (DK), attitude (DA), and practice (DP) and differences in outcomes over time (T2-T1) has a reasonable fit to the data as illustrated by GOF statistics. This model enables examination of the direct or indirect effects of health educational intervention on the change in each outcome variable analyzed separately since they do not constitute a single latent construct. The effect of experimental status on the scores for differences in knowledge (DK), attitude (DA), and practice (DP) and scores for differences in each outcome (DA1C), (DLDLC), (DFC) and (DPPH) was analyzed separately between the two time points and shows some interesting results. The difference in practice scores (DP) directly affected only the difference in glycated hemoglobin (DA1C); the difference in practice scores (DP) did not affect each of the differences in scores for the other outcomes: (DLDLC), (DFC) and (DPPH). The data from this experiment do not support a strong causal path of experimental effects on outcomes via knowledge, attitude, and practice of self-care. The lack of variability in patients treated in a single medical practice with a single provider prevents an adequate demonstration of the viability of the proposed causal model. 


\section{LIST OF REFERENCES}

Abubakari, A., Jones, M., Lauder, W., Kirk, A., Anderson, J., \& Devendra, D. (2011). Associations between knowledge, illness perceptions, self-management and metabolic control of type 2 diabetes among African and European-origin patients. Journal of Nursing \& Healthcare of Chronic Illnesses, 3(3), 245-256.

Adepu, R. R., Rasheed, A. A., \& Nagavi, B. G. (2007). Effect of Patient Counseling on Quality of Life in Type-2 Diabetes Mellitus Patients in Two Selected South Indian Community Pharmacies: A Study. Indian Journal of Pharmaceutical Sciences, 69(4), 519.

Al-Maskari F, El-Sadig M, Al-Kaabi JM, Afandi B, Nagelkerke N, Yeatts, K. (2013) Knowledge, Attitude and Practices of Diabetic Patients in the United Arab Emirates. PLoS One 8(1): e52857.

American Diabetes Association. Standards of Medical Care in Diabetes (2012). Diabetes Care. 2013 Jan; 33 Suppl 1:S11-61.

American Diabetes Association. Standards of Medical Care in Diabetes (2011). Diabetes Care. 2011 Jan; 34 Suppl 1:S11-61.

Anderson, R. M., Fitzgerald, J. T., Funnell, M. M., \& Gruppen, L. D. (1998). The Third Version of the Diabetes Attitude Scale. Diabetes Care, 21(9), 1403.

Anderson, B., Funnell, M., \& Tang, T. (2006). Self-Management of Health. In C. Mensing, M. Cypress, C. Halstenson, S. McLaughlin, E. Walker (Eds.), The Art and Science of Diabetes of Self-Management Education. (pp. 43-58). Chicago: American Association of Diabetes Educators.

Ardena, G. A., Paz-Pacheco, E., Jimeno, C. A., Lantion-Ang, F., Paterno, E., \& Juban, N. (2010). Knowledge, attitudes and practices of persons with type 2 diabetes in a rural 
community: Phase I of the community-based Diabetes Self-Management Education (DSME) Program in San Juan, Batangas, Philippines. Diabetes Research and Clinical Practice, 90(2), 160-166.

Austin, M. (2005). Importance of Self-care Behaviors in Diabetes Management. US Endocrinology, (1):16-21.

Bains, S. S., \& Egede, L. E. (2011). Associations between health literacy, diabetes knowledge, self-care behaviors, and glycemic control in a low income population with type 2 diabetes. Diabetes Technology \& Therapeutics, (3), 335.

Badran, I. G. (1995). Knowledge, attitude and practice the three pillars of excellence and wisdom: a place in the medical profession. Eastern Mediterranean Health Journal, 1(1), $8-16$.

Baradaran, H. R., Knill-Jones, R. P., Wallia, S., \& Rodgers, A. (2006). A controlled trial of the effectiveness of a diabetes education program in a multi-ethnic community in Glasgow. BMC Public Health, 6134-9.

Baranowski, T., Perry, C.L., Parcel, G. S. (2002). How Individuals, Environments, and Health Behavior Interact: Social Cognitive Theory. In. K.Glanz, B. Rimer, \& F. M. Lewis (Eds.), Health Behavior and Health Education Theory, Research, and Practice (pp. 165184). San Franciso: Josey-Bass.

Beeney, L., \& Dunn, S. (1990). Knowledge improvement and metabolic control in diabetes education: approaching the limits? Patient Education And Counseling, 16(3), 217-229.

Berger, D., \& Bratu, E. (2006). Tuberculosis Knowledge, Attitudes and Practices in Romania: A Patient-Centered Assessment. Cognitie, Creier, Comportament/Cognition, Brain, Behavior, 10(1), 93-104. 
Bloomgarden, Z. T., Karmally, W., Metzger, M., Brothers, M., Nechemias, C., Bookman, J., \& Brown, W. (1987). Randomized, Controlled Trial of Diabetic Patient Education: Improved Knowledge Without Improved Metabolic Status. Diabetes Care, 10(3), 263. Centers for Disease Control and Prevention. National center for health statistics. (Online). Available: http://www.cdc.gov/nchs.htm (Accessed 1 October 2012).

Clarke, A. (2009). Effects of routine education on people newly diagnosed with type 2 diabetes. European Diabetes Nursing, 6(3), 88-94.

Cohen, J. (1988). Statistical Power Analysis for the Behavioral Sciences (2nd Edition). Hillsdale, NJ: Lawrence Earlbaum Associates.

Cranor, C., Bunting, B., \& Christensen, D. (2003). The Asheville Project: long-term clinical and economic outcomes of a community pharmacy diabetes care program. Journal Of The American Pharmaceutical Association (Washington, D.C.: 1996), 43(2), 173-184.

Delahanty, L., \& Wylie-Rosett, J. (2006). Lifestyle for Prevention: Choices, Changes, Challenges. In C. Mensing, M. Cypress, C. Halstenson, S. McLaughlin, E. Walker (Eds.), The Art and Science of Diabetes of Self-Management Education. (pp. 21-42). Chicago: American Association of Diabetes Educators.

Dickeson, B., Scheel J. Apparatus, System, and Method for Determining a Change in Test Results, U.S. Patent and Trademark Office. Patent No. 8,721,345. May 13, 2014.

Eagly, A. H., \& Chaiken, S. (2007). The advantages of an inclusive definition of attitude. Social Cognition, (5), 582.

Eigenmann, C. A., Colagiuri, R., Skinner, T. C., Trevena, L. (2009). Are current psychometric tools suitable for measuring outcomes of diabetes education? Diabetes Med. 26(4):42536. 
Eckman, K., \& Walker, R. (2008). Knowledge, Attitudes and Practice (KAP) Survey Summary Report for the Duluth Lakeside Stormwater Reduction Project (LSRP). Duluth: University of Minnesota.

European Quality of Life 5D 5L. (Online.) Available: http://euroqol.org.html.

Farina, K. (2013). Can financial incentives improve self-management behaviors? The American Journal of Managed Care, 19 Spec No. 2E8.

Fradkin, J. (2012). Confronting The Urgent Challenge Of Diabetes: An Overview. Health Affairs, 31(1), 12-19.

Garrett, N., Hageman, C., Sibley, S., Davern, M., Berger, M., Brunzell, C., Malecha, K., Richards, S. (2005). The Effectiveness of an Interactive Small Group Diabetes Intervention in Improving Knowledge, Feeling of Control, and Behavior. Health Promotion Practice, 6(3), 320.

Glanz, K., Rimer, R. K., \& Lewis, F. M. (2002). Health Behavior and Health Education. San Fransico: Jossey-Bass.

Healthy Tutor Modules. (Online). Available: http://www.healthytutor.com.htm.

Horn, S. (1997). Tools and Techniques in Disease Management. Disease Management \& Health Outcomes, 1(1), 17-25.

Hogue, V. W., Babamoto, K. S., Jackson, T. B., Cohen, L. B., \& Laitinen, D. L. (2003). Pooled Results of Community Pharmacy-Based Diabetes Education Programs in Underserved Communities. Diabetes Spectrum, 16(2), 129-133.

Holmes, V., Spence, M., McCance, D., Patterson, C., Harper, R., \& Alderdice, F. (2012). Evaluation of a DVD for women with diabetes: impact on knowledge and attitudes to preconception care. Diabetic Medicine, 29(7), 950-956. 
Hooper, D., Coughlan, J., \& Mullen, M. R. (2008). Structural Equation Modelling: Guidelines for Determining Model Fit. Electronic Journal Of Business Research Methods, 6(1), 5359.

Jaccard, J., Dittus, P., \& Gordon, V. (1996). Maternal correlates of adolescent sexual and contraceptive behavior. Family Planning Perspectives, 28(4), 159.

Janz, N. K., Champion, V. L., Strecher, V. J. (2002). The Health Belief Model. In. K.Glanz, B. Rimer, \& F. M. Lewis (Eds.), Health Behavior and Health Education Theory, Research, and Practice (pp. 45-66). San Franciso: Josey-Bass.

Khandekar, R., Harby, S., Harthy, H., \& Lawatti, J. (2010). Knowledge, attitude and practice regarding eye complications and care among Omani persons with diabetes - A cross sectional study. Oman Journal Of Ophthalmology, 3(2), 60-65.

Kharkar, M., \& Bowalekar, S. (2012). Knowledge, attitude and perception/practices (KAP) of medical practitioners in India towards adverse drug reaction (ADR) reporting. Perspectives In Clinical Research, 3(3), 90-94.

King, H., Aubert, R., \& Herman, W. (1998). Global burden of diabetes, 1995-2025: prevalence, numerical estimates, and projections. Diabetes Care, 21(9), 1414-1431.

Knowler, W. C., Barrett-Connor, E. E., Fowler, S. E., Hamman, R. F., Lachin, J. M., Walker, E. A., \& Nathan, D. M. (2002). Reduction in the incidence of type 2 diabetes with lifestyle intervention or metformin. New England Journal Of Medicine, 346(6), 393-403.

Korhonen, T., Huttunen J. K., Aro, A., Hentinen, M., Ihalainen, O., Majander, H., \& Pyorala, K. (1983). A Controlled Trial on the Effects of Patient Education in the Treatment of Insulin-dependent Diabetes. Diabetes Care, 6(3), 256. 
Leslie, R. (1999). United Kingdom Prospective Diabetes Study (UKPDS): What now or so what?. Diabetes-Metabolism Research And Reviews, 15(1), 65-71.

Lin, Y., Huang, L., Nie, S., Liu, Z., Yu, H., Yan, W., Xu, Y. (2011). Knowledge, Attitudes and Practices (KAP) related to the Pandemic (H1N1) 2009 among Chinese General Population: a Telephone Survey. BMC Infectious Diseases, 11:128.

Maez, L., Erickson, L., \& Naumuk, L. (2014). Diabetic education in rural areas. Rural And Remote Health, 14(2), 2742.

Maina, W. K., Ndegwa, Z. M., Njenga, E. W., \& Muchemi, E. W. (2011). Knowledge, attitude, and practices related to diabetes among community members in four provinces in Kenya: a cross-sectional study. African Journal Of Diabetes Medicine, 19(1), 15-18.

Malathy, R., Narmadha, M., Ramesh, S., Alvin, J., \& Dinesh, B. (2011). Effect of a diabetes counseling program on knowledge, attitude and practice among diabetic patients in Erode district of South India. Journal Of Young Pharmacists, 3(1), 65-72.

Manabe, T., Hanh, T., Lam, D., Do, T., Pham, T., Dinh, T., \& Kudo, K. (2012). Knowledge, Attitudes, Practices and Emotional Reactions among Residents of Avian Influenza (H5N1) Hit Communities in Vietnam. Plos One, 7(10),

Manabe, T., Pham, T., Vu, V., Takasaki, J., Dinh, T., Nguyen, T., \& Kudo, K. (2011). Impact of educational intervention concerning awareness and behaviors relating to avian influenza (H5N1) in a high-risk population in Vietnam. Plos One, 6(8).

Melancon, J., Oomen-Early, J., \& del Rincon, L. M. (2009). Using the PEN-3 model to assess knowledge, attitudes, and beliefs about diabetes type 2 among Mexican American and Mexican Native men and women in North Texas.International Electronic Journal of Health Education. 
Montano, D. E., Kasprzyk, D. (2002). The Theory of Reasoned Action and The Theory of Planned Behavior. In K.Glanz, B. Rimer, \& F. M. Lewis (Eds.), Health Behavior and Health Education Theory, Research, and Practice (pp. 67-98). San Franciso: Josey-Bass.

Morales, L. S., Lara, M., Kington, R. S., Valdez, R. O., \& Escarce, J. J. (2002). Socioeconomic, cultural, and behavioral factors affecting Hispanic health outcomes. Journal Of Health Care For The Poor And Underserved, 13(4), 477-503.

Mplus Manual. (Online). Available: http://www.statmodel.com/download/usersguide/ Mplus\%20Users\%20Guide\%20v6.pdf (Accessed September 2013).

Nafissi, N., Saghafinia, M., Motamedi, M., \& Akbari, M. (2012). A survey of breast cancer knowledge and attitude in Iranian women. Journal Of Cancer Research \& Therapeutics, 8(1), 46-49.

Nath, C. R., Sylvester, S. T., Yasek, V., \& Gunel, E. (2001). Literacy Assessment for Diabetes. The Diabetes Educator, 27(6), 857-864.

National Library of Medicine, National Institute of Health. Medline Plus (Online). Available: http://nlm.nih.gov/medlineplus/diabetes.html.

Ng, Shu Hui, Kheng Hooi, C., Zi Yang, L., Yee Hooi, C., Aishath Noora, ., \& Amudha, K. (2012). Reality vs Illusion: Knowledge, Attitude and Practice among Diabetic Patients. International Journal Of Collaborative Research On Internal Medicine \& Public Health, (5), 723.

Norris, S., Engelgau, M., \& Narayan, K. (2001). Effectiveness of self-management training in type 2 diabetes: a systematic review of randomized controlled trials. Diabetes Care, 24(3), 561-587. 
Norris, S. L., Lau, J., Smith, S. J., Schmid, C. H., Engelgau, M. M. (2002). Self-management education for adults with type 2 diabetes: a meta-analysis of the effect on glycemic control. Diabetes Care, 25(7), 1159-1171.

Ozmen, B., \& Boyvada, S. (2002). Can self-monitoring blood glucose control decrease glycated hemoglobin levels in diabetes mellitus. Endocrinologist, 12(4), 349-356.

Perneger, T., \& Courvoisier, D. (2011). Exploration of health dimensions to be included in multiattribute health-utility assessment. International Journal For Quality In Health Care, 23(1), 52-59.

Polit, D. F., \& Hungler, B. P. (1995). Nursing Research Principles and Methods. Philadelphia: Lippincott.

Pi-Sunyer, X., Blackburn, G., Brancati, F., Bray, G., Bright, R., Clark, J., \& ... Yanovski, S. (2007). Reduction in weight and cardiovascular disease risk factors in individuals with type 2 diabetes: one-year results of the look AHEAD trial. Diabetes Care, 30(6), 13741383.

Polonsky, W., Anderson, B., Lohrer, P., Welch, G., Jacobson, A., Aponte, J., \& Schwartz, C. (1995). Assessment of diabetes-related distress. Diabetes Care, 18(6), 754-760.

Prochaska, J. O., Redding, C. A., Evers, K.E. (2002). The Transtheoretical Model and Stages of Change. In K.Glanz, B. Rimer, \& F. M. Lewis (Eds.), Health Behavior and Health Education Theory, Research, and Practice (pp. 99-120). San Franciso: Josey-Bass.

Raj, C., \& Angadi, M. M. (2010). Hospital-based KAP study on diabetes in Bijapur, Karnataka. Indian Journal Of Medical Specialties, 1(2), 80-83. 
Shah, V., Kamdar, P. P., \& Shah, N. (2009). Assessing the knowledge, attitudes and practice of type 2 diabetes among patients of Saurashtra region, Gujarat. International Journal Of Diabetes In Developing Countries, (3).

Soper, D.S. (2014). A-priori Sample Size Calculator for Structural Equation Models [Software]. Available from http://www.danielsoper.com/statcalc

Thakurdesai, P., Kole, P., \& Pareek, R. (2004). Evaluation of the quality and contents of diabetes mellitus patient education on Internet. Patient Education \& Counseling, 53(3), 309-313.

Tilly, K. F., Belton, A. B., \& McLachlan, J. C. (1995). Continuous Monitoring of Health Status Outcomes: Experience With a Diabetes Education Program. Diabetes Educator, 21(5), 413.

Toobert, D., Hampson, S., \& Glasgow, R. (2000). The Summary of Diabetes Self-Care Activities measure: results from 7 studies and a revised scale. Diabetes Care, 23(7), 943-950.

Upadhyay, D. K., Mohamed, I. M., Alurkar, V. M., Mishra, P., Palaian, S. (2012). Evaluation of Knowledge, Attitude, and Practice of Newly Diagnosed Diabetes Patients - a Baseline Study from Nepal. International Journal of Pharmacy Teaching \& Practices, 3(2), 245252.

Van Geertruyden, J., Ntakirutimana, D., Erhart, A., Rwagacondo, C., Kabano, A., \& D'Alessandro, U. (2005). Malaria infection among pregnant women attending antenatal clinics in six Rwandan districts. Tropical Medicine \& International Health, 10(7), 681688.

Vasconcelos, C., Pinheiro, A., Casteol, A., Costa, L., Oliveira, R. (2011). Knowledge, Attitude and Practice Related to the Pap Smear Test among Users of a Primary Health Unit. Rev. Latino-Am.,19(1), 97-105. 
Venkataraman, K., Kannan, A., Kalra, O., Gambhir, J., Sharma, A., Sundaram, K. K., \& Mohan, V. V. (2012). Diabetes Self-Efficacy Strongly Influences Actual Control of Diabetes in Patients Attending a Tertiary Hospital in India. Journal Of Community Health, 37(3), $653-662$.

Vimalavathini, R., Agarwal, S., \& Gitanjali, B. (2008). Educational program for patients with type-1 diabetes mellitus receiving free monthly supplies of insulin improves knowledge and attitude, but not adherence. International Journal Of Diabetes In Developing Countries, 28(3), 86-90.

Wahed, T., Kaukab, S., Saha, N., Khan, I., Khanam, F., Chowdhury, F., \& Uddin, J. (2013). Knowledge of, attitudes toward, and preventive practices relating to cholera and oral cholera vaccine among urban high-risk groups: findings of a cross-sectional study in Dhaka, Bangladesh. BMC Public Health, 13.

Walker, R. J., Smalls, B. L., Hernandez-Tejada, M. A., Campbell, J. A., Davis, K. S., \& Egede, L. E. (2012). Effect of diabetes fatalism on medication adherence and self-care behaviors in adults with diabetes. General Hospital Psychiatry, 34(6), 598-603.

Wan, T. T. H. (2014). A Transdisciplinary Approach to Health Policy Research and Evaluation. Int. J. Public Policy, 10(4/5), 161-177.

Westland, J.C. (2010). Lower bounds on sample size in structural equation modeling. Electronic Commerce Research and Applications, 9(6), 476-487.

Williams, G., Freedman, Z., \& Deci, E. (1998). Supporting autonomy to motivate patients with diabetes for glucose control. Diabetes Care, 21(10), 1644-1651.

Yang, W., Dall, T., Halder, P., Gallo, P., Kowal, S., Hogan, P. (2013). Economic Costs of Diabetes in the U.S. in 2012. Diabetes Care, 36, 1033-1046. 
Zyskind, A., Jones, K., Pomerantz, K. L., \& Barker, A. (2009). Exploring the use of computer based patient education resources to enable diabetic patients from underserved populations to self-manage their disease. Information Services \& Use, (1). 29. 